University of Louisville

ThinkIR: The University of Louisville's Institutional Repository

Electronic Theses and Dissertations

$12-2010$

\title{
Adult perceptions of the impact of Kentucky Education Reform Act initiatives on achievement : insights of rural gifted students.
}

Jan Kathryn Weaver Lanham 1954-

University of Louisville

Follow this and additional works at: https://ir.library.louisville.edu/etd

\section{Recommended Citation}

Lanham, Jan Kathryn Weaver 1954-, "Adult perceptions of the impact of Kentucky Education Reform Act initiatives on achievement : insights of rural gifted students." (2010). Electronic Theses and Dissertations. Paper 792.

https://doi.org/10.18297/etd/792

This Doctoral Dissertation is brought to you for free and open access by ThinkIR: The University of Louisville's Institutional Repository. It has been accepted for inclusion in Electronic Theses and Dissertations by an authorized administrator of ThinkIR: The University of Louisville's Institutional Repository. This title appears here courtesy of the author, who has retained all other copyrights. For more information, please contact thinkir@louisville.edu. 


\title{
ADULT PERCEPTIONS OF THE IMPACT OF \\ KENTUCKY EDUCATION REFORM ACT INITIATIVES ON ACHIEVEMENT: \\ INSIGHTS OF RURAL GIFTED STUDENTS
}

By

Jan Kathryn Weaver Lanham

B.S., Western Kentucky University, 1975

M.A., Western Kentucky University, 1982

\author{
A Dissertation \\ Submitted to the Faculty of the \\ Graduate School of the University of Louisville \\ and \\ Graduate Studies and Research at Western Kentucky University \\ In Partial Fulfillment of the Requirements \\ for the Degree of \\ Doctor of Philosophy \\ Department of Leadership, Foundations, and Human Resource Education \\ University of Louisville \\ and \\ College of Education and Behavioral Sciences \\ Western Kentucky University
}

December, 2010 
Copyright 2010 by Jan Weaver Lanham

All rights reserved 

ADULT PERCEPTIONS OF THE IMPACT OF

KENTUCKY EDUCATION REFORM ACT INITIATIVES ON ACHIEVEMENT:

INSIGHTS OF RURAL GIFTED STUDENTS

By

Jan Weaver Lanham

B.S., Western Kentucky University, 1975

M.A., Western Kentucky University, 1982

A Dissertation Approved on

November 30, 2010

By the following Dissertation Committee:

Dissertation Director 


\section{DEDICATION}

This dissertation is dedicated to my husband, Kevin,

for his support, his confidence, and his generosity of spirit in completing the process;

to my sons, Michael, Ryan, and Jonathan for their patience;

to my mother, Eloise Weaver,

who instilled a love of learning and a passion for teaching;

and to my father, Bill T. Weaver, who always wanted me to be a doctor. 


\section{ACKNOWLEDGMENTS}

Credit for the completion of this project is shared among many who provided input and support. Thanks to my dissertation chair, Dr. Julia Roberts, for her inspiration in the world of gifted education and for her guidance and vision. I am deeply grateful to each of my committee members, Dr. Ric Keaster, Dr. John Keedy, Dr. Samuel Stringfield, and Dr. Janet Tassell. Each member provided invaluable insights, suggestions, comments, and encouragement.

I wish to thank Dr. Sam Evans for hinting long ago that I should consider the doctoral program and Lynette Baldwin for her lifetime of dedication to gifted students.

My gratitude to the participants in the study is endless for their generosity of time, for their candor in addressing issues, and for their commitment to making the world of education a better place.

The support of all of my family, friends, colleagues, and the Cox's Creek Elementary staff and students combined to make it possible to complete the process in the midst of full-time work and more. I couldn't have done it without you!

Special acknowledgment goes to my sons, Michael, Ryan, and Jonathan, for their patience when the research and writing took precedence over family life.

Words are not sufficient to thank my husband, Kevin, for his ability to say just the right things when it appeared that it couldn't be done. 


\section{ABSTRACT \\ ADULT PERCEPTIONS OF THE IMPACT OF \\ KENTUCKY EDUCATION REFORM ACT INITIATIVES ON ACHIEVEMENT: \\ INSIGHTS OF RURAL GIFTED STUDENTS}

Jan W. Lanham

December 16, 2010

This phenomenological study investigated perceptions regarding the impact of the tenets of the Kentucky Education Reform Act (KERA) on the self-reported achievement and underachievement among adults who had been identified and served as gifted students in a rural Kentucky school district between 1994 and 2004. Through a series of interviews of 30 young adults selected through purposive sampling, the study addressed three research questions relating to (a) the perceptions of the former students regarding each of six KERA initiatives--Portfolios [writing and mathematics], Ungraded Primary, KIRIS/CATS assessment, Proficiency as a performance goal, School Based Decision Making [SBDM] council policies--in fostering or impeding self-reported student and adult achievement, (b) the perceptions of the former students regarding related educational experiences and structures perceived as fostering or impeding self-reported student and adult achievement, and (c) the similarities and differences in perceptions between those adults who self-reported sustained achievement and those who reported underachievement. 
The only KERA initiative credited with positive impact on student and adult achievement was the writing portfolio. The Primary Program, SBDM councils, and Proficiency as a performance goal were identified as initiatives that fostered underachievement and the state assessment and math portfolios had no impact on student achievement. Significant attributes of gifted education and regular education experiences and the impacts on achievement and underachievement were identified. Sustained or pervasive underachievement was reported by 27 of the 30 participants during their middle school experience. Perceptions regarding the KERA initiatives and their rural experiences were the same for those who self-reported achievement and those who reported underachievement. Specific themes and implications are discussed. 
TABLE OF CONTENTS

PAGE

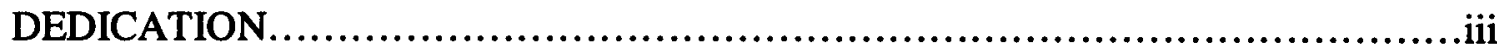

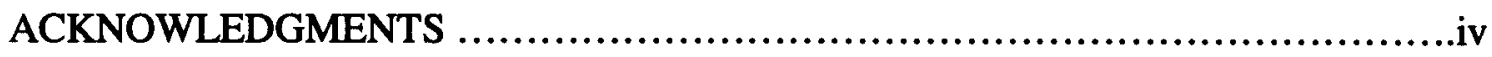

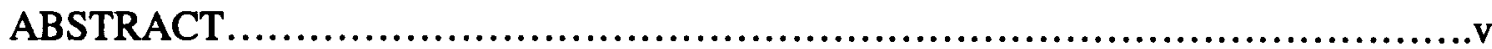

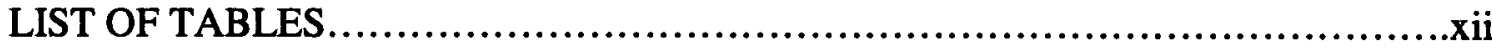

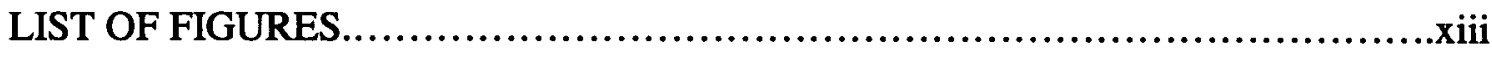

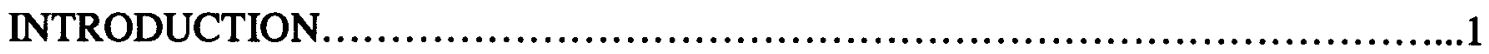

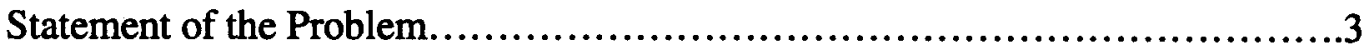

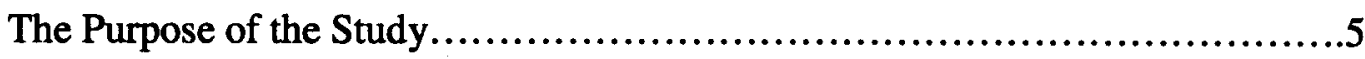

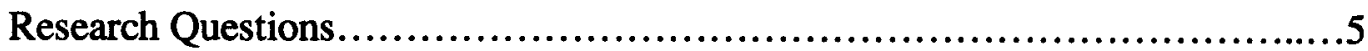

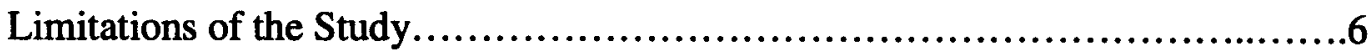

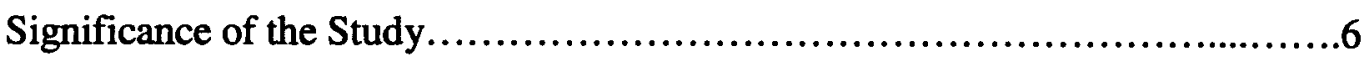

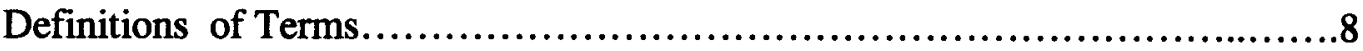

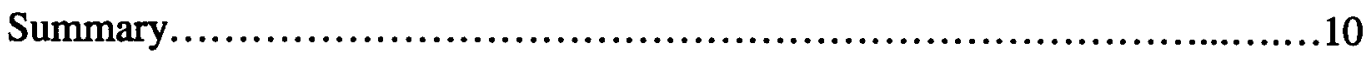

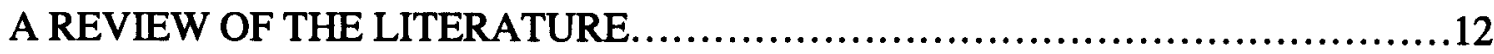

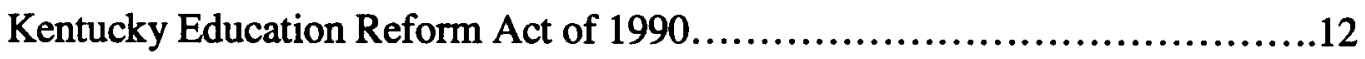

Ungraded Primary.......................................................

High Stakes Accountability System.................................. 16

Portfolio Assessment-Writing and Math............................. 18

School Based Decision-Making Councils (SBDM)....................21

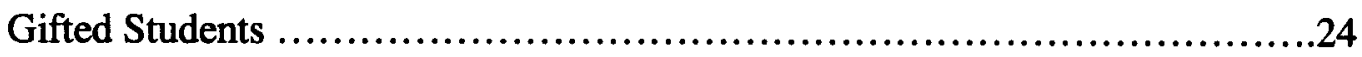




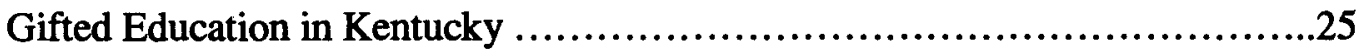

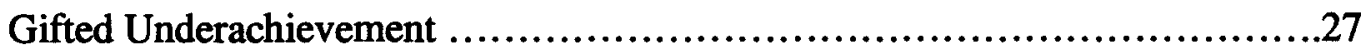

Patterns of Underachievement ........................................29

Student Personality and Self-Concept Causes ...........................30

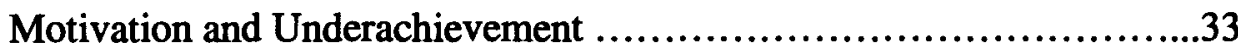

Student Personality and Self-Concept Interventions .....................34

Conflicting Role Identity Causes .......................................37

Conflicting Role Identity Interventions ............................40

Poor Match-Lack of Challenge ...................................42

Interventions to Improve Match ...................................44

Underachievement and Motivation Summary .........................49

Gifted Education in Rural Kentucky .....................................50

Declining Population ............................................51

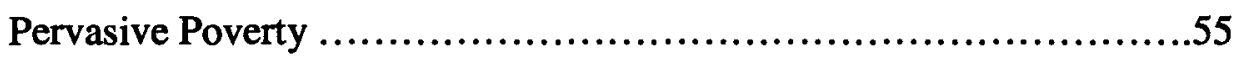

Changing Demographics ........................................56

High Stakes Accountability ......................................58

Gifted Practices in Rural Settings ..........................................59

Acceleration and Rural Students ........................................61

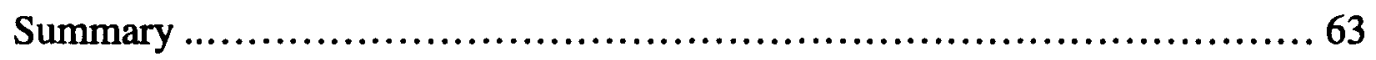

RESEARCH METHODOLOGY ............................................64

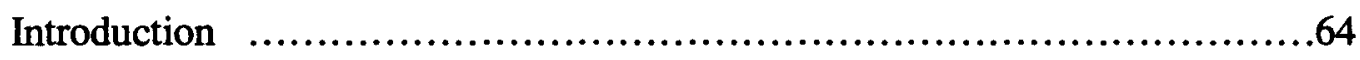

Research Questions........................................................64

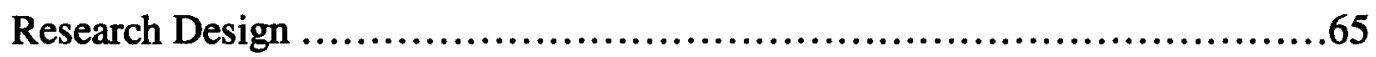


Population and Sample ....................................................67

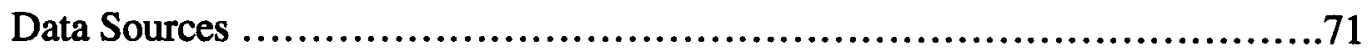

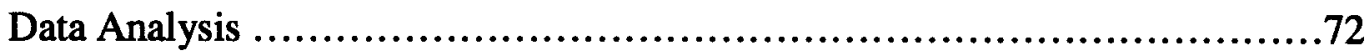

Role of the Researcher ........................................................74

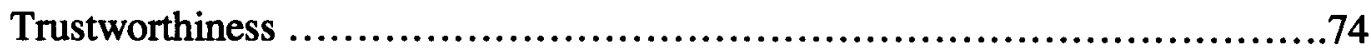

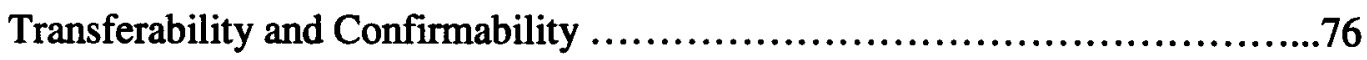

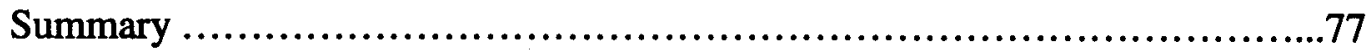

RESEARCH FINDINGS--KERA INITIATIVES................................78

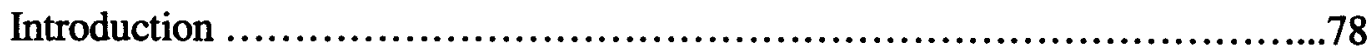

Findings Related to Question Number One .................................. 81

KERA Component-Writing Portfolios .................................... 82

KERA Component-Math Portfolios .......................................91

KERA Component—Ungraded Primary ..................................98

KERA Component-KIRIS/CATS Assessment ...........................107

KERA Component-Proficiency as a Performance Goal .....................114

KERA Component-SBDM Council .....................................121

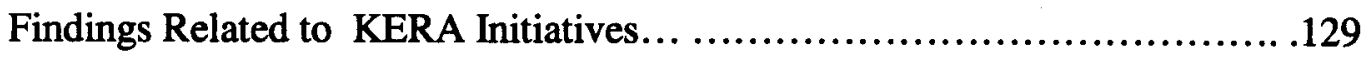

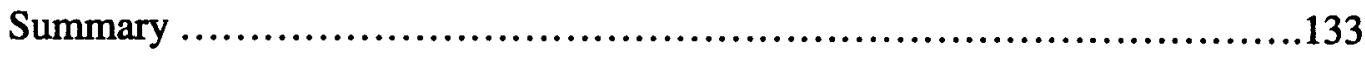

RESEARCH FINDINGS-- RURAL GIFTED AND UNDERACHIEVEMENT.......135

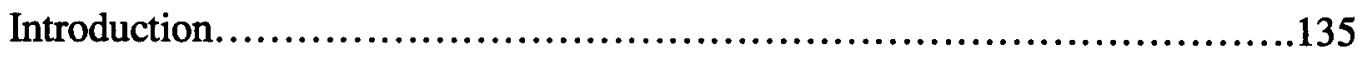

Findings for Research Question Number Two ...............................136

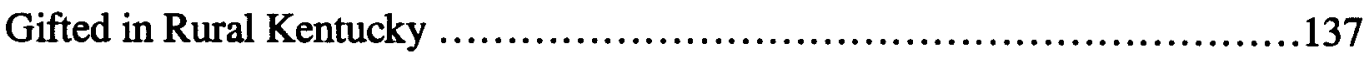

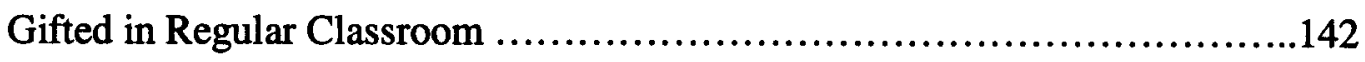


Impact of Peers

Relationship Between Gifted Services and KERA .......................154

Findings for Research Question Number Three ............................164

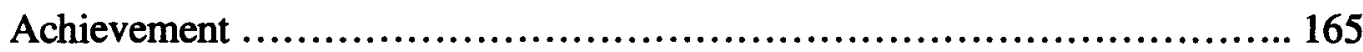

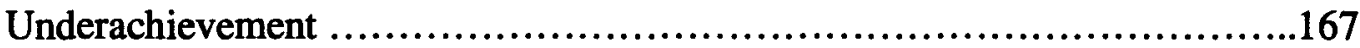

Situational Underachievement $\ldots \ldots \ldots \ldots \ldots \ldots \ldots \ldots \ldots \ldots \ldots \ldots \ldots \ldots \ldots$

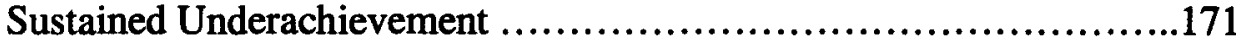

Pervasive Underachievement .........................................172

Fostering Achievement and Reversing Underachievement...................179

Teacher Expectations.............................................179

Parent Expectations..................................................181

Opportunity for Choice...........................................182

Gifted Services......................................................183

Opportunity for Gifted Students to be Together .............. 184

Differentiation and Access to High Level Resources.............185

High Expectations and Exposure Beyond Core Curriculum......186

Travel Opportunities .....................................187

Research and Project Opportunities......................... 188

Performance Opportunities ...............................189

Acceleration .............................................191

Teacher Relationships.......................................193

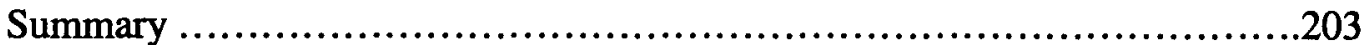

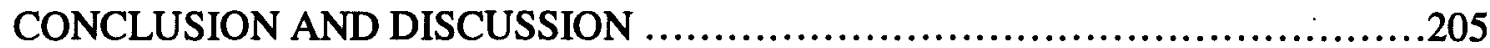




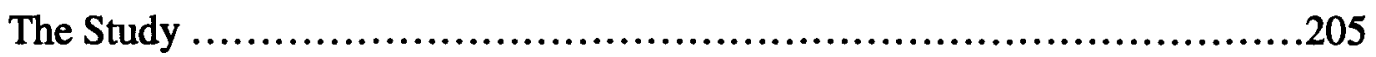

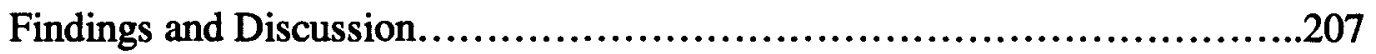

Implications for Further Research...........................................216

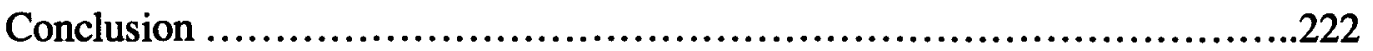

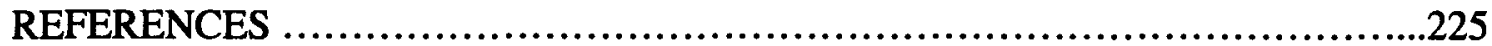

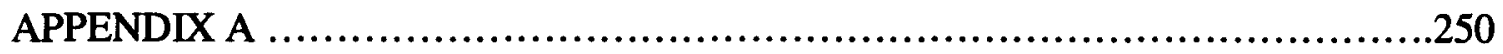

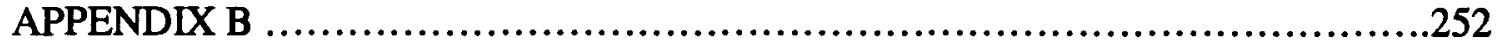

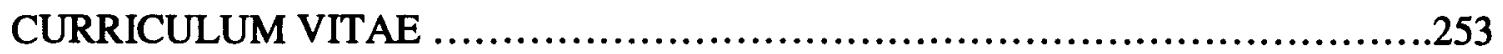




\section{LIST OF TABLES}

TABLES

PAGE

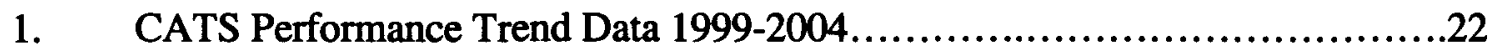

2. Comparison of Rural District and Target District..............................68

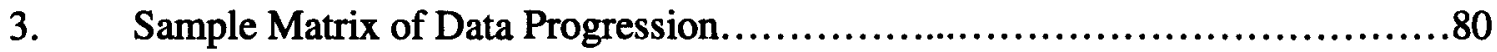

4. Common Themes Across KERA Initiatives...................................131

5. Perception of Impact on Achievement and Underachievement of KERA

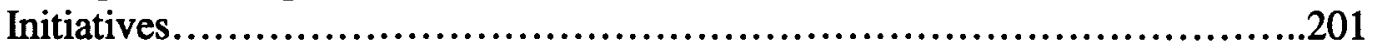




\section{LIST OF FIGURES}

FIGURES

PAGE

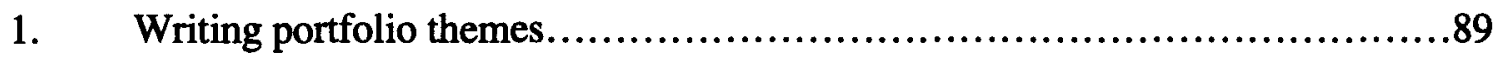

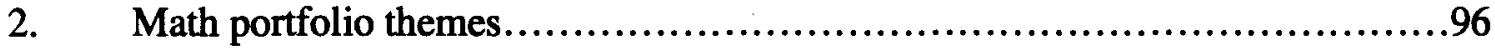

3. Ungraded primary themes............................................. 104

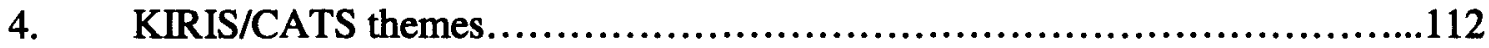

5. Proficiency as a performance goal themes................................118

6. School based decision making council themes..............................127

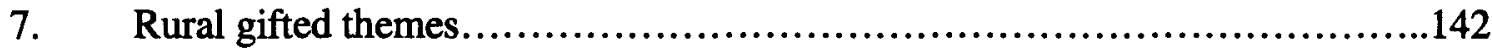

8. Gifted in regular classroom themes.........................................149

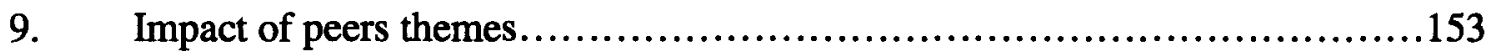

10. Relationships between KERA and gifted themes.........................162

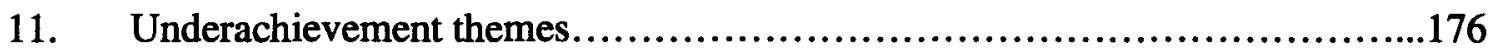

12. Sustaining achievement and reversing underachievement

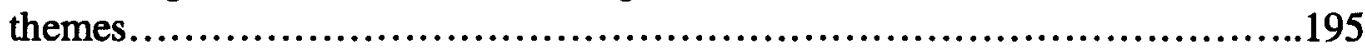




\section{CHAPTER 1}

\section{Introduction}

Under persistent pressure to improve, United States schools invest much time and energy developing mission statements and philosophies that resonate with the emphasis on helping every child reach full potential. These statements express awareness that schools must address the total child, however unique, and must create life-long learners. Reform initiatives such as the Kentucky Education Reform Act [KERA] (Kentucky Department of Education [KDE], 1990), No Child Left Behind [NCLB] (U.S. Department of Education [USDOE], 2002), and Race to the Top (U.S. Department of Education [USDOE], 2009b) continue to be introduced and implemented as efforts to improve education.

Unfortunately, teachers, students, and parents report that the laudable goals of the mission are not typically reached in the daily practice of schools. Heacox (1991) found that up to $80 \%$ of gifted students reported dissatisfaction with the level and pace of instruction and students continue to report similar dissatisfaction (Moon \& Reis, 2004; Smith, 2007). At the same time, teachers admitted that they struggle to meet the needs of their gifted students (Kolb \& Jussim, 1994; Winebrenner, 2009). Colangelo, Assouline, and Gross (2004) reported that educators continue to struggle with identifying and applying best practice that will support student achievement. As accountability pressure increases, the achievement of every child, including gifted students, arises as a concern throughout the educational system (Beisser, 2008). 
The emphasis on student achievement, as reflected in the student accountability standards established through the Kentucky Education Reform Act (KERA) of 1990 and subsequent modifications (KDE, 2009b), charged every Kentucky school with designing an educational setting that would maximize the achievement of all students, without regard for any potentially confounding factor that might interfere with performance. Gifted students who underachieve, those who do not perform at the levels indicated by their potentials, present a particularly troubling challenge to educators attempting to improve school achievement levels ((Beisser, 2008).

Kentucky educators face additional challenges due to the demographics of Kentucky. Over $40 \%$ of Kentucky students are enrolled in school districts serving rural students and $74 \%$ of those students living in rural settings are living in poverty (Johnson, 2009). The trend for rural residents to migrate to urban areas paired with the difficulty rural school districts face in attracting and retaining highly-qualified teachers reduces the educational opportunities for students in rural schools (Arnold, Gaddy, \& Dean, 2004).

Features of rural school settings have been identified by Spicker, Southern, and Davis (1987). Researchers found that small community size, poverty, inability to retain quality teachers, limited financial resources, and geographic or cultural isolation were identified as features that impacted educational opportunities for all students (Collins, 2008; Lawrence, 2009). These challenges, in combination with the unique needs of gifted students, are exacerbated for those students who may represent such a small proportion of the school population that interventions are not considered justifiable due to inconvenience and expense (Lawrence, 2009; Swanson, 1995). These factors place 
students who are gifted underachievers at great risk within rural school settings (Benbow, Argo, \& Glass, 1992; Lawrence, 2009).

\section{Statement of the Problem}

Reform initiatives consistently articulate objectives that relate to high expectations and improvement in student performance with the goal that schools create self-sufficient individuals who are responsible members of their family and community and who are competitive in a global society (KDE, 2000; USDOE, 2009a), yet the measure of success of those initiatives is gauged almost exclusively through normreferenced or criterion-referenced testing (KDE, 2000; USDOE, 2002; USDOE, 2009a). Though the majority of the tenets of the Kentucky Education Reform Act of 1990 are no longer consistently applied in Kentucky schools (Innes, 2010), state and national reform initiatives focus on many of the same philosophical ideas, such as performance-based assessments and portfolios (Duncan, 2010), readiness grouping rather than age grouping such as ungraded primary (Miller, 2005), and school-based governance [School Based Decision Making Councils] (USDOE, 2009a). Identifying and replicating educational factors that promote high achievement and success could have profound impact on future reforms.

The use of standardized testing has been a consistent element in judging the success of reform initiatives in order to establish high-stakes accountability (KDE, 1990; USDOE, 2001; USDOE, 2009a). Beisser (2008) analyzed test data to determine the impact of NCLB on gifted students. She reported that those students who performed at the top $10 \%$ made no gains or smaller gains than students who performed in the average range based on standardized testing data. Colangelo, Assouline, and Gross (2004) found 
that giving reform initiatives credit for even small gains may be misleading because many students may perform at high levels before receiving classroom instruction. Callahan, Tomlinson, Reis, and Kaplan (2000) found that high achieving students make few performance gains based on achievement test data and are low priority, even while district or state achievement performance appears to improve, and they are not performing consistently at the expected levels (Moon, Brighton, \& Callahan, 2003). Critics of the use of assessment data to gauge success of reforms cite narrow curricular focus, low level thinking, questionable validity and reliability of assessments, and incidents of cheating that could minimize the value of the use of test data as the measure of success of reform initiatives and high-stakes accountability measures (Gentry, 2006; Kane \& Staiger, 2002; Kaplan, 2004; Nichols \& Berliner, 2007).

Beisser (2008) determined that the high-stakes accountability mandate to reduce percentages of low-performing students and the emphasis on basic proficiency contribute to educational neglect of high ability students. This combination places gifted students at risk of underachievement in one or more area (Reis \& McCoach, 2000); however, standardized measures may not highlight underachievement because mastery standards such as the Kentucky performance standard of Proficient may be achievable with little effort for those students and may not reflect instruction (Cloud, 2007).

Colangelo, Assouline, and Gross (2004) studied educational responsiveness to the needs of gifted students and concluded that broad-based application of quality instructional interventions does not occur. This dissertation placed those quality instructional interventions within the context of broad-based reform initiatives and explored the context of adult perceptions of the roles of those interventions in 
contributing to their student and adult success. By investigating the perceptions of adults who were products of those reform initiatives this study sought to gauge the long-term success and viability of educational programming and structures and to determine the impact of those initiatives on their underachievement.

\section{The Purpose of the Study}

The purpose of this phenomenological study was to gather the perceptions of adults regarding their experiences as identified gifted students under the tenets of the Kentucky Education Reform Act. Self-reported achievement and underachievement data were gathered from adults who had been served as gifted students in rural Kentucky between 1994 and 2004. The study sought to identify the impact of reform initiatives as educational factors that the participants perceived as fostering or impeding student achievement, reversing or fostering underachievement, and promoting or impeding adult success and sought to compare and contrast the perceptions of individuals who selfreported sustained achievement with those who self-reported sustained/pervasive underachievement. The results then provide a description that reduced the individual experiences to a description of the essence of experiencing KERA reforms as a rural gifted student in Kentucky.

\section{Research Questions}

The study investigated the following questions:

1. What are the perceptions of former students regarding the roles of each of the instructional Kentucky Education Reform Act initiatives (Portfolios [writing and mathematics], Ungraded Primary, KIRIS/CATS assessment, Proficiency as a 
performance goal, SBDM council policies) in fostering or impeding self-reported student and adult achievement?

2. What related educational experiences and structures in a rural setting are perceived by the former students as fostering or impeding self-reported student and adult achievement?

3. What are the similarities and differences in perceptions between those adults who self-reported sustained achievement and those who reported underachievement?

\section{Limitations of the Study}

The study was limited by its relatively small sample size of 30 participants drawn from a representative rural school district. Another potential limitation included the fact that the amount of time that had passed since the educational experiences to be studied may have limited or altered the former students' memories. In addition, students who experienced the KERA initiatives may have had limited awareness of those initiatives at the time. These factors were potential limitations of the study.

\section{Significance of the Study}

By focusing on adult perceptions of individuals who actually experienced Kentucky Education Reform Initiatives in a rural setting, the study provides insight regarding the short-term and long-term impact of those initiatives and of related educational practices or structures. In this era of "high stakes accountability," states, districts, and schools currently report student performance data in a comparative model that reflects performance averages and grade level comparisons to gauge achievement (Beisser, 2008; KDE, 1990), but typically do not use growth models as achievement measures to assess the ongoing impact of instruction on individual students. This use of 
school level data to gauge instructional impact fails to adequately monitor the impact of instruction on individual students (Kane \& Staiger, 2002), yet the true success of educational initiatives is their ability to foster achievement in individuals (Mpofu \& Ortiz, 2009). Participants in this study provided insights as to "what worked for them" in the general curriculum as a result of reform initiatives.

"Better schools" is the mantra of many politicians and one important tenet of reform initiatives is to help students become globally competitive (Chen, 2010; USDOE, 2009a). In order to become more globally competitive, educational systems must prepare students to perform well on international measures, such as the measures used in the International Mathematics Report: Findings from IEA's Trends in International Mathematics and Science Study (TIMSS) report (USDOE, 2007). Even while recent reform initiatives were in place, the performance of U.S. students remained flat as the performance of international students in many countries has improved (Gonzales et al., 2008). As identified gifted students, the participants represented high ability students and the study examined their insights regarding effective and ineffective practices targeted to that population in order to inform decisions regarding future reforms.

A third potential area of significance is in the area of rural education reform. According to the Rural School Community Trust (2009), over nine million students in the United States are educated in rural settings with over $30 \%$ of U.S. schools classified as rural. The participants in this study were rural gifted students within the context of Kentucky Education Reform Act initiatives, providing unique context for the impact of the reform elements on students in rural settings (KDE, 1990). Finally, because underachievement impacts students of every ability level, economic status, and 
geographic location (Clark, 2008), the participants in the current study belonged to several groups with unique needs within the school population.

\section{Definition of Terms}

Operational definitions of key terms used within this study:

Achievement is defined as performance at or above anticipated levels (Reis \& McCoach, 2000). Participants in the study self-reported levels of achievement or underachievement throughout their educational careers.

Gifted is defined as those students identified and served according to 704 KAR 3:285 (1994) as gifted in one of five categories (general intellectual, specific academic aptitude, leadership, creativity, visual/performing arts). Participants in this study were all identified as gifted in the area of general intellectual and at least one other category.

Performance-based assessments are defined as those assessments or evaluations that focus on student ability to use skills and knowledge in simulated, real-world situations (Heine, 2009). Performance-based assessments were used as a part of formative assessment in science and math in preparation for use as accountability scores, but were removed from KIRIS assessment due to controversy regarding validity and reliability and difficulty in scoring (Tung, 2010).

Pervasive underachievement is a significant negative discrepancy between potential and performance across all settings for an identifiable period (Heacox, 1991; Peterson \& Colangelo, 1996; Speirs-Neumeister \& Hébert, 2003).

Portfolios are defined collections of student work designed to represent application of the skills and concepts of the field over time (Heine, 2009). Writing and 
Math Portfolios were a part of the KIRIS accountability until 1996 and Writing was a part of the CATS accountability until 2008 (SB1, 2008).

Rural district is a district composed of settlements of fewer than 2500 residents that is not adjacent to or within an urbanized area (Johnson, 2009; Provasnik et al., 2007). Participants in this study were served as identified gifted students in a rural school district.

School based decision-making council (SBDM) is the system of governance that gives legal authority to school councils, composed of principals, teachers elected by teachers, and parents elected by parents at the school level to adopt policies relating to curriculum, instructional materials, personnel, extracurricular programs, and other aspects of school management (Heine, 2009; KDE, 1990).

Situational underachievement occurs in situations in which an individual consciously or purposely does not put forth effort to succeed (Clark, 2008). The relationship between school structures, KERA initiatives, and student decisions to underachieve will be explored in this study.

Sustained underachievement is defined as a negative discrepancy between potential and performance in one or more areas sustained for more than four semesters (Heacox, 1991; Peterson \& Colangelo, 1996).

Underachievement is the discrepancy that occurs when the performance of a student is below his or her performance potential (Heacox, 1991; Reis \& McCoach, 2000).

Ungraded primary program is the term applied to the first four years of the elementary school career in which traditional K-3 grades were replaced with P1-P4 under 
the Kentucky Education Reform Act (Heine, 2009). Multiage groupings, skill-based progress, and early exit or an extra year in primary were identified as ways to promote continuous progress (KAR 3:315, 1990; KDE, 1999).

\section{Summary}

The research problem identified in this chapter is the fact that although educational reform initiatives are a consistent element in education improvement movements, little research has been done on the perceptions of those most impacted by the initiatives-the students (USDOE, 2009). The purpose of the study was to answer three key questions relating to the perceptions of adults who were gifted students in rural Kentucky. Participants' perceptions of the roles of each of the instructional Kentucky Education Reform Act initiatives in fostering or impeding self-reported student and adult achievement were examined. Their perceptions regarding related educational structures and experiences in fostering or impeding achievement were explored. Examination of the similarities and differences in the perceptions of those adults who self-reported sustained achievement and those who reported sustained or pervasive underachievement was the final question addressed through the study.

Chapter 2 presents a review of relevant research literature related to the four closely related areas of this study_KERA initiatives, gifted education in Kentucky, motivation and underachievement, and gifted education in rural settings. In order to establish the context for the specific instructional components examined in this study, the background and components of the Kentucky Education Reform Act were investigated with particular emphasis on the implementation of portfolios (writing and math), the KIRIS/CATS assessments, ungraded primary, emphasis on Proficiency, and SBDM 
councils. Next, the context of gifted education, with specific emphasis on gifted education in Kentucky, was reviewed in order to provide the backdrop for examination of the impact of reform initiatives. It was important to review the literature on motivation and underachievement as those factors are keys to understanding the relationships among reform initiatives and achievement. Finally, the literature on gifted education in rural settings was examined.

Chapter 3 provides the explanation of the research questions and methodology of this phenomenological study. Chapter 4 and Chapter 5 present the research findings for the three research questions of the study. This was accomplished by using data from interviews and conversations to identify preliminary findings, findings summaries, and themes. Chapter 6 provides the discussion and conclusions for the study with implications for further research. 


\section{CHAPTER 2}

\section{REVIEW OF LITERATURE}

\section{Introduction}

In this examination of the literature related to the dynamics of gifted underachievement within the context of KERA reform initiatives, four key areas of investigation emerge to provide background for the study:

- Kentucky Education Reform Act,

- Gifted Education in Kentucky,

- Motivation and Underachievement, and

- Gifted Education in Rural Settings.

\section{Kentucky Education Reform Act of 1990}

The Kentucky Education Reform Act of 1990 grew out of the Kentucky legislature's response to the 1989 Kentucky Supreme Court ruling that the entire educational system in Kentucky was unconstitutional (KDE, 2000). This ruling followed the lower court finding that the Kentucky General Assembly had, in fact, failed to provide an efficient system of schools and that the funding provided through the state system was discriminatory and inadequate (Weston-Perkins, \& Sexton, 2009). The court required the Kentucky State Legislature to address every aspect of the public school system, including all statutes that create, implement, and finance the schools, all statutes related to the creation of local school districts, school boards, and the Kentucky 
Department of Education, and all statutes related to teacher certification, to school construction, transportation, and maintenance (KDE, 2000).

As a compilation of the work of various task forces that drew from the expertise of external consultants, the final law, known as the Kentucky Education Reform Act (KERA) was signed into law on April 11, 1990. This massive legislation was touted as one of the nation's most comprehensive education reform packages with implications in every facet of educational delivery (Moore \& Benton, 1998). KERA was regarded by many as one of the most important pieces of legislation passed in the state since the adoption of the constitution (Jennings, 1990; Weston-Perkins \& Sexton, 2009). The KERA legislation was considered groundbreaking and was awarded the Innovations in American Government Award by the Ford Foundation and Harvard University (KDE, 2000). Because gifted students are included as a category of exceptional children in KERA (KDE, 1990) and due to the potential impact of KERA Goal Five--Develop students' abilities to think and solve problems (KDE, 2000), the promise for gifted students within reform was seen as having great potential (Moon, Brighton, \& Callahan, 2003).

The Kentucky Education Reform Act was built around three broad categories: curriculum, governance, and finance (Weston-Perkins \& Sexton, 2009). In the area of curriculum KERA established significant structural and philosophical changes around six goals that were to drive instruction and assessment. Schools were charged to develop students' ability to do the following: 1) use basic communication and math skills; 2) apply core concepts and principals from math, science, art, humanities, social studies, and practical living studies; 3) become self-sufficient individuals; 4) become responsible 
members of a family, work group, or community; 5) think and solve problems; and 6) connect and integrate experiences and new knowledge to past learning and experiences. All KERA initiatives were intended to support those goals (KDE, 1990).

While all elements of KERA reforms were enacted with the over-arching goal of improving student achievement (KDE, 1990), the reforms that impacted day-to-day instruction for students were the establishment of the ungraded primary program, the use of portfolios and performance-based assessments, criterion-referenced testing in the form of the Kentucky Results Informational System (KIRIS) tests until 1998, followed by the Commonwealth Accountability Testing System (CATS) with the grades tested and accountability weights adjusted over time (KDE, 2000). Coupled with the direct curricular innovations was the establishment of school governance through a School Based Decision Making Council (SBDM) that was charged with the responsibility of establishing policy to improve student achievement (Heine, 2009; KDE, 1990).

Each of these facets of KERA influenced instructional philosophy and the delivery of instruction as they were implemented at the school level (Weston-Perkins \& Sexton, 2009). Though research has been conducted to look at the impact of reform initiatives across the state of Kentucky as measured by test results (KDE, 2009c) and teacher and administrator perceptions (Pancratz \& Petrosko, 2000), the perceptions of rural gifted students during KERA have not been analyzed.

\section{Ungraded Primary}

A significant part of the Kentucky Education Reform Act (KDE, 1990) was the establishment of the primary school program as that part of the elementary school program in which children are enrolled from the time they begin school until they are 
ready to enter fourth grade (KDE, 1998). The intent of the primary program was to assure the inclusion of six critical attributes: developmentally appropriate practices, continuous progress, multi-age and multi-ability classrooms, authentic assessment, qualitative reporting, professional teamwork, and positive parent involvement (KDE, 1999). Viewed as a critical component in the implementation of restructuring Kentucky's public schools, the primary program challenged Kentucky teachers to make significant changes in their practices (Pankratz \& Petrosko, 2000).

Implementation of the attributes of the primary program was inconsistent across the state of Kentucky (Pankratz \& Petrosko, 2000) with schools adopting a variety of configurations to address the attribute of multi-age, multi-ability classrooms. These inconsistencies make it difficult to attribute the assessment performance of primary students to the primary program itself (Heine, 2006; Pankratz \& Petrosko, 2000), but existing accountability measures for the P4 grade level (CTBS scores) showed gains. Reading scores on the Comprehensive Test of Basic Skills for P4 students (at the end of primary) showed gains from an average at the $50^{\text {th }}$ percentile in reading across the state in 1997 to an average at the $65^{\text {th }}$ percentile in 2005. Mathematics performance showed similar gains as the $1997 \mathrm{P} 4$ average in Kentucky was at the $49^{\text {th }}$ percentile in math and increased to the $67^{\text {th }}$ percentile by 2005 (Heine, 2006). Current data analysis reveals performance gaps that must be addressed to provide support for low-performing populations in the primary grades and within the primary program (Heine, 2006; $\mathrm{KDE}$, 2009), but identification of the impact of the primary program on gifted students has not been addressed. 


\section{High Stakes Accountability System}

The Kentucky Education Reform Act established a system of accountability designed to align with the goals and philosophy of the extensive reforms of the act (KDE, 1990). The original test, the Kentucky Instructional Results Information System (KIRIS) test was primarily performance-based to assure school's accountability to student achievement. The test was a combination of multiple choice and structured response (open-response) items designed to assess levels of mastery of the skills and knowledge included in the Core Content. Though the test included multiple-choice items, those were not included in the computation of the accountability index because they were not considered performance assessments (KDE, 2000; Pankratz \& Petrosko, 2000). Paired with the accountability was a system of rewards and sanctions to recognize schools for success and to provide opportunities for improvement through curriculum audits, improvement plans, and state assistance (Wolf, Borko, Elliott, \& McIver, 2000).

The accountability system was built around both academic and non-academic data. Academic data were generated through school level performance on the KCCT assessment in combination with the indices for student performance on writing portfolios and math portfolios (Wolf et al., 2000). Academic performance was weighted $85 \%$ in the index. Non-academic measures (attendance, dropout rates, retention rates, and transitions post-high school) made up the other 15\% of each school's accountability index (Pankratz \& Petrosko, 2000).

KIRIS assessments drove curriculum offerings as testing in arts and humanities, practical living, and on-demand writing was added. As state funding increased to enhance curricular offerings and to equalize opportunities across the state, schools added 
personnel and provided professional development to provide the experiences and instruction to enhance student achievement in those areas (Callahan, 2006; Jones \& Whitford, 1997; Wolf et al., 2006).

In order to assist schools in offering quality instruction, the Kentucky Department of Education defined core content for elementary, middle, and high schools in each of the seven areas to be assessed. This was followed by the Kentucky Program of Studies (KDE, 1998) that defined what should be taught at each grade level (Pankratz \& Petrosko, 2000; Westin-Perkins \& Sexton, 2009).

Kentucky assessment results on KIRIS school accountability indices showed steady improvement, but the results on the criterion-referenced test proved difficult to compare with national, norm-referenced tests. Student performance on the National Assessment of Educational Progress and the ACT did not reflect similar gains for the same time periods (Hambleton, Jaeger, Koretz, Linn, Millman, \& Phillips, 1995; Pankratz \& Petrosko, 2000; Strong \& Sexton, 2000). As a result, the Commonwealth Accountability Testing System (CATS) replaced the KIRIS assessment in 1998. Multiple-choice items and the administration of norm-referenced tests at specific grade levels was added in order to increase the ability to compare performance of Kentucky students to students across the country (Pankratz \& Petrosko, 2000; Weston-Perkins \& Sexton, 2009).

The accountability system established performance standards for each of four performance levels (Novice, Apprentice, Proficient, and Distinguished) with Proficient as the goal. Cut scores were established for each performance level and each performance level was assigned a value used in determining the school's academic index (Heine, 
2009; Pankratz \& Petrosko, 2000). Consistent focus in test data disaggregation has seen the reduction of the number of students who score at the Novice level and the reduction of performance gaps (disparate performance of at-risk groups such as free/reduced lunch student, minority, or special education) through improvement of the core curriculum and targeted interventions (Lyons, 2004). It will be important to examine the impact of focus on low-performing students on the motivation and performance of high ability students in order to assure high achievement for all (Kaplan, 2004).

\section{Portfolio Assessment-Writing and Mathematics}

As a part of the Kentucky Education Reform Act, beginning in the 1991-92 school year, Kentucky students in assessment grade levels completed writing portfolios as a part of the statewide accountability assessment. The portfolios were created to include a specified variety of writing forms with the intent that they reflected student writing over time with the opportunity to select their best work (Heine, 2006). The requirements for the portfolio and curriculum standards were established through the Writing Portfolio Procedures regulation, 703 KAR 5:010, and supported through state and district documents (KDE, 2008). Holistic scoring of portfolios was used until 2006 when an analytic process was adopted (KDE, 2006).

The process of portfolio development was intended to involve ongoing professional training for teachers in order to involve them in school-wide writing instruction and to prepare them for accurate scoring (Callahan \& Spalding, 2006; KDE, 2008). The portfolio was intended as a driving force to embed writing across the curriculum with goals that included: 1) provide students with the skills, knowledge, and confidence necessary to become independent thinkers and writers; 2) promote each 
student's ability to communicate to a variety of audiences for a variety of purposes; 3 ) document student performance on multiple tasks over time; 4) integrate performance assessment with classroom instruction; and 5) provide information to guide development of curriculum that is responsive to student needs (Callahan \& Spalding, 2006). Though touted as important as an individualized product that could be meaningful for students with clear real-world connections, the writing portfolio was dropped from the CATS accountability system beginning with the 2008-2009 school year. Schools are still expected to maintain writing as an emphasis of instruction that will be assessed through a Writing Program review, but the portfolios are no longer used as a part of accountability in Kentucky Senate Bill 1 (2009).

Mathematics portfolios were also included as a part of accountability in the Kentucky Education Reform Act. The intent of the mathematics portfolios was similar to that of the writing portfolios--to provide opportunities for students to show their skill at applying mathematics skills to real-world problems (Kuhs, 1994). Student entries in portfolios typically reflected low-level problem solving and reflected an add-on to the class, rather than reflecting a natural outgrowth of rigorous instruction (Kuhs, 1994; Tung, 2010). Math portfolios were used as a part of the accountability system until they were removed in 1996 as a result of lack of confidence in the scores (Tung, 2010).

In 2000, ten years after the passage of KERA, the Center for Business and Economic Research published an analysis of reform using comparison data that examined spending, teacher-pupil ratios, KIRIS test performance compared with NAEP performance, graduation rates, attendance rates, dropout rates, and college attendance rates (Hoyt, 2000). According to the report, the impact of KERA was judged to be 
minimal because the statistical data in every area showed little improvement. Student performance among rural, disadvantaged, and minority students did not appear to be positively impacted by reform initiatives. The report compared Kentucky statistics to surrounding states and national rankings and found that the slight gains in ranking in the areas of teacher salaries and teacher-pupil ratio were not sustained and that Kentucky actually lost ground over time. The report did not analyze specific reform initiatives related to curriculum and instruction (KDE, 1990), but concluded that the testing results implied that instruction had not improved as a result of KERA initiatives. However, the author did acknowledge that systemic change takes time and that increasing teacher salaries was only a small piece of improving teacher quality and instruction (Hoyt, 2000).

The Kentucky Department of Education also published a report to mark the $10^{\text {th }}$ anniversary of the KERA legislation (KDE, 2000). The assessment growth, showing both KIRIS and CATS data, was based on state average indices for targeted grade levels and showed small performance increases. Individual schools with significant achievement levels or dramatic improvement were included in the report. The report also highlighted next steps, calling for a sustained focus on student achievement and fidelity to the KERA initiatives to foster that achievement (KDE, 2000; Weston-Perkins \& Sexton, 2009).

The issues of significance for high ability students were that, for many students, Proficient scores did not equate with high quality instruction because they entered the course at the Proficient level; and that many students who did not always score Proficient or Distinguished on Kentucky assessments scored very well on national assessments (Petrosko, 1997; Strong \& Sexton, 2000). 


\section{School Based Decision Making Councils (SBDM)}

An additional tenet in the Kentucky Education Reform was the establishment of a local governance structure in the form of School Based Decision Making Councils (SBDM) composed of the building principal, two teachers, and two parents. The SBDM councils were charged with the responsibility of improving student achievement through the policy development and oversight (KDE, 1990; Pankratz \& Petrosko, 2000; Petrosko, 1996). Decisions regarding curriculum, student access to courses, scheduling, use of school space, and other policies relating to student instruction and delivery had the potential to directly impact student achievement with implications for gifted students (Kaplan, 2004; Weston-Perkins \& Sexton, 2009).

Pankratz and Petrosko (2000) compiled a comprehensive examination of the components of KERA and the relative successes of their implementation in the context of the legislative intent. KIRIS and CATS data and funding data were used to examine equity and to assess progress (KDE, 2000). District, teacher, and KDE self-reports were used to examine the implementation strategies, the relative success of implementation, and barriers to success for each of the key KERA components (Pankratz \& Petrosko, 2000).

Through analysis of patterns of implementation across Kentucky, punctuated with anecdotal reports from individual stakeholders, the findings show that the KERA reform initiatives had positive impact on instruction in Kentucky in many areas by 2000 (KDE, 2000; Petrosko, 1996). Based on KIRIS assessment data from across the state of Kentucky, percentages of students who scored Novice in reading at the elementary level decreased from $32 \%$ to $15 \%$ between 1993 and 1998 . For the same period, percentage of 
Novice at the high school level decreased from $57 \%$ in 1993 to $16 \%$ in 1998. However, mathematics performance percentages remained flat. In $1995,29 \%$ of students at the elementary level scored Novice and by 1998 the percentage of Novice math students was $28 \%$. Middle school and secondary mathematics performance was also unchanged through the period between 1995 and 1998 (Pankratz \& Petrosko, 2000). Following the change from the KIRIS assessment to the CATS assessment system, the number of students performing at the Novice level in reading and mathematics declined at each level while the percentage of students performing at the Proficient and Distinguished levels increased between 1999 and 2004 (KDE, 2005).

Table 1

CATS Performance Trend Data 1999-2004

\begin{tabular}{|c|c|c|c|c|c|}
\hline & & \multicolumn{2}{|c|}{ Reading } & \multicolumn{2}{|c|}{ Mathematics } \\
\hline & & $\begin{array}{c}\text { Novice } \\
\text { Percentage }\end{array}$ & $\begin{array}{l}\text { Proficient \& } \\
\text { Distinguished } \\
\text { Percentage }\end{array}$ & $\begin{array}{c}\text { Novice } \\
\text { Percentage }\end{array}$ & $\begin{array}{l}\text { Proficient \& } \\
\text { Distinguished } \\
\text { Percentage }\end{array}$ \\
\hline \multirow{3}{*}{1999} & Elem & 19 & 67 & 43 & 28 \\
\hline & Mid & 16 & 50 & 39 & 12 \\
\hline & High & 21 & 24 & 44 & 25 \\
\hline \multirow{3}{*}{2000} & Elem & 17 & 57 & 39 & 31 \\
\hline & Mid & 15 & 51 & 34 & 25 \\
\hline & High & 18 & 27 & 42 & 26 \\
\hline \multirow{3}{*}{2001} & Elem & 16 & 58 & 35 & 34 \\
\hline & Mid & 13 & 54 & 32 & 28 \\
\hline & High & 18 & 29 & 40 & 29 \\
\hline \multirow{3}{*}{2002} & Elem & 15 & 60 & 33 & 36 \\
\hline & Mid & 12 & 56 & 32 & 26 \\
\hline & High & 18 & 28 & 37 & 29 \\
\hline \multirow{3}{*}{2003} & Elkm & 13 & 63 & 31 & 38 \\
\hline & Mid & 11 & 57 & 28 & 31 \\
\hline & High & 16 & 30 & 35 & 33 \\
\hline \multirow{3}{*}{2004} & Elem & 12 & 67 & 23 & 48 \\
\hline & Mid & 8 & 60 & 26 & 33 \\
\hline & High & 14 & 34 & 33 & 36 \\
\hline
\end{tabular}


What are not clear from the data are the impacts of high-stakes accountability testing on the performance and achievement of gifted students. Moon, Brighton, and Callahan (2003) identified a number of potential outcomes of the current emphasis on standardized testing. Because teachers are under pressure to raise test scores by reducing the number of low-performing students, classroom emphasis shifts to basic skills instruction, drill, and recitation. This has potential to negatively impact gifted students who need learning experiences that are academically rigorous (Kaplan, 2004).

According to teacher perceptions (Moon, Brighton, \& Callahan, 2003), high stakes accountability influences teachers' instructional planning, narrowing the curriculum at the cost of in-depth explorations or the development of broad, enriched studies. As a result, teachers reported that standardized testing limited instructional opportunities for gifted students and may create a cycle of underachievement (Kaplan, 2004). As a result, up to $80 \%$ of gifted students do not receive instruction geared to their interests and needs (Gardner, 2010).

Pankratz and Petrosko (2000) summarized stakeholder insights regarding the barriers to implementation, the impact of KERA on their own work at the school or district level, and their perceptions about reform. Key insights regarding reform implementation were identified with recommendations for sustaining and refining KERA implementation. Available statistical and anecdotal data assessed the success of KERA initiatives within the context of the existing measures identified for accountability (KCCT testing, non-academic data such as attendance, drop-out rate, retention rates, and post-secondary transition) and questions surrounding implementation. 
Wolf, Borko, Elliott, and McIver (2000) examined exemplary school change efforts as measured by state assessment as a part of KERA by looking at the effect of the assessment on school structures, professional relationships, classroom practices, and analysis of the assessment data. They identified factors in school success that included shared vision, effective relationships among stakeholders, commitment to improvement, increased financial resources, and increased collaborative efforts. Though implementation of writing was discussed as one of the changes at one site, the primary focus on teacher and administrator perceptions of change components left student perceptions unaddressed.

As students who are products of the Kentucky Education Reform Act enter the workforce, it is important to gauge their perceptions of the elements in their educational programming and structure that facilitated or impeded their success and to gauge their perceptions of the impact and relative effectiveness of reform initiatives on their experiences in order to inform decisions about strategies to further improve education for all students.

\section{Gifted Students}

Gifted individuals are those who operate or perform, or show promise of operating or performing, at high levels in any of the areas of human ability (Clark, 2008) and who require services or activities beyond what is ordinarily provided by the school in order to fully develop such capabilities (Marland, 1972). In classrooms, these abilities are typically identified in the areas of general intellectual aptitude, specific academic aptitude, creative thinking, leadership ability, and/or ability in visual and performing arts (Clark, 2008; Karnes \& Bean, 2005; KDE, 1994). These students present unique 
challenges in the typical classroom as they may enter with mastery of the content or skills around which the course or lesson is structured and may require differentiated instruction in order to address their learning needs and assure continuous progress (Clark, 2008; Karnes \& Bean, 2005; McGrail, 2005).

Failure to address the needs of gifted students may result in a number of adverse effects including disruptive behaviors, underachievement, negative self-perception, and failure to develop necessary executive function skills (Clark, 2008; Rayneri, Gerber, Wiley, 2003; Winner, 1996). This potential loss of talent must be addressed in the classroom in order to help these students fully actualize their gifts (Karnes \& Bean, 2005).

\section{Gifted Education in Kentucky}

Kentucky acknowledged the needs of gifted students in 1978 through the creation of an experimental program serving 23 school districts in the form of competitive grants (KDE, 1978). The legislative mandate for gifted services was expanded to unit funding for all Kentucky school districts (KDE, 1983) and the definition of gifted was expanded to require districts to identify and service students through articulated services P-12 in all five areas of giftedness in Kentucky—general intellectual ability, specific academic aptitude, creative or divergent thinking, leadership skills, and visual or performing arts as a part of the Kentucky Education Reform Act (KDE, 1990).

As a part of the Kentucky Education Reform Act, KRS 157.200 (1990), gifted students are included as a category of "exceptional students" who are identified as possessing demonstrated or potential ability to perform at an exceptionally high level in general intellectual aptitude, specific academic aptitude, creative or divergent thinking, 
psychosocial or leadership skills, or in the visual or performing arts (KDE, 1990). These students represent a diverse group that possesses characteristics of advanced learners that require attention in order to assure maximum achievement of each individual (Karnes \& Bean, 2005).

Gifted identification and services in Kentucky are outlined in regulation 704 KAR 3:285 (KDE, 1994). As defined in Kentucky's gifted regulation, districts are required to use multiple measures that are appropriate to the category for gifted identification. Once identified, students must be provided multiple service delivery options for grades P-12 in order to assure a continuum of services to address the multiple needs of gifted and talented students (KDE, 1994; Renzulli \& Reis, 1997).

As the configuration of Kentucky primary grades was modified to create the ungraded primary program as a part of KERA (KDE, 1990), the processes for identification and provision of services to students below fourth grade were changed to create the Primary Talent Pool (KDE, 1994). Kentucky schools serve up to $25 \%$ of their P1-P4 students by selecting students who demonstrate high potential through informal measures within the Primary Talent Pool. Representing a range of services matched to the potentials demonstrated by the members of the Primary Talent Pool, this component of Gifted Education services is intended to nurture and develop potential prior to formal identification in grades 4-12 (KDE, 2009).

The Kentucky gifted regulation (KDE, 2009) requires districts to develop mechanisms for development of an individual Gifted Student Services Plan (GSSP). The GSSP documents the student's area(s) of identification, performance goals, services to be provided, and the individual(s) responsible for service delivery. Schools are responsible 
for regular progress monitoring based on GSSP goals and the provision of professional development in gifted education for all teachers in acknowledgment that gifted students' needs must be addressed across settings (KDE, 1994).

Though Kentucky has a strong gifted regulation in KAR 3:285 (1994), consistent application of differentiation and grouping practices to assure continuous progress does not occur (Colangelo, Assouline, \& Gross, 2004). As a result of a poor match between the needs of gifted students and their instruction, the academic performance of gifted students consistently demonstrates that they are at risk of underachievement (Reis \& McCoach, 2000). Understanding underachievement and existing research on underachievement are important in identifying the role of KERA initiatives in impacting patterns of success and underachievement.

\section{Gifted Underachievement}

Underachievement impacts students of all abilities, but it is of particular significance in addressing the needs of gifted learners in order to maximize student potential (Rimm, 1990). Underachievers are a heterogeneous group with diverse behaviors, motivations, and interests (Neihart, 2002; Rogers, 2002; Siegle \& McCoach, 2003). It is important to gain as much insight as possible into the phenomenon of underachievement in order to identify effective intervention strategies (Reis, 2000). The academic success of students is directly linked to motivation. Students adopt a range of

goals and purposes for their behaviors in a school setting and the degree to which they are engaged and put forth effort is a choice (Pintrich, Marx, \& Boyle, 1993). Study of student motivation and the factors that influence motivation of gifted students is essential to understanding underachievement. This section will examine research on 
underachievement and motivation as they relate to indicators that reverse or prevent underachievement and that increase motivation among students.

Underachievement, the failure to perform at a level commensurate with potential, manifests in many forms. Underachievement may be the discrepancy between a demonstrated ability and performance (Baum, Renzulli, \& Hébert, 1995; Clark, B., 2008; Reis, 2000,). This form of underachievement is commonly reflected in "bright" students who make poor grades (or grades that are not A's). They have demonstrated the expected performance ability at one time, but cease to demonstrate it. Underachievement may be the discrepancy between predicted ability and performance (Reis, 2000; Renzulli, Reid, \& Gubbins, 1992). This may be reflected in a student whose test scores show a high IQ, but the performance is not commensurate with the measure of potential (SpeirsNeumeister \& Hébert, 2003).

Underachievement may also be defined as the failure to develop a latent potential (Reis, 2000). Students may experience short-term lags in achievement (situational underachievement) that have multiple causes and that are addressed with interventions that are different than those of chronic underachievement (Clark, 2008). Patterns of achievement or underachievement become habituated the longer they are in place, making unproductive academic habits difficult to overcome (Peterson, 2000).

Reis (2000) outlines a number of factors that may contribute to underachievement: family dynamics, influence of peers, cultural differences, and poor match between educational programming and student needs, including educational gaps. Suggestions to address the underachievement factors include strengthening reward systems, filling educational gaps, and identifying motivational factors. By creating a 
favorable environment for achievement, by identifying student strengths and interests, and by adjusting the curriculum and classroom situation, some success has been achieved in reversing chronic underachievement (Reis, 2001; Speirs-Neumeister, \& Hébert, 2003).

Due to the complexity of underachievement issues and the levels of concern that underachievement raises among educators, multiple studies into causes and interventions have been conducted (Hoover-Schultz, 2005). Of particular importance to this study are research projects that examine underachievement patterns, factors influencing student motivation, and successful interventions (Grobman, 2006; Speirs-Neumeister \& Hébert, 2003).

\section{Patterns of Underachievement}

In research examining underachievement patterns, factors most significant in causing underachievement and those most significant in reversing underachievement have been studied. Studies looking at the causes of underachievement and strategies to reverse underachievement have identified a number of broad causative categories that manifest in student performance that is lower than expected. The broad categories are personality and self-concept including perfectionism, motivation, conflicting role identify, and external locus of control (Csikszentmihalyi, 1990; Emerick, 1992; Hébert, 2001; Hoover-Schultz, 2005; Speirs-Neumeister \& Hébert, 2003), family factors such as conflicting expectations (Luscombe \&Riley, 2001; Peterson, 2001), poor match between the classroom and the needs of the student, especially lack of challenge (Baum, Renzulli, \& Hébert, 1995; Clark, 2008; Davalos \& Griffin,1989, Gentry, Rizza, \& Gable, 2001), and lack of a significant support individual (Baker, Bridger, Evans, 1998; Baum, Renzulli, \& Hébert, 1995; Clark, 2008). 


\section{Student Personality and Self-Concept Causes}

Student personality and self-concept impact student achievement significantly. Emerick (1992) found that students identified themselves as one of the six critical factors in their underachievement and its reversal. They reported that their academic selfconcept, the degree to which the students saw themselves as able to be academically successful, impacted their effort and success (Emerick, 1992; Ford, 1989; Ford, 1992; Hoekman, McCormick, \& Gross, 1999; Van Boxtel \& Monks, 1992). Underachieving students were found to have an external locus of control, believing that their success was more closely related to innate ability (they should be able to naturally succeed) or to conditions beyond their control, rather than equating success with effort (Csikszentmihalyi, 1990; Ford, 1992; Luscombe \& Riley, 2001; Peterson, 2001; Van Boxtel \& Monks, 1992).

Studies relating to perfectionism, focus on high personal standards resulting in being highly critical of one's own work (Clark, 2008), examined the role of perfectionism, both self-directed and societal-directed, in fostering underachievement. Peterson (2001) found that high ability students struggled with the balance between personal goals and the expectations of others, often resulting in a motivational "crisis" that impacted identity and achievement. LoCicero and Ashby (2000) identified strong adaptive tendencies leading to perfectionism across the gifted population as students focus on high expectations. Underachievement emerged as a significant risk for gifted students, however, when the student experiences increased distress due to the discrepancy between their standards and their performance (Ablard, 1997; Grant \& Dweck, 2003;

LoCicero \& Ashby, 2000; Peterson, 2001; Siegle \& Schuler, 2000). 
Perfectionism may be exacerbated by the misalignment of expectations of the student and of significant others such as parents or teachers (Gentry \& Owen, 1999; Supplee, 1989). Students reported being conflicted as they tried to live up to the expectations of others; and the belief that they cannot succeed fostered underachievement (Ford, 1992; Gallagher, Haradin, \& Coleman, 1997; Peterson, 2001). Perfectionism manifested itself as assessment anxiety (Elliott \& Dweck, 2005), as task avoidance (Kanevsky \& Keighly, 2003; Reis \& McCoach, 2000), or as the inability to complete a task because it will never be good enough (Heacox, 1991; Schuler, 1999).

Conflicting role identity is often closely related to perfectionism as the student works through how they see themselves and how others see them (Peterson, 2001). Gifted students strive to balance identity at three levels-how they see themselves, how they are seen by those who are significant in their lives, and how they are seen by society in general (for most students that is their school environment). Failure to achieve a balance creates ongoing conflict that impacts students' school performance and their perceptions of their own ability (Ablard, 1997; Emerick, 1992; Heacox, 1991; Supplee, 1989; Van Boxtel \& Monks, 1992). Students report employing varied strategies to try to balance the perception conflicts. Many gifted students report efforts to avoid standing out by underachieving in an attempt to fit in at school (Ablard, 1997; Ford, 1989; Gentry, Rizza, \& Gable, 2001; Luscombe \& Riley, 2001). Students' perceptions of cultural and peer expectations contribute to non-performance and underachievement patterns (Kavensky \& Keighley, 2003).

Peterson (2001) found that gifted students reported significant struggles with career, vocation, and academic focus, experiencing difficulty dealing with multi- 
potentiality. Gifted students may see themselves as conflicted between what they want to do, what they want to try out, and the expectations of others (Porath, 1996). Difficulty resolving conflict with family and establishing independence in the face of low selfconfidence exacerbated the risk of underachievement (Peterson, 2001; Porath, 1996; Rimm, 1995). Issues with identity development and finding direction significantly impacted motivation.

Particularly vulnerable to underachievement conflict are gifted females (Kerr, 1994; Luscombe \& Riley, 2001; Reis, 1998; Siegle \& Schuler, 2000). Females frequently reported that they made choices that would keep them from standing out in order to fit in and find social acceptance (Kline \& Short, 1991). Luscombe and Riley (2001) found that gifted females rated themselves as less capable, less acceptable, and with fewer options. Vulnerability to external influences increased as the degree of giftedness increased (Rimm, 1995).

Kerr (1994) found differences in teacher feedback to females increased underachievement by failing to reinforce the relationship between effort and success (Clark, 2008; Ford, 1992; Kerr, 1994). Social expectations and gender stereotypes had the potential to limit opportunities and alter expectations for gifted females (Kerr, 1994; Reis, 2003; Siegle \& Schuler, 2000).

An additional self-concept dimension that impacts underachievement is the student-held belief that the student is not capable of what is being asked of him or her (Ablard, 1997, Clark, 2008; Siegle \& Schuler, 2000). This belief may stem from inadequate feedback (Baum, Renzulli, \& Hébert, 1995), lack of organizational skills or related skills to complete the task (Baum, Renzulli, \& Hébert, 1995; Clark, 2008; Elliott 
\& Dweck, 1995; Heacox, 1991; Karnes \& Bean, 2005; Lamb \& Daniels, 1993), or a view that mistakes are not fixable based on an inaccurate perception of personal abilities (Reis \& McCoach, 2000; Siegle \& Schuler, 2000).

Hoekman, McCormick, and Gross (1999) identified optimism as an important factor influencing motivation as students see a positive relationship between their expectations, their experiences, and their environments. They found that there were significant interaction effects in both high and low reports of satisfaction with school. Data showed that students reported an increase in burnout as optimism increased-the higher the student's expectations for the experience, the greater the likelihood of burnout. This supports potential dissatisfaction arising from a competing sense of the ideal, coinciding with adolescent needs within the gifted population (Silverman, 1993). Another key finding among gifted students was that burnout was common when students reported "under load" or lack of challenge. When repeatedly faced with inadequate challenge, students stopped making an attempt (Hoekman, McCormick, \& Gross, 1999). This justifies current concerns about the school context and the potential mismatch between developmentally appropriate provisions and the needs of gifted students.

\section{Motivation and Underachievement}

The lack of motivation to learn can result from a curriculum directed at a level too low for gifted children (Keating, 1991). Intrinsic motivation appeared difficult to maintain for the students who faced instruction at inappropriate levels. An additional factor in motivation appears to be linked to organizational and study skills. Students who do not believe they possess needed skills reflect a decline in motivation. 
Because children's theories of competence are related to their knowledge of what is expected and valued in school, efforts to improve achievement include supportive feedback focused on ability ( Baum, Renzulli, \& Hébert, 2004; Rayneri, Gerber, \& Wiley, 2006). Expectations that are clearly articulated and appropriate to the needs and abilities of gifted students support achievement and help to reverse underachievement (Speirs- Neumeister, \& Hébert, 2003). Hoekman et al. (1999) identified the relationship between motivation and gifted learners based on recognition of the unique profiles of individual gifted learners. Baker, Bridger, and Evans (1998) found that student study skills, parenting, and quality of academic programming all influenced student motivation and achievement.

Student achievement and self-concept are directly related. As dimensions of selfconcept are studied (physical, moral, personal, family, social, academic/work, identity, satisfaction, and behavior), those gifted students who rated themselves high in selfconcept dimensions also were rated high in student achievement (Luscombe \& Riley, 2001). Gender differences revealed that gifted females of equal ability scored themselves lower in measures of self-concept. The "disappearance" of gifted females in the school setting (Kerr, 1991), lower self-concept among gifted females (Van Tassel-Baska, Olszewski-Kubilius, \& Kulieke, 1994), and the tendency of gifted females to underachieve to fit social situations (Silverman, 1993) are all important factors in female motivation and underachievement with implications for future studies.

\section{Student Personality and Self-Concept Interventions}

Dimensions of underachievement based in student personality and self-concept can be addressed through the careful attention to students' perceptions of their abilities 
(Ablard, 1992; Ford, 1992). Students who spend the majority of their class time in settings where the work is too easy develop a self-concept that diminishes the connection between effort and success. Consequently, at-risk underachievers have little task persistence and may not attempt a task at which they may not be successful (Elliott \& Dweck, 2005; Reis \& McCoach, 2000). Students develop avoidance strategies as a form of self-protection. They cannot fail at a task they do not attempt (Clark, 2008; Heacox, 1991; Reis et al., 1993).

Comparisons among gifted students revealed that students who are underachieving have low ratings in the areas of academic self-concept, perception of cognitive functioning, and social self-concept (Van Boxtel \& Monks, 1992). Among underachieving gifted students, perceptions of their ability are shown to decline over time (Porath, 1996) and those students have high levels of dependence on teacher affirmation and external rewards (Porath, 1996; Van Boxtel \& Monks, 1992).

Use of pre-assessments to determine levels of student readiness is an important intervention when paired with appropriate instructional delivery and meaningful groupings (Colangelo, Assouline, Gross, 2004; Emerick, 1992). Providing instruction in courses that students perceived as providing both intellectual and creative challenges after validating the skills and knowledge students already possess are important factors in making achievement relevant to students in a pattern of underachievement (Emerick, 1992). Assuring that high ability students spend time with students of similar interests, needs, and abilities in settings that reflect appropriate instruction and content combine as important interventions to address student self-concept (Emerick, 1992; Hoekman, McCormick, \& Gross, 1999; Reis et al., 1993). 
In addition to lack of challenge, students may underachieve to mask skill deficits or may simply lack the executive function skills to assure success (Reis \& McCoach. 2000). Effective interventions require careful task analysis and attention to the student's organizational and task skills that will foster success (Ford, 1989; Redding, 1990; Reis \& McCoach, 2000; Siegle \& Schuler, 2000).

Perfectionism-based underachievement interventions require the development of strategies that enable the student to see mistakes as fixable (Reis, 1998; Siegle \& Schuler, 2000 ) and the development of strategies to establish realistic expectations tied to priorities (Baum, Renzulli, \& Hébert, 1995; Renzulli, Reid, \& Gubbins, 1992; Reis, 2000). Growth-based goals and related feedback for tasks are identified as significant in increasing academic motivation (Emerick, 1992). Attention to student learning styles and strengths for instruction proves to be beneficial in increasing motivation and student selfconcept (Ford, 1992; Gohm, Humphreys, \& Yao, 1998; Hayes, Norris, \& Flaitz, 1998; Hébert, 2001; Porath, 1996). Strategies to improve students' views of self-worth linked in-school and out-of-school interests that allowed students to "escape" negative school experiences while identifying the in-school learning experiences that were relevant to their areas of personal interest (Emerick, 1992). Each of these interventions has the potential to link to KERA (1990) and current reforms (USDOE, 2009) with emphasis on performance-based assessments and authentic assessment.

Student self-reports of conflicts between their personal goals and attempts to live up to the expectations of others are pervasive across studies on underachievement (Baum, Renzulli, \& Hébert, 1995; Gallagher, Haradine, \& Coleman, 1997; Gohm, Humphreys, \& Yao, 1998; Hébert, 2001; LoCicero \& Ashby, 2000; Luscombe \& Riley, 2001; Peterson, 
2001). Effective interventions involve teaching and using executive function skills, teaching and monitoring goal-setting, and using pro-active communication to balance the conflicting demands of personal expectations, family expectations, and societal expectations (Baker, Bridger, \& Evans, 1998; Elliott \& Dweck, 2005; Peterson, 2001).

\section{Conflicting Role Identity Causes}

Gifted students at all levels report conflicting role identities that may place them at risk for underachievement (Grobman, 2006). This conflict occurs both at school and at home, as gifted students strive to identify what is expected of them across settings and to balance those expectations with their personal expectations (Elliott \& Dwek, 2005; Emerick, 1992). The levels of conflict increased as students progressed through school (Baker, Bridger, \& Evans, 1998; Elliott \& Dwek, 2005; Gentry, Rizz, \& Gable, 2001). Students with the highest abilities reported the most conflict (Ablard, 1997), females reported significant conflict that resulted in underachievement (Ablard, 1997; Lamb \& Daniels, 1993; Peterson, 2001; Rimm, 2004), and students with multi-potentiality (strengths in more than one area) reported guilt and difficulty performing as expected (Ablard, 1992; Peterson, 2001; Redding, 1990).

Ford (1989) found surprising consistencies in the responses of gifted students who characterized themselves as "average" and recited extensive accounts of shortcomings and evidence to prove they were less than exceptional. Students indicated that they did not want to stand out and they were embarrassed about doing well without working. Students reported putting little effort or thought into the completion of their work while the adults were telling them to "do their best." The responses were viewed as precursors to conscious underachievement (Heacox, 1991; Rimm, 1995). 
As with the perception of difference from peers, gifted students express guilt over the expectations of others and their concern that they were not measuring up (Ablard, 1997; Ford, 1989; Porath, 1996). Students express concern that they do not have the skills to assume the roles that others seemed to expect of them and decline in their perceptions of academic ability over time (Porath, 1996). Students report dissatisfaction with behavioral expectations when bright students are used as monitors or mediators, and they reported dissatisfaction with the frequent role of tutor to other students (Ford, 1998).

Patterns of conflict in the students take many forms (Ford, 1998; Heacox, 1991; Rimm, 1995; Rimm, 2004). The students set high standards for themselves, yet they suffer guilt of failure to live up to the expectations they believe others had for them. The students report confusion by their abilities, yet boredom with school. They spend time on tasks they considered meaningless and that fostered intellectual laziness, knowing that they had not really done their best (Ford, 1998; Grobman, 2006). Student insights reveal that the gifted students are at risk of underachievement as these affective areas are the foundation of motivation.

Ablard (1997) examined the self-perceptions and needs in academic and social areas of academically talented middle-school students, specifically looking at differences by academic ability and gender. Gifted females had more positive social self-concepts than males. In addition, students who were moderately high in academic domains reported significantly higher social self-perceptions than students rated high or very high in academic domains (Ablard, 1997). Those students who were more different from the norm report more identity conflict (Ablard, 1997; Elliott \& Dwek, 2005). Similarly, students with moderately high verbal abilities were more likely than students with high 
verbal ability to describe themselves as cooperative, generous, and engaging in behaviors that benefit others. They were more likely to portray themselves as affectionate, friendly, and sociable (Ablard, 1997, Brounstein et al., 1991; Hoge \& McShreffrey, 1991).

Gifted students report higher academic self-perceptions than their normative peer group and feelings that they are different and are not treated the same as others (Ablard, 1997, Brounstein et al., 1991; Hoge \& McShreffrey, 1991). These self-perceptions may contribute to feelings that their advanced abilities isolate them from others and translate into a social handicap (Rimm, 2004). Due to feelings of isolation or lack of acceptability, highly-able students may use strategies to mask their abilities and compromise academic achievement (Coleman \& Cross, 1988; Coleman \& Sanders, 1993; Cross et al., 1993), resulting in underachievement.

Self-perceptions and needs vary by degree and type of academic ability (Ablard, 1997; Rayneri, Gerber, Wiley, 2003). The students with the highest ability describe behaviors and interests that would be less apt to lead to popularity among peers (less nurturing and less interested in opposite-gender relationships). Similarly, the perceptions of students with high verbal ability indicate they viewed themselves as less nurturing and less interested in opposite-gender relationships than the students with high mathematical ability (Ablard, 1997).

One of the difficulties inherent in working with underachievement is arriving at a clear operational definition because, like the term gifted, it means different things to educators and parents as they attempt to ameliorate the problem. In fact, more than 15 definitions of underachievement have been recognized in scholarly literature (Dowdall \& Colangelo, 1982). However, student perceptions may impact underachieving behaviors 
far more than the definition used (Smutney, 2004). Consequently, an important process in developing understanding of underachievement is to gain insight into the perspectives of the underachieving student.

\section{Conflicting Role Identity Interventions}

The characteristics and strengths of gifted students place them at risk for underachievement as they work to "fit in" and to live up to the expectations of those with whom they interact (Clark, 2008; Elliott \& Dwek, 2005). Communication of clear, positive expectations with the support to reach those expectations is a key to reversing underachievement (Baum, Renzulli, \& Hébert, 1995; Wendel \& Heiser, 1989). Pivotal in that intervention is the development of a strong relationship with a significant adult.

Students report that a key teacher or other significant adult was the most important factor in reversing their underachievement (Ablard, 1992; Emerick, 1992; Porath, 1996) and that the teacher served a number of important roles. Studies identify teachers as vital to articulating performance standards and progress toward those standards (Baum, Renzulli, \& Hébert, 1995; Reis, 1998). In addition, teachers used diagnostic strategies to identify skill gaps and student learning styles in order to adjust instruction to facilitate success (Baum, Renzulli, \& Hébert, 1995; Ford, 1992; Karnes \& Bean, 2005; Wendel \& Heiser, 1988). Teachers who played significant roles in reversing underachievement addressed the language of learning, study skills, and conflict resolution strategies to get them through situations where the rigor was increasing appropriately, but students lacked requisite skills (Hébert \& Olenchek, 2000; Redding, 1990). Effective teachers were reported to assist underachieving students by teaching them to "play the 
game" in order to minimize conflicts between the student and the learning environment (Hébert \& Olencheck, 2000).

Students reported that teachers and parents must sustain and project positive, consistent faith in the abilities of the student while maintaining high expectations (Ablard, 1997; Baum, Renzulli, \& Hébert, 1995; Emerick, 1992), must project the message that the total worth of the student is more than their academic success (Heacox, 1991), and must value the interests and goals of the student (Baum, Renzulli, \& Hébert, 1995; Peterson, 2000; Peterson, 2001). The perception that key adults are open-minded, non-judgmental, consistent, and advocates is reflected consistently in studies on the individuals who are influential in reversing underachievement (Baum, Renzulli, \& Hébert, 1995; Hébert \& Olencheck, 2000).

Implications for education can be drawn from the effectiveness of use of language of learning in improving student achievement (Davalos \& Griffin, 1989). Teachers who equipped their gifted students with the terminology and concepts to describe the learning process and learning goals also equipped the students to take more control over their own learning and improved student satisfaction with the learning environment (Heacox, 1991; Rayneri, Gerber, \& Wiley, 2003).

Davalos and Griffin (1989) identified conditions which must be met if gifted underachieving students are to be adequately served in the regular classroom (a) the regular classroom teacher must understand the benefits of individualized instruction and must be motivated to use individualization as an instructional technique, (b) the classroom teacher must be willing to share control of learning with the students, (c) the teacher must understand the academic, social, and emotional needs of gifted learners and 
be prepared to support those needs, and (d) the regular classroom teacher must facilitate the development of a shared language of learning among students and instructors.

Establishing excellence and valuing learning as the cultural norm of the classroom and school setting are critical to addressing conflicts of identity and expectations (Baum, Renzulli, \& Hébert, 1995; Rimm, 1995). Student goal-setting and interpersonal relationships within the classroom and school are also critical (Rayneri, Gerber, \& Wiley, 2003).

\section{Poor Match—Lack of Challenge}

Failure to provide instruction at the optimal level of challenge creates anxiety, lack of intrinsic motivation, dissatisfaction, burnout, and diminished confidence (Clark, 2008; Hoekman, McCormick, \& Gross, 1999; Speirs-Neumeister \& Hébert, 2003)

Student modalities and learning styles impact the match between instruction and achievement. Learning preferences and skills are reflected in varying levels of performance across tasks that differ according to the type of cognitive processing they require (Hayes, Norris, \& Flaitz, 1998; Redding, 1990). Many gifted underachievers exhibit relative performance deficits on tasks which require analytic information processing. Though they perform at high levels on tasks which require synthesizing, many do not perform as well on detailed, computational, or convergent problem-solving tasks (Peterson, 2001; Redding, 1990; Smutney, 2004).

Berlin (2009) found that student perceptions regarding ability and likelihood of success significantly impacted motivation and achievement. In addition, the perceptions of parents and teachers influenced the degree to which achievement patterns of gifted achievers differ from underachievers. Despite common stereotypes about gifted 
individuals, gifted achievers show unevenness in their levels of success (Grobman, 2004) and those normal patterns of strengths and relative weaknesses often feed student perceptions of lack of ability or unworthiness (Hoover \& Schultz, 2005; Kanevsky \& Keighley, 2003). Learning styles impact both the way achievers and underachievers interact with content and the expectations of others (Crandall, Katkovsky, \& Preston, 1960; Gohm, Humphreys, \& Yao, 1998; Grobman, 2006).

Gohm, Humphreys, and Yao (1998) compared the performance and perceptions of students gifted in spatial ability to students gifted in mathematical ability, though both groups scored well above average on all measures of aptitude, indicate a pattern of choices and behaviors with long-term implications. Spatially-gifted groups indicated more time spent in hands-on activities and in courses that included hands-on activities. Spatially-gifted students reported high rates of lack of interest in schoolwork, failure to pay attention in class, and doing only enough to get by (Gohm, Humphreys, \& Yao, 1998; Kanevsky \& Keighley, 2003; Reis \& McCoach, 2000). Males in the spatiallygifted group reported that they spent less time per week studying, that they perceived that they had less ability, and that they did not enjoy learning (Gohm, Humphreys, \& Yao, 1998; Reis \& McCoach, 2002; Rimm, 1995). The spatially-gifted group had lower grades, had lower post-high school aspirations, and had more plans to defer college than the mathematically-gifted group (Gohm, Humphreys, \& Yao, 1998).

Gohm, Humphreys, and Yao (1998) reported that spatially-gifted groups reported receiving less college guidance from school personnel and from fathers than the mathematically-gifted groups, though the gifted groups, both boys and girls, received more guidance on their plans after high school than the general population. As a part of 
the longitudinal data participants reported that the spatially-gifted group achieved fewer advanced degrees and entered occupations that yielded lower annual income.

Gohm, Humphrey, and Yao (1998) found that though students were capable of doing equally well academically, the students in the spatially-gifted group did not fully utilize their capabilities in high school and college. They went on to lower paid occupations than their mathematically-gifted counterparts. The patterns of dissatisfaction with school reported by spatially-gifted participants remained pervasive through their educational careers, limiting their options in career and occupational choices. Students performing in the top $1 \%$ of the population in spatial ability reported disconnect and disenchantment with school settings, causing them to underachieve.

\section{Interventions to Improve Match}

Acknowledgment of the skills and concept mastery that students bring to the classroom is powerful in sustaining motivation (Emerick, 1992). As teachers identify and respond to the levels of instructional readiness of their students, underachieving students report improvement in positive attitudes toward instruction and increased effort (Baum, Renzulli, \& Hébert, 1995; Emerick, 1992). Allowing students to move at a rapid pace and giving credit for what students know were identified as powerful motivators. When classroom teachers appeared to value what they know, students' attitudes changed and they began to show what they knew and were capable of doing (Emerick, 1992).

Additional qualities of teachers have been identified as influential in reversing underachievement. Emerick (1992) reported that the teachers who had profound impact on student achievement were those who demonstrated that he or she cared for and liked the students as individuals. Though the manner in which that caring was demonstrated 
varied greatly, the student belief that the teacher truly cared appears to be paramount (Emerick, 1992; Grobman, 2006; Speirs-Neumeister \& Hébert, 2003).

Students responded well to the teacher's willingness to communicate with the student as a peer, as an equal as well as a facilitator for learning, and the teacher's enthusiasm and knowledge about the content that created a contagion for learning (Emerick, 1992). Influential teachers held high, but realistic standards for the students based on a true knowledge of the individual students (Grobman, 2004; McCoach \& Siegle, 2001) and approached instruction through a variety of strategies and resources calling for direct involvement of students with an emphasis on engagement (Rayneri, Gerber, Wiley, 2006; Speirs, Neumeister, \& Hébert, 2003; Siegle \& Schuler, 2000). Baum, Renzulli, and Hébert (1995) identified teacher behaviors influential in reversing underachievement. Teachers who took the time to get to know the student and demonstrated a belief in the abilities of that student were able to establish a relationship the made the teacher influential in changing behavior patterns. In addition, teachers who emphasized positive qualities in the student and an enthusiasm for teaching were important in helping students overcome underachievement. As the relationships with students were developed, students reported that influential teachers were important in assuming the roles of facilitator and of researcher in the learning of the students (Kanevsky \& Keighley, 2003; Rayneri, Gerber, \& Wiley, 2003).

Attention to student learning style in delivery and assessment of learning is a factor that impacts the achievement of gifted students (Baum, Renzulli, \& Hébert, 1995; Rogers, 2002). Rayneri, Gerber, and Wiley (2006) studied the learning style preferences of gifted achievers and underachievers. The learning style preferences of both groups 
showed marked similarities; however, the underachievers reported stronger need for those preferred modalities.

Teacher practices to individualize and group students have positive impact on student achievement (Colangelo, Assouline, \& Gross, 2004; Davalos \& Griffin, 1989; Speirs-Neumeister \& Hébert, 2003). Though the teacher's degree of control and basic teaching style impact the success with which they could implement individualization strategies, the use of contracts, individualized projects, higher-level thinking activities, and computer programs had positive impact on student achievement and reversing underachievement (Rayneri, Gerber, \& Wiley, 2006). Teachers who needed to maintain a high degree of control tended to make fewer substantive changes in the classroom environment or instruction (Davalos \& Griffin, 1989).

Students view a significant change in their concept of self as necessary for the reversal of the underachievement pattern (Davalos \& Griffin, 1989). Students who overcome underachievement believe that they have undergone such a change and that without that change other factors would have had little or no personal impact (Peterson, 2001; Rayneri, Gerber, \& Wiley, 2006). As students develop more self-confidence through small successes experienced both in and out of school, they report that they see academic success as a personal responsibility and as something that gives personal satisfaction, rather than as a means to please others (Ford, 1992; Ford, 1996; Kanevsky \& Keighley, 2003). Students report that the ability to assume personal responsibility is linked to the students' ability to see the "big picture" if they are to successfully reflect on and understand factors that contribute to their underachievement patterns (Peterson, 2001; Rayneri, Gerber, \& Wiley, 2006). 
Reversing underachievement patterns may require careful examination of the curriculum and classroom situation of underachievers. Whitmore (1980) and Butler-Por (1987) reported that placing a gifted child in his or her "least restrictive environment" will minimize underachievement. Consequently, continually upgrading content and skills, minimizing repetitive and redundant lessons, addressing student learning styles, and providing educational challenges in the classroom are found to be keys to reversing underachievement (Rayneri, Gerber, \& Wiley, 2006). Reform efforts that emphasize real-world connections and opportunities for alternative assessments can be important initiatives to support high levels of achievement among gifted students (Rayneri, Gerber, \& Wiley, 2003; Renzulli \& Reis, 1985; Treffinger, 1986).

Attention to the factors that impact achievement in educational programming and delivery could aid gifted underachievers in the reversal of underachievement patterns. In addition, the characteristics of an educational experience that engages gifted underachievers strongly resemble the characteristics of effective education designed to close achievement gaps across all population groups (Goodlad, 1984; Rayneri, Gerber, \& Wiley, 2003; Renzulli \& Reis, 1987). By making these factors standard in classrooms, all students may benefit.

Underachievers express disconnect from the curriculum of the school and from the teacher, and they hold an external locus of control, attributing their success or failure to factors outside of themselves (Ford, 1992). Educational experiences matched to the needs of underachievers make the curriculum relevant to the interests and needs of the students and build connections with well-trained teachers who can serve as mentors and model coping strategies (Hébert, 1997). Counseling efforts must be implemented to aid 
students in addressing the conflicts between their ideology and the realities in their lives (Baum, Renzulli, \& Hébert, 1995).

A survey of the literature on gifted underachievement reveals that gifted students report lack of challenge in their academic settings (Clark, 2008); that gifted students need additional diverse and more complex materials (Maker \& Nielson, 1995); and that gifted students need instructional time with similarly-paced peers (Van Tassel-Baska \& Olszewski-Kubilius, 1989).

Teacher training and support are additional interventions to address underachievement (Johnsen, Haensly, Ryser, \& Ford, 2002). Ford (1992) found that gifted students report sympathy for the teacher's task of meeting the wide range of needs in a classroom, yet they report a decline in motivation and achievement as they "wait." Providing teachers with the information, strategies, and support to adequately meet student needs is essential to the development and delivery of successful gifted services and to the prevention or reversal of underachievement (Grobman, 2006).

The effective use of grouping to match instruction to student needs is one intervention to improve student achievement. Gentry and Owen (1999) studied the effects of total-school cluster grouping on student achievement, underachievement, classroom practices, and identification. Teachers received training in gifted education and talent development based on the Schoolwide Enrichment Model (Renzulli \& Reis, 1985) and participated in cluster grouping training with on-going training in curriculum compacting, curricular and instructional differentiation, and thinking skills. Teachers then placed students in flexible cluster groups for instruction based on the categories of highachieving, above-average, average, low-average, and low. Support resource personnel 
(gifted, special education, Chapter I, paraprofessionals) were maximized by assignment to appropriate target groups (Gentry \& Owen, 1999). Following interventions, the number of students identified as high achieving increased and the number of students identified as low achieving decreased. Teachers reported that the restricted range of achievement levels created more time to work with students and to modify for higher rates of success for all students (Gentry \& Owen, 1999; Neihart, 2007; Rogers, 2002).

The positive classroom environments, reported by students, parents, and teachers, grew out of teaching strategies and curriculum modifications to benefit students as more teachers reported adjusting assignments and working to build student success with a recurring theme of concern and caring (Gentry \& Owen, 1999). These findings supported results of exemplary programs investigations by Delcourt and Evans (1994), who identified flexible curriculum and instruction matched to student needs, supportive atmosphere and environment, and strong leadership. Flexible achievement grouping appeared to produce academic gains for all students and to have positive implications for preventing underachievement (Gentry \& Owen, 1999).

\section{Underachievement and Motivation Summary}

The field of underachievement will be enhanced through further studies into the role of the teacher and significant personal characteristics as the basis for development of effective interventions. The link between the underachiever's areas of interest and academic pursuits also needs to be studied further. Due to the uneven progress of the reversal of underachievement, the need for additional study of the continuum of progress, factors relating to failure to progress, and personality characteristics of underachievers is indicated. The most significant implication of the review of underachievement literature 
is, however, that some forms of underachievement can be reversed and additional research into causes and interventions must follow.

Research implications arise out of the links among challenge, satisfaction, motivation, and achievement. As schools seek to maximize student achievement, the roles of each of these factors in creating (or reducing) underachievement must be studied. As state and national reform efforts seek to address the "achievement gap," gifted underachievers represent an important component in that phenomenon, particularly if educators and decision-makers can acknowledge and respond to the unique needs of gifted students as they identify future reform initiatives with the greatest potential for success.

\section{Gifted Education in Rural Kentucky}

An important element in putting the KERA initiatives in context in Kentucky is to examine the unique attributes of rural schools. The U.S. Department of Agriculture (2010) and the Rural School and Community Trust (2009) define a rural school as a school or district that is located in a community with fewer than 2,500 people that is not within or adjacent to an urban area. In the United States, 9,063,790 students were enrolled in public schools in rural districts during the 2006-2007 school year (Johnson, 2009) while Kentucky served 259,067 students in rural schools with $49.8 \%$ of Kentucky schools classified as rural serving $40 \%$ of Kentucky's students, while one out of five students nationally attends a rural school (Johnson, 2009). Therefore, almost half of the gifted students in Kentucky are facing the unique challenges of students who attend rural schools (Howley, Rhodes, \& Beall, 2009). Kentucky is ranked number two in the U. S. 
in the number of Title I eligible students (Johnson, Strange, \& Madden, 2010) and is $47^{\text {th }}$ in high school graduation rate (USDA, 2007).

The specific challenges of rural education in Kentucky provide a unique context for examining instructional initiatives and gauging their success. The diverse features and instructional needs of rural schools impact the perceptions of success regarding past reform initiatives and the applicability of new reform initiatives as they are considered (Johnson, 2009).

Howley, Rhodes, and Beall (2009) conducted a meta-analysis of current research with rural gifted students and identified four pervasive issues that are faced by students and educators in rural settings-declining population, pervasive poverty, changing demographics, and high stakes accountability. Each issue has implications for gifted students within the classroom and within the community. In combination with the unique features of rural culture (Lawrence, 2009), the issues facing rural gifted students pose specific challenges in order to assure appropriate educational opportunities.

\section{Declining Population}

Declining population limits human resources and increases perceptions of gifted students that they must leave the community to achieve success (Johnson, 2009; Lawrence, 2009). As a result, some rural families discourage their children from accessing all available opportunities out of fear that young people will leave the community and will not return (Johnson, 2009; Kannapel et al., 1999). This has the potential to place gifted advocates at odds with family or community norms (Corbett, 2007; Johnson, 2009). 
An additional issue related to declining population is the loss of human resources in a rural community. As enrollment in a school declines, the funding based on enrollment is reduced, leaving fewer financial resources to address increasing needs (Howley, Rhodes, \& Beall, 2009). Specialized services, increased technology support, alternate resources, and specially trained staff all depend on resources that may not be available in a rural setting with a declining population (Montgomery, 2004). Rural students expressed concerns about lack of opportunities (Lawrence, 2009).

Consolidation of schools is frequently a consequence of declining student populations (Howley, Rhodes, \& Beall, 2009; Lawrence, 2009; Montgomery, 2004). Though this may increase access to some resources, the loss of community base is a negative outcome (Montgomery, 2004). If the school remains open with fewer students, the opportunities for the gifted students to work with intellectual peers are fewer and access to resources is limited (Howley, 1998). The school and priorities of the school, if they are seen as an avenue to encouraging the student to leave the community, may be cast in an adversarial role and teachers may perceive that parents do not support education (Howley, 2009).

The rural culture elements centered on a small population may also represent positive educational features. Lawrence (2009) asserts that in many rural communities, the school is such an integral element in the community that school personnel and school activities are perceived as extensions of the family, providing levels of awareness and support that help to prevent underachievement. In addition, the affiliations of many rural gifted students in community activities, church, and extended family have the potential to 
reduce the stigma of being bright that was expressed by suburban students (Hébert \& Beardsley, 2001; Lawrence, 2009).

Rural gifted students reported the important role of extracurricular involvement in obtaining positive reactions from others and in the development of perceptions of their own strengths (Battle, Grant, Heggoy, 1995; Howley, Rhodes, \& Beall, 2009; Montgomery, 2004). Though offerings are typically limited in rural areas, participation allowed students to develop a niche that forged connections among peers who shared common interests and to develop friends and acquaintances beyond the local community (Lawrence, 2009; Montgomery, 2004).

Successful rural gifted students reported patterns of accomplishment established through persistent involvement and commitment to academic work and extracurricular activities (Lawrence, 2009). Students took advantage of a wide variety of opportunities to demonstrate skills that provided connections far beyond the local community and participated in activities with opportunities for state and national recognition, providing opportunities for travel and experience outside of their hometowns (Battle, Grant, \& Heggoy, 1995; Howley, Rhodes, \& Beall, 2009). This early and persistent participation forged friendships beyond the boundaries of home and provided non-judgmental acceptance and encouragement that was not available at high school where depth of experience was not available (Battle, Grant, \& Heggoy, 1995).

Rural students who are high achievers identify qualities that they attribute to their success, including a high degree of goal direction (Siegle \& Schuler, 2000). Skills in problem identification and problem solving were identified by the participants as important characteristics in achievement motivation (Battle, Grant, \& Heggoy, 1995; 
Stanley \& Baines, 2002). Family support emerged as a major factor in the decisionmaking experiences of all high achievers and families influenced decision-making (Battle, Grant, \& Heggoy, 2007).

Davalos and Griffin (1989) identified the relatively stable rural population and opportunities to participate in community-based activities as positives that are available in a rural area. For some gifted students, this created the ability to foster deep friendships over time (Battle, Grant, \& Heggoy, 2007). However, that stability had the potential to create difficulties for new students or students who deviated from the cultural norms (Davalos \& Griffin, 1989). Students with no standing in the community-those who do not belong to a church or who do not have a family history in the community-may be excluded and lack the community support to succeed (Hébert \& Beardsley, 2001).

Student interests or talents that deviate from the community norm may place the rural gifted student at risk (Lawrence, 2009). An artistic male in a sports-oriented community or a mathematically-precocious girl in a traditional community may lack the support and role models to sustain the interest and necessary goal orientation needed to fully actualize their gifts (Montgomery, 2004). While this is a challenge for all students, it may be more difficult in a setting that is deeply rooted in traditional cultural norms (Howley, Rhodes, \& Beall, 2009).

Of significance for rural gifted students is the development of relationships with a key adult who recognizes and fosters interests and talents. Studies of rural gifted students who reversed underachievement and experienced academic success identified an influential adult as a determining factor in that success (Hébert, 1998; Battle, Grant, \& Heggoy, 1995). The classroom experiences of the rural students shared a strong link to a 
favorite teacher who motivated and inspired them to achieve through the provision of challenge and through the establishment of a good teacher-student relationship. Participation in gifted services, recognition of their abilities, and high peer and teacher expectations helped rural students see themselves as capable and able to make a contribution (Battle, Grant, \& Heggoy, 1995; Lawrence, 2009; Montgomery, 2004).

\section{Pervasive Poverty}

Pervasive poverty in rural settings impacts both the school environment and the community at large (Howley, Rhodes, \& Beall, 2009). Poverty limits access to resources, access to experiences, and may limit student aspirations (Johnson, 2009; Montgomery, 2004). Analysis of test data showing the performance of students of poverty reveals links between poverty and low achievement showing the negative impact of limited financial resources (KDE, 2006). As school funding that is dependent on enrollment and a local property tax rate in a rural area is reduced, those limited funds will typically be channeled to meet the needs of students who are underperforming (Lawrence, 2009). Finding resources to fund differentiated resources or extension activities represents a significant challenge in rural districts (Howley, Rhodes, \& Beall, 2009).

Poverty impacts the level and quality of enrichment experiences as gifted students may be needed at home for care of siblings, household chores, work to help support the family, etc. (Lawrence, 2009). Students may not be available to participate in activities outside of school hours and those students may not be recognized as gifted by teachers because they have not had the experiences associated with economically advantaged students (Howley, Rhodes, \& Beall, 2009; Lawrence, 2009). Providing appropriate 
experiences to strengthen talent development and identification require proactive and creative solutions in a rural setting (Montgomery, 2004).

Mismatch between the goals of the classroom and the needs of gifted students often results in a poor fit (Hébert \& Beardsley, 2001) that is exacerbated by teacher expectations. That mismatch may be more profound in a rural setting where the range of expectations is narrow and the resources are limited (Lawrence, 2009). Use of strategies to identify students' strengths, interests, and learning styles is especially important in designing instruction for diverse gifted students in a rural setting (Clark, 2008).

\section{Changing Demographics}

The changing demographics of rural communities pose an additional challenge for the provision of appropriate gifted services. Across the United States, rural communities have experienced an increase in minority populations to $23 \%$ (Howley, Rhodes, \& Beall, 2009). This reflects a cultural shift for rural communities that traditionally represented a very stable population of families with strong roots in the community and a homogenous population (Montgomery, 2004). Rural areas that were once primarily agricultural or mining-based offer limited appeal to many young people who migrate to urban areas (Howley, Rhodes, \& Beall, 2009).

As local youth seek employment opportunities that differ from traditional work roles within the community, those traditional roles may be filled through an influx of individuals representing minority groups that the schools have not had much experience serving (Lawrence, 2009). The stress on the general school staff is reflected by the teachers of the gifted who are charged with identifying and serving students from all demographics. Lack of resources and lack of experience put those gifted students at risk 
(Howley, Rhodes, \& Beall, 2009). Appropriate services require the addition of services for English language learners and a shift in identification and service policies for gifted students in an effort to find and serve students across all populations (Clark, 2008; Howley, Rhodes, \& Beall, 2009; Lawrence, 2009).

Projects developed to focus on under-represented rural minority children address culturally fair identification procedures, teacher and administrator training, and systematic implementation of best practice strategies. Through Project SEARCH, Swanson (1995) implemented a Javits grant project designed to identify and serve potentially gifted rural African-American children in the regular classroom using a range of identification procedures intended to minimize cultural bias. Project STAR (VanTassel-Baska, Johnson, \& Avery, 2002) provided additional research on the use of performance tasks and a talent-development protocol designed to augment the identification of economically disadvantaged and minority students.

The rural setting made effective staff development and on-going support difficult (Lawrence, 2009; Swanson, 1995), but adjustments throughout the life of the project were implemented to meet the specific needs of the project teachers. Through purposeful teacher training and implementation of instructional strategies, teachers identified more students with high potentials and added learning centers and opportunity for choice of classroom instruction. The SEARCH project offered an important intervention as a school-based, substantive change in instruction to better serve the needs of students within the classroom (Swanson, 1995). 
Continued attention to the needs of diverse gifted students in a rural setting will be important to assure that talent is identified and nurtured and that educational initiatives are tailored to the unique needs of the rural clientele.

\section{High Stakes Accountability}

The issue of high stakes accountability measures focuses resources on students who are not successful leaving fewer resources to provide enrichment or extension for those students who need additional challenge (Beisser, 2008; Lawrence, 2009). As the curriculum to address the assessment requirement is delivered, it lacks the depth and rigor to provide appropriate challenge to high potential students (Beisser, 2008). Because schools do not see a reward for focusing on high performing students, the time and resources are channeled elsewhere (Howley, Rhodes, \& Beall, 2009). While the state and national focus on No Child Left Behind intensifies and Race to the Top initiatives continue (USDOE, 2009), rural schools face increased pressure to eliminate all Novice performance and to increase the number of Proficient students. For students who begin the year at a Proficient level, there is no incentive to make sure those students progress (Lyons, 2004; Renzulli \& Reis, 1991).

In order to assure continuous progress for rural gifted students, practices beyond test preparation must be implemented. Rural schools must (a) use technology to access resources not available locally, including taking advantage of distance learning opportunities (Lawrence, 2009); (b) use varied acceleration options as a low-cost way to provide appropriate challenge (Colangelo, Assouline, Gross, 2004); and (c) expand the use of local leadership opportunities to strengthen ties to the community and establish in- 
depth applications of academic and creative skills beyond the school doors (Howley, Rhodes, \& Beall, 2009).

Reform initiatives must consider the unique needs of gifted students in rural settings in order to assure appropriate progress for those students. The insights of students who experienced the initiatives of KERA have potential to inform future educational practices.

\section{Gifted Education Practices in Rural Settings}

Gentry, Rizza, and Gable (2001) found that implementation of gifted regulations and best practices were limited in rural schools. Fewer students were identified as gifted in rural settings and rural students scored their classrooms as less frequently interesting and challenging than the urban and suburban students. Rural middle school students reported fewer opportunities for challenge and a lower frequency of enjoyment than the suburban students.

This comparison of student perceptions yielded findings consistent with the work of Reis et al., (1993), Goodlad (1984), and Westberg et al., (1993), all of whom found a lack of challenge in America's classrooms, especially for gifted students and those findings have been consistently replicated (Fredricks, Alfeld, \& Eccles, 2010; Gentry, Rizza, \& Owen, 2002). Middle school rural gifted students reported considerably less challenge than their suburban peers, revealing the risk to the cognitive and affective needs of these students in their current educational settings. In contrast, rural elementary students reported higher levels of enjoyment, a finding that may provide a foundation on which to build methods and processes of interest, challenge, and enjoyment in the middle school (Gentry, Rizzo, \& Gable, 2001). 
Rural districts are less likely to report identification and services of gifted students $\mathrm{K}-12$, are less likely to offer ability grouping as a strategy to meet student needs, are likely to offer fewer service options, and are more likely to classify gifted offerings as extra-curricular or intermittent (Colangelo, Assouline, \& Gross, 2004; Jones \& Southern, 1992; Montgomery, 2004). Rural districts are less likely to offer early entrance or radical acceleration as a service option for gifted students, though it can be implemented at low cost (Colangelo, Assouline, \& Gross, 2004; Jones \& Southern, 1992).

Study findings place renewed importance on application of existing program options in rural schools. Collaborative programs such as StAts (Gentry \& Ferriss, 1999), SEARCH (Swanson, 1995), and PACER (Haas \& Lambert, 1995) offer opportunities for rural districts with limited resources. In addition, rural districts struggle with providing a continuum of services (Renzulli, 1994) in order to meet the needs of students with special attention to student interests, opportunity for student choice, and the delivery of appropriate challenge.

The role of the individual teacher and the imperative that students have access to teachers trained in the nature and needs of gifted students is heightened in a rural setting as there are fewer intellectual outlets beyond the school setting (Lawrence, 2009). Hébert (1997) identified characteristics and actions of teachers of underachievement rural gifted students considered critical in addressing student needs. Effective teachers of rural gifted students provide opportunities for student choice and create opportunities for experiences beyond the classroom environment when it is apparent that those experiences will not be provided outside of school (Hébert, 1997; Hébert \& Beardsley, 2001; Peterson, Bennet, \& Sherman, 1991). 
Rural gifted students need intellectually challenging experiences. Expectations for these students need to remain high, and they need long-term, personalized support (Hébert, 1997). As educators seek to close the achievement gap, they must encourage all children, including gifted underachievers, to reach beyond their current academic levels in a personally relevant learning environment (Rimm, 1995).

The dynamics of being gifted in a rural setting are complex, as these students may face educational and affective challenges that are heightened by geographic isolation, smaller schools with fewer course offerings, fewer resources (financial and human), and traditional/rigid expectations (Swanson, 1995). Understanding underachievement of rural gifted youth requires background into the impact of rural life on the lives and educational settings of these students.

Implications for further study and for educators are numerous. Rural educators must remain aware of the critical role of the school in providing opportunities that are unavailable in the rural cultural setting and make efforts to provide them to gifted rural students. The lack of access to teachers trained in gifted education and the limited array of service options must be addressed through creative programming by maximizing available resources. Further study of effective options in rural gifted education will be important in meeting the needs of students in rural districts. Studies that examine the unique issues (cultural and academic) facing rural gifted students will be important to meeting student needs.

\section{Acceleration and Rural Students}

Though acceleration could be an economical method for meeting the needs of gifted students that overcomes some of the logistic or access problems of other options, it 
appears to be used infrequently in rural areas (Benbow, Argo, \& Glass, 1992; Colangelo, Assouline, \& Gross, 2004; Howley, 1986). The use of the 18 different forms of acceleration has been proven effective in meeting the needs of gifted students, but those strategies are not universally available in rural settings to increase the access of rural gifted students to appropriate pacing and levels of challenge to assure continuous progress (Colangelo, Assouline, \& Gross, 2004).

The effectiveness of acceleration is perceived as successful by students, with the most significant issue listed as needing help explaining to peers (Rimm \& Lovance, 1992). Parents indicated that any grade skipping required a period of adjustment for all parties, while students stated they did not experience adjustment problems. While parents and students indicated that they would make the same acceleration again, some parents reported that they should have made the decision to accelerate sooner. Students reported improved academic adjustment-effort and achievement—but all required (or will require) additional curriculum adjustments in the form of additional subject or grade skips, high level honors or Advanced Placement courses, or early exit from school to avoid reverting to underachievement (Benbow, Argo, \& Glass, 1992).

As schools strive to bridge achievement gaps and create environments in which all students achieve to their full potential, it is important to examine the role of adjusting curriculum pacing to provide a best match. As students believe they can achieve and they are rewarded for their success by acknowledging their mastery of content, the tide of achievement can rise for all students and schools are less likely to lose the abilities of underachievers (Bloom, 1985). This research is significant to rural education because successful acceleration is a cost-effective way to foster high student achievement and 
reverse or prevent underachievement and connections may be made to current reform initiatives such as Kentucky's early college or early exit programs (KDE, 2009).

\section{Summary}

This chapter provides an overview of the multiple facets of interest as background to this study. Divided into four major topics, (a) the Kentucky Education Reform Act; (b) Gifted Education in Kentucky; (c) Motivation and Underachievement; and (d) Gifted Education in Rural Settings, the chapter examined the background and literature by identifying the related topics that inform the research problem.

The questions answered in this study address the perceptions of adults who were identified as gifted students in a rural Kentucky school district during the implementation of the Kentucky Education Reform Act (KERA). Through a series of interviews, the participants provide insights that allow the iteration of themes to describe impact of the KERA initiatives on student and adult achievement, insights regarding the impact of related educational structures on their achievement and underachievement, and comparison of the perceptions of those who self-report achievement with the perception of those who self-report underachievement. 


\section{CHAPTER 3}

\section{RESEARCH METHODOLOGY}

\section{Introduction}

To gauge the impact of reform initiatives on the achievement and underachievement of rural gifted rural students, this phenomenological study investigated the perceptions regarding the impact of the components of the Kentucky Education Reform Act on the achievement of young adults who were identified as gifted students while attending a rural Kentucky school district. Through a series of interviews of 30 participants who graduated from a rural Kentucky high school between 1994 and 2004, the study identifies similarities and differences among perceptions of those who selfreport underachievement and those who self-report achievement. This chapter describes the methods used to gather and analyze data to answer the research questions.

\section{Research Questions}

The questions to be addressed in this study will be the following:

1. What are the perceptions of former students regarding the roles of each of the instructional Kentucky Education Reform Act initiatives (Portfolios [writing and mathematics], Ungraded Primary, KIRIS/CATS assessment, Proficiency as a performance goal, SBDM council policies) in fostering or impeding self-reported student and adult achievement? 
2. What related educational experiences and structures in a rural setting are perceived by the former students as fostering or impeding self-reported student and adult achievement?

3. What are the similarities and differences in perceptions between those adults who self-reported sustained achievement and those who reported underachievement?

\section{Research Design}

To gain additional insight into cultural and social norms and for exploratory research, qualitative methods provide important tools (Creswell, 1994; Spradley, 1979). Through the use of narrative data gained through interviews and conversation, qualitative methods allow the researcher to use an iterative process between data collection and data analysis that can yield new information through exploratory research (Teddlie \& Tashakkori, 2009). This process is appropriate for exploring abstractions and phenomena that are based in cumulative experiences (Kvale \& Brinkmann, 2009).

Creswell (2006) identifies the basic purpose of phenomenology as the synthesis of individual experiences with a phenomenon to a description of the universal essence. A phenomenological approach is well-suited to studying rural gifted education in reform, because education and educational reform are social abstractions that are enlightened through the experiences of those who make up the organization or who carry out the process (Seidman, 2006). Use of descriptions of the experiences generated by those directly involved is an important strategy for answering the questions related to "What was it like?" This is the key question when identifying participant perceptions surrounding the impact of their educational experiences (Creswell, 2006; Kvale \& Brinkmann, 2009; Seidman, 2006). 
The phenomenological project used the language and perceptions of the participants to produce a description of the educational culture during the implementation of reform initiatives and the impact of those cultural elements on their achievement (Spradley, 1979; Teddlie \& Tashakkori, 2009). Because this research sought to discover what the participants could reveal about their educational experiences and sought to use the participants' classifications and explanations of their experiences to increase understanding in the field of educational reform, the research was a phenomenological study (Seidman, 2006). This project provided opportunity for both in-depth analysis of specific reform elements and opportunity to identify relationships among the domains to generate a holistic view of the issues involved (Creswell, 1998; Seidman, 2006; Spradley, 1979).

This research project was a qualitative study targeting young adults who were identified and served as gifted students in a rural Kentucky school district between 1994 and 2004. A three-interview series of 40 to 60 minutes in length was used to provide opportunity for the researcher and participant to fully explore responses and to place experiences in context (Seidman, 2006; Spradley, 1979). Repeated interviews were used to help provide authenticity and increase validity as responses determined whether the method of investigation and the questions explored what they were intended to discover (Kvale \& Brinkmann, 2009). Internal consistency between interviews and prolonged engagement were important elements in establishing trustworthiness of the data gleaned from the interview process (Seidman, 2006; Spradley, 1979; Teddlie \& Tashakkori, 2009). 
The structured questions for the interviews were designed by the researcher and piloted with four individuals who met the participant criteria as students who graduated from the target district between 1994 and 2004 and who were identified and served as gifted students. Two of the individuals self-reported pervasive underachievement, a significant discrepancy between potential and performance across all settings for an identifiable period (Heacox, 1991; Peterson \& Colangelo, 1996; Speirs-Neumeister \& Hébert, 2003), and two self-reported academic success throughout their school careers. The questions and process were refined for use with the research sample.

Prior to interviews, the purpose and structure of the study were reviewed with the participants, the informed consent forms were reviewed, and signatures were obtained. Participants were reminded that they were free to stop the interview at any point. The structured interviews were audio-taped and notes were taken simultaneously in order to provide an accurate record of the event and to promote active listening by the researcher (Kvale \& Brinkmann, 2009; Seidman, 2006). Interview questions were open ended to promote opportunities for participants to fully express their thoughts and to allow the interviewer to pursue lines of questioning presented by the respondents (Kvale \& Brinkmann, 2009; Spradley, 1979).

\section{Population and Sample}

The target population in this study is adults who were identified and served as gifted students in rural Kentucky public schools between 1994 and 2004. This time period was selected to reflect the period in which the Kentucky Reform initiatives were in place with the highest degree of fidelity. The Kentucky Education Reform Act (KERA) was enacted in 1990 (KDE, 1990). The substantive changes of curriculum and 
programming required by KERA were gradually implemented with the major aspects in place by 1994 and sustained with some adjustments through the next decade (Innes, 2010; Pankratz \& Petrosko, 2000). Students selected who graduated from high school by 2004 had time to graduate from post-secondary programs and/or become established in graduate studies or their occupation of choice in order to more accurately self-assess their own adult achievement.

Sampling was purposeful and included persons who were identified and served as gifted students in a rural Kentucky school district. The participants in the study were young adults who attended Kentucky schools in a district classified as rural by the Rural School and Community Trust (2009) and who were identified as having been served as gifted students according to the Kentucky Gifted Regulation 3:285 identification guidelines (1994). Kentucky's percentage of students who attend a rural school is $40 \%$, the $7^{\text {th }}$ highest rate in the United States (Johnson, 2009). The sample district, as a rural Kentucky district, is representative of rural districts across Kentucky on a number of indicators.

Table 2

Comparison of Rural Kentucky Districts and Target District (USDA, 2010b)

\begin{tabular}{|c|c|c|c|c|c|c|c|c|}
\hline & \multirow{2}{*}{$\begin{array}{l}\text { Geographic } \\
\text { Area }\end{array}$} & \multicolumn{2}{|c|}{ Gender } & \multicolumn{3}{|c|}{ Race } & \multirow{2}{*}{$\begin{array}{l}\text { Unemployment } \\
\text { Percentage } \\
\text { Rate }\end{array}$} & \multirow{2}{*}{$\begin{array}{c}\text { Percent of } \\
\text { Families } \\
\text { Below } \\
\text { Poverty } \\
\text { Level } \\
\end{array}$} \\
\hline & & Male & Female & White & Black & Other & & \\
\hline $\begin{array}{l}\text { Target } \\
\text { District }\end{array}$ & 347 sq. mi. & 50.6 & 49.4 & 89.2 & 9.1 & 1.7 & 7.3 & 15.8 \\
\hline $\begin{array}{c}\text { Kentucky } \\
\text { Rural } \\
\text { District } \\
\text { Average } \\
\end{array}$ & 356 sq. mi & 49.3 & 50.7 & 90.1 & 8.2 & 1.7 & 7.9 & 19.9 \\
\hline
\end{tabular}


The target school district is a rural district that served between 2,000 and 3,000 students in seven schools at a poverty rate of $>55 \%$ free and reduced lunch rate (OEA, 2009). The average per pupil expenditure for the target district places it in the bottom $10 \%$ for the state (KDE, 2009d). The target district boasts high school graduation rates and percentages of students who graduate from college at the median rate for rural districts (ThinkKentucky, 2005). Percentages of students under age 18 in poverty in the target district exceed the state average and are comparable within two percentage points of $71 \%$ of Kentucky's rural districts (SAIPE, 2006). Though there are rural districts in Kentucky with smaller populations and higher poverty rates, the statistics of the target district make it comparable to $79 \%$ of the rural districts in Kentucky (Johnson, 2009).

Gifted services for the students in the study were provided by gifted-endorsed teachers through (a) one-day-per-week pull-out services at a central location for elementary students K-6 at a central location,(b) half-day or full-day pull-out services for grades 7-8, and (c) gifted English classes for grade 9-12. Participants frequently referred to their pull-out gifted services as "The Little Yellow House," described as a building adjacent to the school that was the central location where the pull-out services were provided for students from across the rural district.

The sample was a total of 30 adults who were identified and served as gifted students in the target district between 1994 and 2004. Participants in the study were drawn from a data base of 308 students who graduated from the target school district as identified gifted students during the target 10-year period from 1994 to 2004 . Invitations to participate in the study were sent out electronically through a gifted social networking site (Facebook), through e-mail, through mailed invitations, through face-to-face 
contacts, and through telephone calls to individuals who were part of the target population but were not members of the social network. Contact included background information regarding the purpose of the study, explanation of the interview process, and review of the informed consent paperwork from both institutions involved in the study.

The researcher issued invitations to a total of 261 individuals for whom contact information could be obtained and 113 individuals responded. All individuals who responded agreed to participate in the study.

In order to establish a purposive sampling, the researcher balanced participants equally based on graduation rates and gender. This was accomplished by coding the respondents and organizing by year of graduation and gender. Three coded cards were drawn from each year, yielding 33 initially selected, in order to allow for participants who might not be able to complete the study. The participants were balanced for gender with 16 males and 17 females. The sample included 29 Caucasian participants and 4 African-American participants. As the study progressed, three participants were not able to complete the interview process.

The sample, a total of 30 adults, was grouped according to those who selfreported achievement through their school career and those who self-reported sustained underachievement or pervasive underachievement. The operational definitions of sustained underachievement (a discrepancy between potential and performance in one or more area sustained for $>4$ semesters (Heacox, 1991; Peterson \& Colangelo, 1996) and pervasive underachievement (a significant discrepancy between potential and performance across all settings for an identifiable period (Heacox,1991; Peterson \& 
Colangelo, 1996; Speirs-Neumester \& Hébert, 2003) were explained and discussed with the participants.

\section{Data Sources}

Data for the study were gathered through three 40-60 minute interviews. Interview questions (Appendix A) included self-report data on student underachievement based on student's identification of performance that was not commensurate with their ability to perform and questions about the degree to which KERA components contributed to underachievement or success.

The first round of interviews was conducted using a standardized open-ended set of questions (Creswell, 2006; Seidman, 2006; Spradley, 1979; Teddlie \& Tashakorri, 2009) that asked participants to reflect on the impact of KERA elements at each phase of their school career. As the participants reflected on each phase, the former students were asked to 1) self-report their perception of their ability and performance success; 2) identify the role of each KERA initiative (Portfolios [math and writing], Ungraded Primary, KIRIS/CATS testing, Proficiency as a performance goal, and SBDM policies) in enhancing or impeding achievement; and 3) identify related educational practices and experiences that enhanced or impeded their success. For those items that participants reported as having had no impact, follow-up interview questions were asked to clarify the degree to which that item was a part of their instructional program and how it was implemented (if it was present) during their school career.

The second and third rounds of interviews were built upon standardized, openended questions designed to expand or clarify responses from prior interviews (Spradley, 1979; Teddlie \& Tashakorri, 2009) in combination with cumulative or clarification 
questions that were unique to the previous responses of the participant (Seidman, 2006). It was important to use interpreting questions and negative case analysis to clarify responses that were not consistent with the responses of other participants and to strengthen the accuracy of the interviewer's interpretations of the language used by respondents (Creswell, 2006; Eisner, 1998; Spradley, 1979; Teddlie \& Tashakorri, 2009).

Face-to-face interviews were conducted in a neutral environment at the convenience of the participant. For those participants who were unable to meet, the interviews were conducted on the telephone at a time that was convenient to the participant in order to assure the time to establish a comfortable rapport and the time to ask follow-up questions. The researcher used participant responses to trigger additional questions to clarify or to elicit additional information or detail (Creswell, 2006; Eisner, 1998). For example, if a participant reported that the perception of his or her ability and success in middle school declined, the interviewer asked follow-up questions to clarify that perception and to explore causative factors. Additional phone and e-mail contacts with respondents were made to check interpretations and to ask participants to respond to themes as they emerged. Identifying information was removed from the data and as quotes were used throughout the study, names were fictionalized in order to assure anonymity.

\section{Data Analysis}

Interview data were used to establish context as participants discussed their educational programming and structures and their relative achievement and underachievement. Self-reported achievement and underachievement data and perceptions of the impact of KERA initiatives were used to identify questions and 
direction for follow-up interviews and to generate narrative categories (Creswell, 2006; Kvale \& Brinkmann, 2009; Spradley, 1979; Teddlie \& Tashakkori, 2009). Interviews were audio-recorded, transcribed, and data were put into categories for interpretation (Creswell, 1998; Creswell, 2006; Spradley, 1979; Teddlie \& Tashakkori, 2009). Data were collected and categorized as it relates to the reform initiatives of the Kentucky Education Reform Act, related educational services, the broad categories of educational programming and instructional delivery identified by the participants, and influences on achievement and underachievement.

The perspectives of the participants and the context of their descriptions were organized in order to interpret those perspectives (Creswell, 2006; Moustakes, 1994). Data were distilled to units of information that could be analyzed for significance and interpreted for research purposes (Creswell, 1998). Data units were combined by organizing the data into relevant categories. By breaking down, categorizing, and comparing data, small fragments of conversation and ideas were dissected to reveal common ideas and interrelated parts to generate themes (Creswell, 2006; Kvale \& Brinkmann, 2009; Moustakes, 1994; Seidman, 2006). The themes generated from identification of connections were used to generate textural descriptions of the experiences of the participants as gifted students who were a part of the KERA initiatives (Moustakes, 1994). Finally, the insights of the participants were connected back to the framework questions of the study (Goetz \& LeCompte, 1984). As the themes from the interviews emerged, questions for follow-up interviews were developed and the process was repeated until the exploratory research yielded a final analysis and universal themes (Creswell, 2006; Moustakes, 1994; Spradley, 1979; Teddlie \& Tashakorri, 2009). 
Participant responses of those individuals who self-reported sustained underachievement or pervasive underachievement during their school careers were compared with the responses of those adults who self-reported achievement throughout their school career. Those comparisons were examined for possible themes related to achievement/underachievement in the context of gifted students in rural Kentucky.

\section{Role of the Researcher}

The interviewer/researcher was responsible for demonstrating knowledge of and interest in the research themes and familiarity with the context of the components of the Kentucky Education Reform Act, gifted education in Kentucky, and the unique challenges of rural education in order to develop questions and interpret and categorize responses (Creswell, 2006; Kvale \& Brinkmann, 2009). Using the recordings, transcribed interviews, notes, and cards, the researcher categorized and sorted the language and ideas gleaned through the interviews in order to identify the themes around which educational practices that fostered or impeded success could be built. Those themes were then further refined, making it possible for conclusions to be drawn that are carefully grounded in the research and that are supported by the data (Bogdan \& Biklen, 2003; Creswell, 1994; Creswell, 2006; Kvale \& Brinkmann, 2009; Spradley, 1979).

\section{Trustworthiness}

At the end of a research project, the inferences drawn should capture the meaning of the phenomenon based upon the perceptions of the participants (Creswell, 2006; Teddlie \& Tashakorri, 2009). This required the use of processes that supported credibility in the alignment between the perceptions of the participants and the manner in which those perceptions are portrayed (Lincoln \& Guba, 1989). 
In order to assure that the research was credible and trustworthy, the researcher used prolonged engagement, persistent observation, member checking and negative case analysis. Prolonged engagement took the form of active research related to the issues to be studied and multiple interviews over time to foster opportunities to establish and maintain relationships that provided insight into the culture being studied (Spradley, 1979; Teddlie \& Tashakorri, 2009). Persistent observations took the form of a minimum of three interviews with each participant in order to establish contextual relationships and understanding of the interviewees (Seidman, 2006; Spradley, 2009). The researcher used member checking by asking individuals who were not a part of the research study, but who are members of the cultural or phenomenological group to verify the interpretations or generalizations made by the researcher to assure credibility of interpretation (Creswell, 2006; Teddlie \& Tashakorri, 2009). Four individuals who had agreed to participate in the study, but were not selected, were used as a focus group to verify the generalizations regarding the perceptions surrounding the phenomenon of KERA initiative impact on the achievement of rural gifted students.

As themes were developing, follow-up questions at subsequent interviews were used for additional clarification. Questions that garnered additional information on a topic and questions that tested the accuracy of the researcher's interpretations were important to increasing the credibility of the findings (Bowen, 2005; Creswell, 2006; Saldana, 2009; Teddlie \& Tashakorri, 2009). The use of a set of interviews facilitated that process (Spradley, 1979). Negative case analysis was also used. Once themes emerged, the researcher examined all data to determine that there was no disconfirming evidence that 
would eliminate or change a theme and made revisions to the themes and theories if those non-conforming cases did occur (Teddlie \& Tashakkori, 2009).

\section{Transferability and Confirmability}

A primary goal of any research project is to generate data that can be used to inform future research and practice. In order to realize that goal, research findings must be transferable from the specific context of the research project to other contexts (Teddlie \& Tashakorri, 2009). The researcher used thick description that outlined the context and process of the research project. By providing information about the processes, settings, situations, and people, the researcher provided a basis by which others will be able to judge the transferability of the findings (Lincoln \& Guba, 1985; Teddlie \& Tashakorri, 2009).

Confirmability is the overall determination regarding the extent to which the findings of the research project are confirmable, grounded in the data, and based upon logical inferences (Teddlie \& Tashakorri, 2009; Seidman, 2006). The researcher recorded the research processes in a reflexive journal that recorded methodological decisions, reflections on processes, and personal reflections that influenced the dependability of the research process and provided an additional source for the development of thick descriptions (Kvale \& Brinkmann, 2009; Seidman, 2006; Teddlie \& Tashakorri, 2009).

In order to increase the transferability of the findings of the study, interview follow-up questions were used to establish broad contexts and narrative descriptions of findings were applied (Bowen, 2005; Creswell, 2006). 


\section{Summary}

This chapter provided an overview of the research methodology, the rationale for the research, the population, and the purposeful sampling used to select subjects for the study. The description of the data gathering procedures utilized in this study and the procedures that were used for data analysis were also outlined.

Chapter 4 and Chapter 5 present the results of the research as responses to the three research questions. The key themes generated from each set of interview questions are synthesized to identify major themes for the study.

Chapter 6 provides the discussion of the findings and the conclusion. The implications for further study are also discussed. 


\section{CHAPTER 4 \\ RESEARCH FINDINGS-KERA INITIATIVES \\ Introduction}

To gain insight into the perceptions of adults who were products of KERA reform initiatives, this phenomenological study examined the long-term success and viability of educational programming and structures and the impact of those initiatives on the achievement and underachievement of individuals who had been gifted students in rural Kentucky. Three research questions guided the interview and interpretation process:

1. What are the perceptions of former gifted students regarding the roles of each of the instructional Kentucky Education Reform Act initiatives (Portfolios [writing and mathematics], Ungraded Primary, KIRIS/CATS assessment, Proficiency as a performance goal, SBDM council policies) in fostering or impeding self-reported student and adult achievement?

2. What related educational experiences and structures in a rural setting are perceived by the former gifted students as fostering or impeding self-reported student and adult achievement?

3. What are the similarities and differences in perceptions between those adults who self-reported sustained achievement and those who reported underachievement?

A total of 30 adults who were identified and served as gifted students in a rural Kentucky school district between 1994 and 2004 were interviewed. A series of face-to- 
face and telephone interviews were conducted as a phenomenological study. The results of those interviews were recorded through notes and audio-recordings that were transcribed, then read and reread by the researcher. Additional follow-up interviews were conducted in order to clarify responses. Significant statements were extracted and organized into themes. Clusters of themes were organized in order to develop an accurate description. As description was developed, the researcher returned to the participants to verify that the essence of their experience was accurately represented (Creswell, 1998; Creswell, 2006; Kvale \& Brinkmann, 2009; Miles \& Huberman, 1994; Moustakas, 1994; Seidman, 2006).

Participants in the study represented all schools in the district (seven elementary schools, two middle schools, and one high school). Gifted services for the students in the study were provided by gifted-endorsed teachers through (a) one-day-per-week pull-out services at a central location for elementary students K-6 at a central location, (b) halfday or full-day pull-out services for grades 7-8, and (c) gifted English classes for grade 912. Pull-out gifted services for students from across the district were provided in a central location in a building adjacent to a district elementary school. Participants in the study frequently referred to that site and their gifted services as "The Little Yellow House."

The next two chapters are organized around the research questions and the KERA initiatives contained within. The interview questions, comments or quotes related to the questions, preliminary findings, and findings summaries are used to structure the results for each research question. Chapter 4 reflects the research findings around the first research question through the identification of themes. Key themes are those topicspecific themes that were universally expressed by the participants regarding the reform 
initiative or its implementation. Major themes, broad-based themes that included the topic-specific themes, are those that emerged through additional synthesis of the topicspecific key themes.

The process used to analyze the data started with transcription of the interviews. On each reading of the transcript, a process of highlighting was used, color-coding significant sentences, phrases, and words. Key ideas were transferred to color-coded poștit notes that were placed on a large matrix representing the research questions and the related interview questions. As additional interviews were conducted, the process was repeated and the coded notes were clustered under each question. As clusters developed, the researcher identified additional questions that emerged from the responses and coded data. Those questions were asked in follow-up interviews (Miles \& Huberman, 1994).

Table 3

Sample Portion of Matrix of Data Progression

\begin{tabular}{|l|l|l|}
\hline \multicolumn{2}{|c|}{ Impact of Writing Portfolio } & \\
\hline Significant Statement & Interpretive Meanings & Themes \\
\hline $\begin{array}{l}\text { "When the writing portfolio was well-implemented, } \\
\text { it represented personalized instruction that was a } \\
\text { match to my goal of being a better writer, but it was } \\
\text { entirely dependent on the commitment and }\end{array}$ & $\begin{array}{l}\text { *effectiveness of portfolio } \\
\text { dependent on teacher } \\
\text { implementation }\end{array}$ & $\begin{array}{l}\text { Fidelity of } \\
\text { implementation } \\
\text { influenced } \\
\text { instructional } \\
\text { effectiveness }\end{array}$ \\
$\begin{array}{l}\text { wanted to get it done, to check it off, it was a total } \\
\text { waste of time." }\end{array}$ & $\begin{array}{l}\text { *teacher attitude was } \\
\text { important factor }\end{array}$ & \\
$\begin{array}{l}\text { at can remember the implementation being a big deal } \\
\text { to writing and critical thinking in my gifted program, } \\
\text { so it wasn't that big of a shift for me. I do remember } \\
\text { a lot of the teachers being stressed about the changes } \\
\text { and they didn't really care about the product." } \\
\text { "When teachers bad-mouthed the portfolio, it was } \\
\text { hard to believe them when they later said 'This is } \\
\text { important!"” }\end{array}$ & Lack of teacher support & \\
"The attitude of the teacher...their belief in the & Lack of teacher support \\
benefit made such a difference & & \\
\end{tabular}


As represented in Table 3, a second matrix was developed as more data became available. The topic-focused matrices were built with interview text placed on index cards and key ideas in post-it notes. Columns were added to the matrix to continue the process of categorizing the data and moving to more generalized themes. Key themes that emerged related to specific topics and the data from follow-up interviews were coded and added. Interpretations of the data were shared with the study participants on the second and third interviews to clarify interpretations, to add data, and to verify findings. The processes of interpreting the data included making comparisons between the perceptions of the participants and comparison between the responses regarding impact for each KERA component. Contrasts were identified and addressed, and counting was used to quantify some responses (Miles \& Huberman, 1994).

The findings were clustered based upon the relationships among the themes as they related to the research question or KERA component. The process of clustering allowed the researcher to identify perceptions that were specific to the topic, but were either linked to or subsumed by the major themes that emerged from the question and the visual representation of each of those clusters are found within the text of the chapter (Creswell, 1994; Miles \& Huberman, 1994).

\section{Findings Related to Research Question Number One}

Research Question \#1-What are the perceptions of former gifted students regarding the roles of each of the instructional Kentucky Education Reform Act initiatives (Portfolios [writing and mathematics], Ungraded Primary, KIRIS/CATS assessment, Proficiency as a performance goal, SBDM council policies) in fostering or impeding self-reported student and adult achievement? 


\section{KERA Component-Writing Portfolios}

I loved writing, but I have to say that the success of the portfolio really depended on the individual teacher. The teachers that implemented the writing portfolio with fidelity—with emphasis on the writing process—got great products out of students and impacted our writing permanently.--Robert

A fundamental component of the Kentucky Education Reform Act was the implementation of writing portfolios for assessment at three points during students' educational careers - fourth grade, seventh grade, and twelfth grade (KDE, 1990). The portfolio was to be a reflection of systematic writing instruction providing the student opportunity to write in all content areas and to select and revise pieces over time in order to gather a representative sample of their best work (KDE, 2003). Holistic scoring was used through 2006 to determine the performance rating of the portfolio (Novice, Apprentice, Proficient, or Distinguished) based on the broad categories of audience/purpose, idea development/support, sentences, language, and correctness and was to include writing samples that represented reflective writing, personal/expressive writing, literary writing, and transactive writing. The portfolio required that some of the writing should be generated in classes other than English/language arts (KDE, 2003).

Adults who had been served as gifted students in a rural Kentucky school district were asked about their perceptions of the impacts of the writing portfolio on their achievement and underachievement. Structured interview questions included:

1.1a. What can you tell me about the implementation of writing portfolios in your school career?

1.1b. What impact did the writing portfolio have on your achievement as a student? 1.1c. What impact did the writing portfolio have on your achievement as an adult? 
The process of writing portfolio development was implemented immediately upon passage of the Kentucky Education Reform Act (KDE, 1990), so all participants experienced this facet of KERA throughout some part of their school careers. Consequently, all 30 participants in the study reported a high level of awareness of the writing portfolio as an instructional component in their educational programming. All reported that the emphasis on writing was apparent in classes other than English and language arts and every participant reported pride in their end products.

Some level of positive impact of the writing portfolio on educational performance was reported by every participant. According to Liz, "The portfolio meant that writing was embedded in every class and, as a writer, I was suddenly more engaged in content classes that had not captured my interest before." Participants acknowledged the value of writing regularly, the importance of writing as personal communication, their own personal enjoyment of writing, and the ability to see improvement over time. Allen emphasized "We wrote in some capacity every day. Through the use of the rubrics, the standards were clearly defined and I was able to see my own growth based on my own personal goals no matter what was going on around me." However, the effectiveness of the portfolio depended heavily on individual teachers.

When the writing portfolio was well-implemented, it represented personalized instruction that was a match to my goal of being a better writer, but it was entirely dependent on the commitment and knowledge level of the teacher. If the teacher believed in the process, it was very effective. If the teacher just wanted to get it done just to say it was complete, it was a total waste of time. --Julia 
Instructional and achievement impacts were reported as increased emphasis on writing in most classes and some increase in critical thinking. However, all participants reflected that because writing was already an integral element in their gifted services, the addition of writing in other classes was not a major change for them. One participant explained, "Writing and critical thinking were woven together in my gifted education experience, so it was a natural progression to do the same in my regular classes." By increasing the emphasis on writing in all classrooms, participants noted that the frequency and types of writing they were expected to do increased. As Sammy indicated, "If it took the portfolio to make that happen outside of Gifted, then it was beneficial to my achievement ..." Monty expanded on that theme by stating the following: The writing portfolio is difficult to separate from the writing I did in gifted classes, but I think the existence of the writing portfolio likely created assignments in classes such as chemistry or biology that wouldn't have existed otherwise. I think that having these assignments positively impact instruction and forced some creativity and flexibility into writing styles. Conflicts regarding performance expectations were repeatedly articulated. Teachers' expectations for the portfolios were in conflict with student perceptions of their abilities as reported by all participants. Because many teachers focused on Proficient portfolios as the goal, conflict between teachers' relatively low expectations and the high expectations of the students emerged as a theme. Most participants felt they were capable of distinguished writing and struggled with balancing their personal expectations with teacher expectations. 
Allen reflected that, "I usually had proficient writing on first drafts. Teachers were content to let me veg while they helped other folks, not caring whether my writing improved or not." All participants articulated that they held the hope, as students, that their assignments would be challenging and that teachers would focus on opportunity to improve, but all participants reflected their disappointments, as students, that so many teachers and tasks did not live up to that hope. Matt recalled, "I loved to write and approached writing tasks eagerly, eager for the challenge. For those teachers who saw the portfolio tasks as something just to get done, the enthusiasm was hard to maintain ... One more boring task."

Echoing the perception that teacher expectations were not focused on improvement or growth of the students as writers, Thomas reported, "I would throw something together. I knew I had cut corners, sort of wanting to get busted, but I got praise for hard work when I hadn't worked hard at all. I just was an automatic Proficient portfolio and that seemed to be good enough."

A closely related theme was that of inadequate educational relevance of some portfolio components. Participants frequently struggled with the contents of the portfolio itself and the process in which it was produced in those classes that did not make writing an authentic part of the instruction. James noted, "Obviously, practicing writing made me a better writer in general, but I always felt the portfolio itself was artificial." That viewpoint was echoed repeatedly in comments such as those voiced by Sarah. "I never could understand the purpose of the letter to the reviewer as a product to show either my writing skill or an instructional integration." 
The portfolio process in which the students used articulated criteria on the holistic scoring guide to establish standards of quality was a positive instructional implication articulated by all 30 participants. The value of the clearly established performance standards was a theme that emerged in examining the impact of the writing portfolio. When they sat down and showed us the rubric that showed what it took to be Novice, Apprentice, Proficient, and Distinguished in order to get the work to a certain level-that was the most significant thing for me. I could "see" what success would look like and it helped us internalize the consistent standards for success.-Monty

Every participant reported that the writing portfolio had positive impact on their achievement beyond high school and that impact could be grouped around basic influences-communication skills, critical thinking and logic skills, ability to use organization and time management skills, or ability to internalize standards for various levels of performance. Participants reported that they continued to see the benefits from the writing instruction they received in their daily activities as adults.

I find that in my professional career, my job performance, especially in written endeavors, seems to stand out compared to my colleagues, both younger and older. Because my goal was always a distinguished portfolio, I internalized those standards and worked to make them a part of my daily writing. --Annie Adults in a variety of fields of endeavor articulated strong perceptions about the lifelong value of the writing process as represented in the writing portfolio for a number of reasons. Jennie found that "Everything in life has steps in which you get things done, and the writing portfolio was kind of a symbol for that life skill of being reflective and 
doing things step-by-step." Mark emphasized the importance of thinking skills by explaining that "Good writing is related to clear thinking and I think the writing portfolio strengthened my ability to do both." Some participants extended the value of the portfolio beyond written communication.

The process of editing and the process of thinking analytically about what I wanted to communicate were invaluable. I was always a good writer and always used writing as a very personal form of communication, but the process of selecting documents that represented me without actually being present is a process that has benefited me as an adult and as an artist.-Joseph

In contrast with perceptions regarding other KERA initiatives, every participant in the study supported the idea behind the portfolio-increased emphasis on writing—and identified benefits of that emphasis that extended beyond the classroom. Participants credited the writing portfolio with having an impact on their student achievement and identified lasting positive impacts into their college experiences, in their work experiences, and in their daily lives.

Key themes-writing portfolio. Key themes that emerged from participant perceptions related to the writing portfolio were

1. Conflict occurred when teacher expectations were lower than student expectations regarding academic performance.

2. Inadequate instructional relevance negatively impacted achievement.

3. Fidelity of implementation impacted instructional effectiveness.

4. Poor implementation fostered underachievement.

5. Internalizing standards positively impacted achievement. 
6. Emphasis on writing grew out of gifted services--writing emphasized critical thinking.

7. Writing skills as communication tools were vital to students and adults. Through clustering, emerging themes are represented in their relationships to the major themes in Figure 1 (Miles \& Huberman, 1994). For each cluster, major themes are represented in larger circles and bold type, with the size of the circle representing the frequency and intensity of the response related to those themes. Related themes are linked through interlocking circles. Themes that are related but subsumed by a major theme are illustrated within the larger circle. The links and relationships among the theme circles represent the relationships among the themes generated by participants responses.

Specific themes that emerged from the data, such as writing emphasized critical thinking, were developed through the iterative process. Because those themes were specifically articulated by every participant, they are important as key themes, but when clustered, they are subsumed by the major theme-emphasis on writing grew out of gifted education. Clustering represents the relationships between and among the themes in order to better understand the phenomenon of the experience of the KERA writing portfolio by rural gifted students (Creswell, 1998; Miles \& Huberman, 1994). 
Figure 1. Writing Portfolio Themes-Links and Relationships

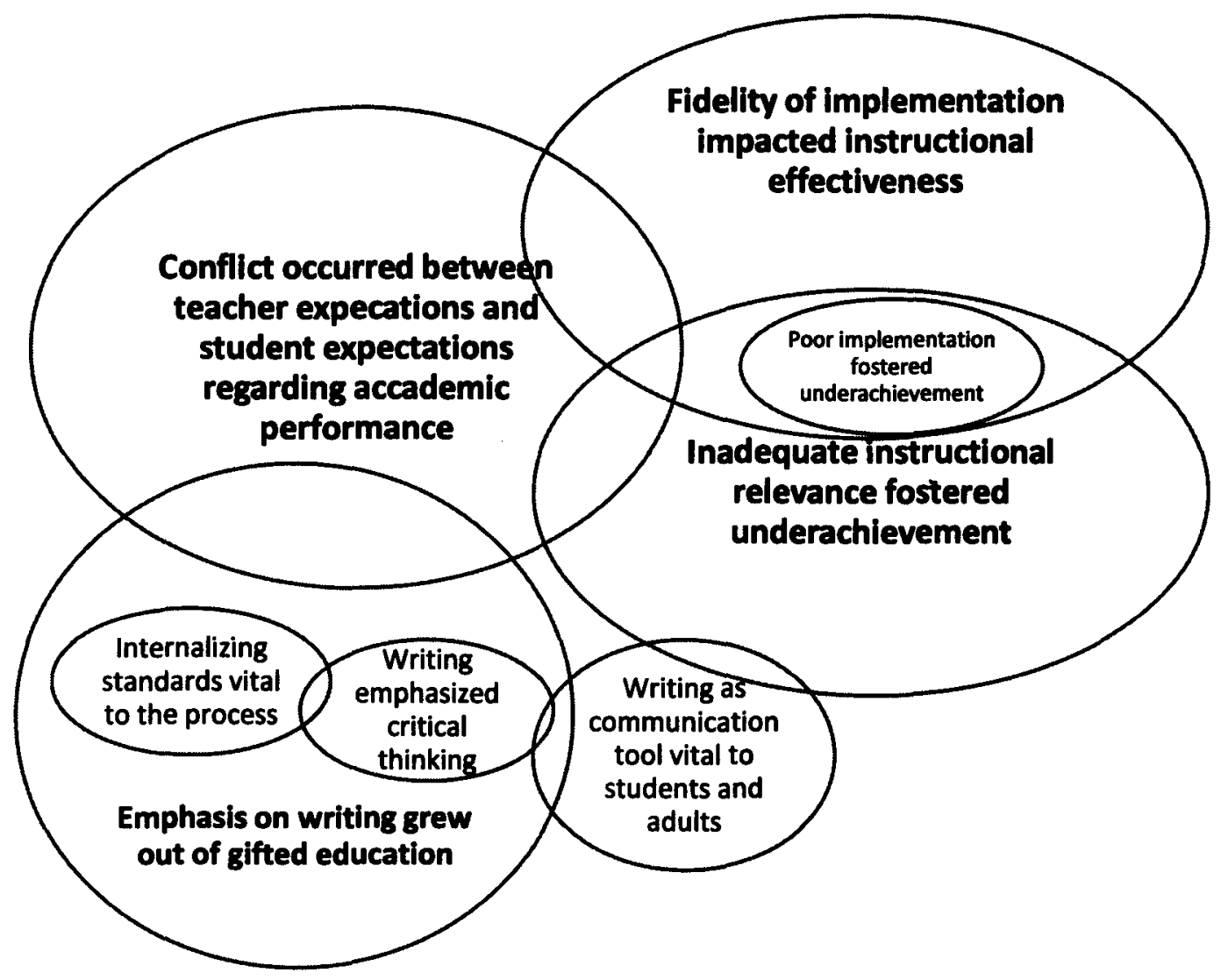

Findings summary. Figure 1 provides a graphic illustration of the interrelationships among the key themes that emerged around the topic of writing portfolios using a clustering process (Miles \& Huberman, 1994). Those themes were categorized to generate four major themes to describe the perceptions regarding the writing portfolios. The four major themes are (a) Conflicts arise between teacher and student expectations regarding academic performance; ( b) Lack of instructional relevance fostered underachievement; (c) Fidelity of implementation impacted effectiveness; and (d) Writing emphasis grew out of gifted education. The four major themes were reflected in the responses of every participant. 
The most significant issue among the participants was the conflict between teacher expectations for writing performance and the standards that the individuals held for themselves. As writers, they expressed the desire and intent to achieve excellence, but expressed frustration that teacher attention and feedback projected the impression that Proficient was good enough and that the teachers were not willing to expend additional time or energy to guide the students to Distinguished. Participants repeatedly reported that their personal goals and the standards of the teacher were not aligned. Consequently, that underestimation of the abilities of the students often reflected in diminished efforts and withdrawal from the process on the part of the students. Anna noted that "The teachers often projected the philosophy that Proficient was good enough. Even when I was engaged by the task, it was hard to sustain the effort to make it my best writing when the feedback from the teacher was minimal."

Participants also identified lack of instructional relevance and lack of fidelity to quality instruction as barriers to the development of quality writing pieces. Teachers who assigned writing tasks that were not related to the interests and readiness levels of the students created disconnects for the students as writers. When the writers perceived the portfolio pieces as artificial, motivation to generate writing of the best quality declined. Similarly, when teacher feedback did not link effort and performance, participants indicated that they were less motivated to work hard on their writing.

The fact that teachers varied greatly in their commitment and enthusiasm for writing and in their ability to teach writing skills was identified as a critical element in fidelity of implementation. This made the development of portfolio pieces dependent on a combination of the student's innate ability and desire with the abilities of the teacher. 
The philosophy behind the writing portfolio-making writing an integral part of instruction and developing the writing over time- was endorsed by all of the participants. They identified benefits of looking at writing after allowing it to rest and even rereading when they were "more mature." Every participant identified critical thinking skills as a part of effective communication and praised writing as one of the best ways to get there. As Joel reflected, "Writing is one of the most essential communication skills and it serves as a vehicle for crystallizing your thinking. By training us to write with insight, the portfolio truly fostered critical thinking skills."

It was clear that every participant perceived writing as a vital communication skill for both students and adults, and that to be successful, writing must reflect internalized standards of quality. For these participants, their personal expectations were that those standards should be high. The emphasis on writing within the gifted program laid groundwork that the participants felt could extend throughout their general education curriculum and they were willing and eager to write across settings.

Though participants expressed some concerns about the process of the portfolio development and discussed individual teachers or grades where the process was weaker or stronger, every participant agreed that the portfolio had long-term, positive benefits on their achievement, both as students and as adults.

\section{KERA Component-Math Portfolios}

I thought the math portfolio was a little ridiculous because I thought maybe we should be checking our actual math proficiency instead of whether we could write about it. I never saw it was applicable to anything.-Bonnie 
As a part of the Kentucky accountability system, the math portfolio was considered an innovative element of KIRIS (Sexton, 1996). It was intended to be an authentic means to measure students' comprehensive understanding of mathematics and mathematics processes. Originally designed to include a table of contents, a letter to the reviewer, written by the student to describe the portfolio, and five to seven entries, the entries were intended to be drawn from varied core content areas and to represent a variety of types of tasks (e.g., investigations, applications, non-routine problems). To complete the mathematics portfolio entries, students were to use a range of appropriate tools (e.g., calculators, models, manipulatives, and measurement instruments). The portfolios were included in assessment system through the 1995-96 testing cycle (Borko \& Elliott, 1999). The participants in the study were asked about their perceptions of the impacts of the math portfolio on their achievement and underachievement.

Structured interview questions included:

1.1d. What can you tell me about the implementation of math portfolios in your school career?

1.1e. What impact did the math portfolio have on your achievement as a student?

1.1f. What impact did the math portfolio have on your achievement as an adult?

With the exception of one participant who reported that because math was not an area that she felt comfortable in and that all she wanted to do was write, "I felt comfortable using my language arts skills to write about math and that allowed me to be more willing and comfortable to think about math in a new way," every other participant indicated either a neutral or negative perception of the math portfolio. Neutral comments included Jeff's admission that "It [the math portfolio] had no impact on my achievement either way. It was just one more assignment that was viewed as rather laid back and it got short shrift." His perspective was echoed by Anna, who reported that "The math 
portfolio had zero impact on my achievement, unless you count the fact that I just thought it was a waste of time and sort of tuned out."

Many participants thoughtfully analyzed the portfolio process to identify specific issues related to the math portfolio. One consistent concern was explained by Stephen. "I struggled with completing it because the purpose and the standards were so vague." As good students who held themselves to high expectations, many of the participants expressed high levels of frustration with the math portfolio. Monty summed it up with an emotional statement:

Without a clear purpose or audience, I felt somewhat lost about what to do to create a Distinguished math portfolio and no one could tell me. I scored 5's on both AP Calculus and AP English and had a Distinguished writing portfolio, but nobody could figure out what it took to be Distinguished on the math portfolio. What was it measuring?

As with the writing portfolio, participants felt that the math portfolio process also suffered from a lack of instructional relevance and a conflict between teacher expectations and student expectations. Danny reflected that "It was like the teachers were trying to superimpose something on the math instruction, even if it wasn't a good fit." As students, the participants reported that they wanted to do well, usually expecting Distinguished performance of themselves. However, teachers did not hold that expectation for the process of math portfolio development. Angela summed it up, saying "With a weak list of contents, whole class prompts, and a vague rubric, it was very difficult for a highly motivated student to figure out how to do well. No teacher seemed to care if anyone achieved a Distinguished." 
Not surprisingly, the perceptions regarding impact of the math portfolio on adult achievement were neutral or negative. Feedback that reflected neutral impact on achievement was representative of the feelings of those students who saw themselves as either strong in math or disinterested in math. Their insights are represented by Sam's comment that “. . . nothing in the math portfolio was meaningful for later writing. As I later had to write mathematics papers and professional scientific papers, there was nothing in the math portfolio that proved to be beneficial. The portfolio was artificial."

A recurring reflection was that the math portfolios were "recycled," indicating a serious issue with the fidelity of implementation of the math portfolio process. Rather than growing out of the math instruction they were receiving, many participants reported that they wrote a math portfolio in the fourth grade and rewrote the same pieces every year to use them in their seventh grade portfolios. As Lana recalled, "There was this problem about creating an array of cookies on a cookie sheet. It was mildly interesting as a fourth grader, but had absolutely no relevance to my level of math instruction in fifth, sixth, and seventh grade."

For those participants who saw themselves as less confident in math or who were very interested in math, their opinions are reflected in Elaina's insight that "The math portfolio was not a useful exercise. It would have been more beneficial to learn more complex math than to write simplistic descriptions about simple math problems."

Key themes-math portfolios. The themes that emerged from the participant perceptions related to the mathematics portfolio were:

1. Conflict occurred when teacher expectations were lower than student expectations regarding academic performance. 
2. Inadequate instructional relevance negatively impacted motivation.

3. Fidelity of implementation impacted instructional effectiveness.

4. Students were unable to internalize standards of the math portfolio because they were not communicated clearly.

5. Skills fostered in the process of developing the portfolio were not those needed by adults in the field of mathematics or science.

6. Higher level math instruction more beneficial than practice writing about low level problems.

Key themes are clustered in Figure 2 in order to represent their relationships to the major themes related to math portfolios (Miles \& Huberman, 1994). The key themes related to math portfolios were articulated by every participant and were then clustered to show that the themes of 1 ) Students were unable to internalize the standards of the math portfolio because they were not clearly communicated, 2) Skills fostered in the process of developing the portfolio were not those needed by adults in the field of mathematics or science, and 3) Higher level math instruction would have been more beneficial than practice writing about low level problems are subsumed by the major themes. Figure 2 represents the relationships between and among the themes in order to better understand the phenomenon of the experience of the KERA math portfolio by rural gifted students (Creswell, 1998; Miles \& Huberman, 1994). 
Figure 2. Math Portfolio Themes-Links and Relationships

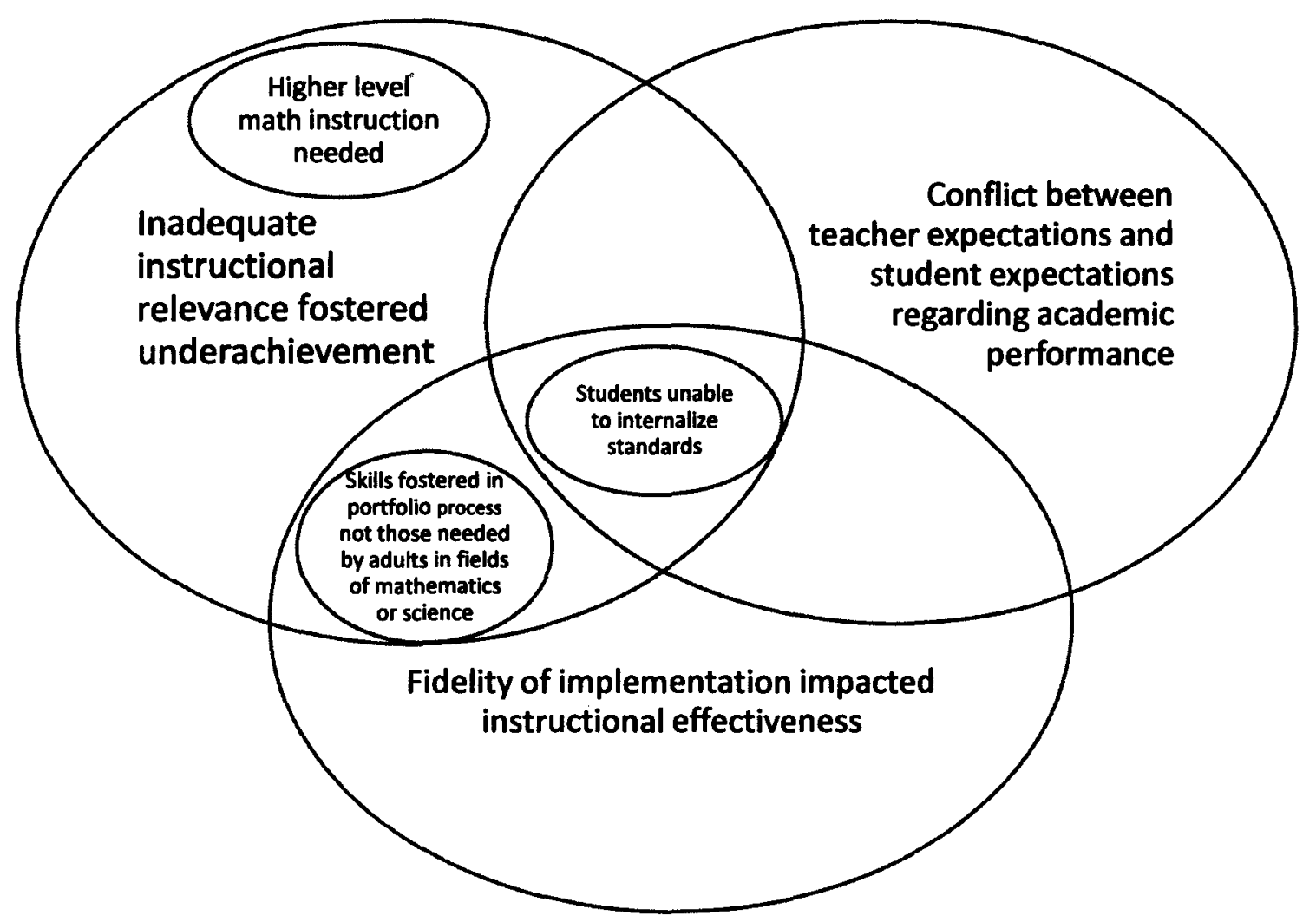

Findings summary. From its implementation to the present, the participants in

the study were unable to identify significant benefits of the math portfolio. Though a few individuals who saw themselves as weaker in math admitted that they liked "writing and drawing about the cookies on the tray because it kept me from having to do math," they also admitted that the levels of writing about simplistic problems didn't improve either their math or their writing skills.

As illustrated in Figure 2, the interrelationships among the key themes that emerged around the topic of math portfolios can be aggregated to generate three major themes: (a) Conflicts arose between teacher and student expectations regarding academic performance; (b) Inadequate instructional relevance fostered underachievement; and (c) Fidelity of implementation impacted effectiveness. The participants identified a conflict 
between teacher expectations of student performance and the levels of expectations that the students held for themselves.

The majority of the participants expected that they would produce Distinguished work and approached the math portfolio with that objective. The common prompts, vague rubrics, and low expectations on the part of the teachers served as barriers to students who truly wanted to excel. Student products were generated to look alike and the teachers were reported to have indicated that was good enough. The participants who wanted to achieve at a higher level had nowhere to go for guidance or support.

According to the participants, instructional relevance was lacking from the portfolio prompts. Even those students in high level math courses such as AP calculus reported that they used common prompts from other classes and the problems were unrelated to their ongoing classroom instruction. In the estimation of the participants, the writing was not measuring anything that they had learned. The loss of instructional time in learning to do more complex problem-solving was seen by the participants as a negative that outweighed any benefit of writing about a simple problem.

All participants were unable to identify any benefit to achievement, as students or as adults, of the math portfolio. Instead, many articulated the view that the types of writing required in the math portfolio were totally unrelated to mathematical or scientific writing that students might encounter as adults. They expressed the wish that the writing in math had been more focused on professional writing in the field in order to prepare students for what they would face in college and in their careers. 


\section{KERA Component-Ungraded Primary}

At regular school we were supposedly in mixed 1-3 classes, but after homeroom, we just all went to a regular grade and stayed there 'til the end of the day. I was always working in the grade level group for my age and never had a chance to go any faster.-Jerry

Based on the acknowledgement that children learn at different rates and in different ways, the Kentucky Education Reform Act established the Kentucky Primary School Program which became known as Ungraded Primary (KDE, 1990; Pankratz \& Petrosko, 2000). The critical attributes of the Ungraded Primary Program included a number of factors with great promise for gifted students including developmentally appropriate educational practices, multi-age and multi-ability classrooms, continuous progress, authentic assessment, and qualitative reporting methods (KDE, 2003; Pankratz \& Petrosko, 2000).

The implementation of the Ungraded Primary Program took a variety of forms across Kentucky and in the rural school district in the study. The grade level designations were replaced with P1-P4 labels to indicate the number of years students had been in the primary school. Some schools included all primary students to create P1-P4 classroom configurations while some schools separated kindergarten students to create P2-P4 configurations. A third configuration took the form of dual age groupings so that students were in P2/P3 or P3/P4 configurations (KDE, 2003). In addition to the variety of grouping configurations that were used to establish classrooms in the district from which the participants were drawn, there was a wide variation among the instructional 
strategies employed and fidelity with which the critical attributes of the Ungraded Primary Program were applied.

An additional feature that was significant to the discussion of the participants' primary experience was the gifted services they received. Primary talent-pool and gifted services in the district from which the participants are drawn were provided through pullout services. All participants, drawn from all of the district elementary schools, were served at a central location one day per week. Primary gifted students were served in K-2 or K-3 groupings with services provided in general intellectual and specific academic aptitude gifted.

Participants in this study were asked to identify the impact of their primary school years in the context of the specific organizational structure that they experienced. The following questions were used as structured interview questions:

1.2a. Tell me about the organizational structure of your primary school experience. 1.2b. What impact did the organization and structure of your primary school experience have on your achievement?

Due to the time span from which the participants were drawn, 14 of the participants experienced traditional straight grades or "split class" instruction during their primary years and 16 of the participants experienced the Ungraded Primary Program. All felt strongly about the impact of those early years on their achievement or underachievement and follow-up questions were used to identify specific features in their experiences that they felt were significant.

The feedback from the participants who experienced some form of Ungraded Primary structure and those who experienced straight grades was strikingly similar around the themes of lack of challenge and instructional focus on students who struggled. 
Experiences for students of primary age were reported to be non-responsive to student needs. Tina's quote reflected the experiences of many of the participants when she reported, “There really wasn't any effort to move me any faster or to do more advanced work." Even those participants who expressed awareness of some teacher efforts on their behalf reported waiting. Tonya summed it up by admitting that "... some tried to challenge me, or at least tolerated me, but I spent a lot of time waiting for the instruction to catch up."

Three of the participants did report that their primary teachers provided opportunities for continuous progress. Those options ranged from the chance to “... do a little research or read a book in addition to the one the class was reading" to opportunities to move up to a higher group. As adults, the participants reflected awareness that the quality and success of their primary experiences were teacher dependent and that, at one school, the Ungraded Primary program seemed to be done more effectively than at the other schools in the district. Todd recalled that he changed schools during his primary years to find that in his new location, the structure was different and more responsive to his needs.

I was in a school with a 1-3 structure that was made up of a three teacher team. One of them had the "youngers," one had the "tweeners," and one had the “olders." I remember that they shared us depending on what we were ready for. It was kind of by grade levels, but I did have a chance to move up to a higher level when I was supposed to be a "tweener" for reading and for math.--Todd When asked about the critical attributes of the Ungraded Primary Program (developmentally appropriate educational practices, multi-age/multi-ability classrooms, 
authentic assessment, continuous progress, and qualitative reporting methods), the participants recalled few applications of those attributes in their regular school day. Whole group instruction dominated the instructional strategies reported by the participants and Anna confided that, "We never got individual or small group instruction if you were a little bit ahead or a lot ahead." Participants' perceptions link Ungraded Primary to the recurring theme of lack of fidelity in implementation of the program. The critical attributes of the Kentucky Primary Program, such as continuous progress, should have been wonderful for gifted students, but it seemed to break down in implementation.

Whether in straight grades or multi-age configurations for their primary years, 23 participants attributed the lack of challenge in those early years to the development of patterns of underachievement. Matt explained that "I got too comfortable doing things that were easy. I had teachers that let me slack off and soon I believed, 'I can't do this anymore." Marcus admitted, "I learned to take a book to school and plan to entertain myself. I learned to try to be lazy because it was so easy." Todd concurred, sharing the fact that "I was usually pretty bored in school and got in the habit of acting up because I could 'get it' even when I seemed to be halfway listening."

Nine participants reported that they were able to read when they started school, but they recalled very little adjustment to their kindergarten or first grade experience in response to their reading instruction needs. Todd recalled,

We'd work on a letter each week like it was this great ah-ha experience. Even though the teacher knew I could already read, letters, sounds, and a few utility words like 'the' and 'me' were the extent of the in-class exposure in kindergarten, 
and first grade was no better. Teachers told my parents I was 'immature' because I had a terrible time sitting and waiting to finally get to learn something.

Four participants reported that they benefited from some form of subject level or grade level acceleration at some point during their primary school careers. They reflected that the acceleration experiences were vital to helping them continue to be motivated and to stay connected to their school environment. When asked if those opportunities were made available for other students, the participants reflected that they realized that there were other students who would have benefited, especially from subject level acceleration, but the teachers just didn't do it.

The participants viewed their gifted services throughout their primary years as important to preventing pervasive underachievement. "The gifted exposures as a primary student made my school experience so rich and by pushing me, sort of saved me from the bad habits I was putting in place in the regular classroom."-Todd

The features of the gifted services that had impact on achievement were identified by the participants and the attributes they identified were features that were intended to be the attributes of the Kentucky Primary Program. Jenny recalled, "Primary gifted provided true challenge. It was hands-on, project-oriented, and child-involved in a multiage setting—what ungraded primary was supposed to be!"

As the participants shared perceptions of the impact of their primary years on their achievement, Jon reported that

I can't think of any way that ungraded primary helped my achievement. I sort of tolerated it, waiting for my gifted day, but I started putting bad habits in place at an early age because of the slow pace and low expectations. 
Key themes-Primary Program. The themes that emerged from the participant perceptions related to the Primary Program were:

1. Conflict occurred when teacher expectations were lower than student expectations regarding academic performance.

2. Inadequate instructional relevance negatively impacted motivation.

3. Fidelity of implementation impacted effectiveness.

4. Both "straight grade" and multi-age structures reflected dominance of whole group instruction.

5. Instruction focused on struggling students.

6. Gifted services exemplified the critical attributes of the Ungraded Primary Program.

7. Gifted services important to meeting primary students' instructional needs.

8. Teachers in the regular classroom knew about acceleration options, but did not readily implement them.

The relationships between and among the key themes related to Ungraded Primary are shown in Figure 3. By clustering the themes and using an iterative process with the themes articulated by all participants, the links and connections emerged and provided data that allowed for the identification of major themes. The major themes subsumed the majority of the Ungraded Primary themes through aggregation (Miles \& Huberman, 1994). The Ungraded Primary themes also yielded findings that are connected through comparison. Those themes are linked but only overlapped, because they represent themes that do not clearly fit within the major themes identified for previous KERA initiatives. 
Figure 3. Ungraded Primary Themes-Links and Relationships

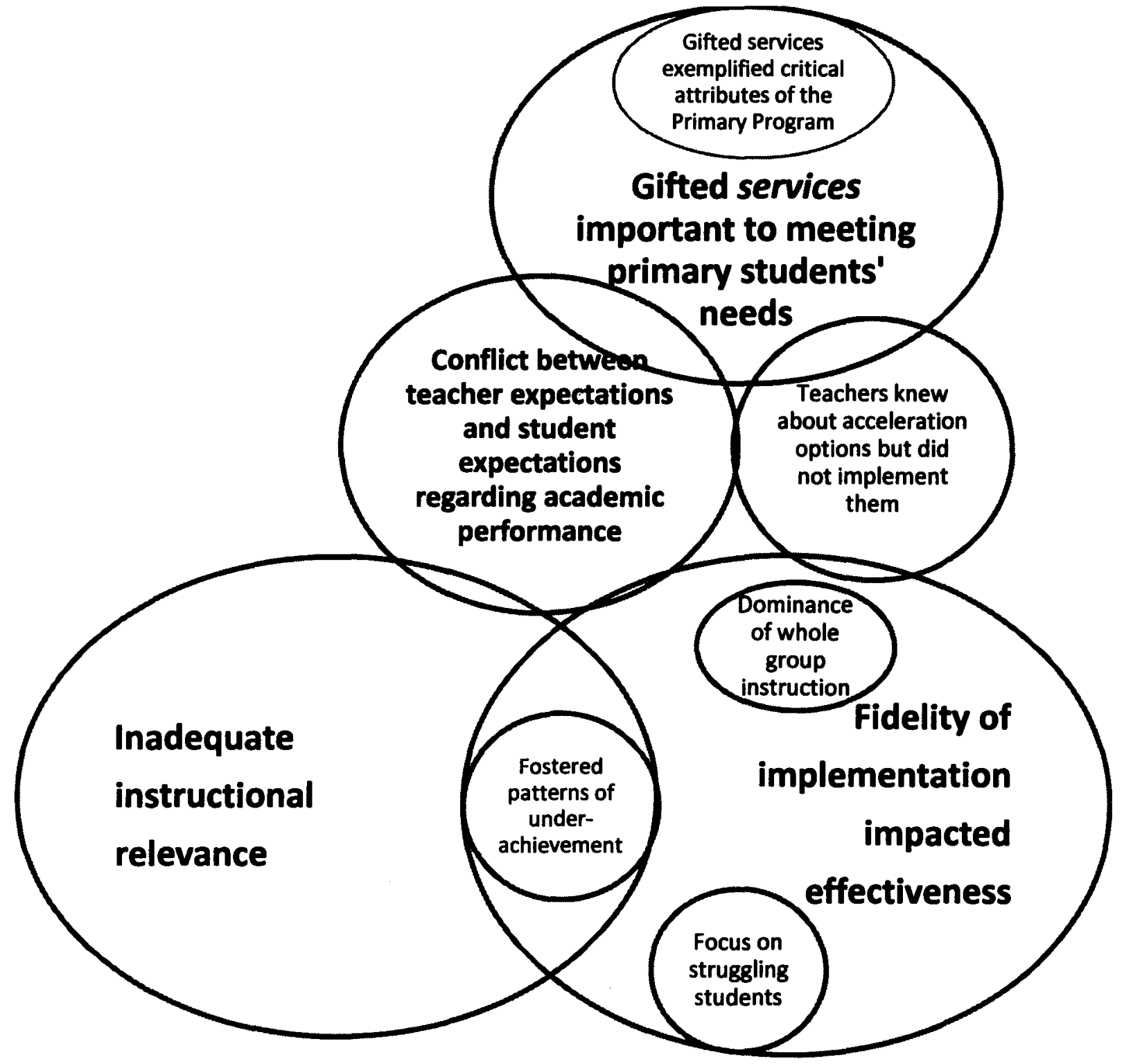

Findings summary. Analysis of the key themes yielded the connections and interrelationships illustrated in Figure 3. Four major themes emerged around the topic of Ungraded Primary. Those four themes are (a) Conflicts arose between teacher and student expectations regarding student performance; (b) Lack of fidelity in 
implementation impacted effectiveness; (c) Inadequate instructional relevance fostered underachievement; and (d) Gifted education services provided essential support.

The conflict between teacher expectations of student performance and the expectations that the participants held for themselves was a major theme in reflecting on the primary years. Even in "multi-age" settings, the fundamental instructional structure was whole group with students divided by age, leaving those students who were ready to move ahead at a faster rate unable to do so. Very few participants reported that teachers made any accommodations in the level or pace of instruction, though some did report that the teacher did let them read a book when they finished and one reported that "My teachers liked me and gave me jobs like watering the plants and running errands to keep me occupied."

Lack of fidelity in implementation of the Ungraded Primary was a major theme that emerged as participants discussed critical attributes of their experiences. Continuous progress was not a significant element. Even when teachers knew about acceleration options, those options were used very sparingly to meet student needs. Instead, participants reported that they felt like they were "always waiting" and that bad habits went into place because "things at school were too easy."

Inadequate instruction relevance emerged as a major theme as the participants described their experiences and the pervasive lack of challenge. The opportunity to work with students of different ages was socially stimulating to many of the participants, especially when they had the opportunity to work with older students, but academic challenge was missing from the experience for the majority of participants. 
Perceptions of the impact on achievement of the primary years were varied.

Participants were able to name specific teachers who provided rich, responsive classroom experiences, even if they were not particularly challenged in those settings. The fact that there was something new and engaging in those classrooms helped to sustain their interest. Seven participants reported that thematic instruction—building reading and writing instruction around a theme such as architecture or fables-allowed their teachers to individualize the writing and to provide more opportunities for leveled reading materials and they felt challenged and engaged in those settings.

Though the specific examples of effective implementation of the critical attributes of the Primary Program were limited to four participants, in those situations where it was implemented with fidelity and where students had the opportunity to move at their own pace, the impact on achievement was positive. Participants reported that they had increased confidence in their abilities from working with a range of students on activities that were appropriately challenging and that they did not avoid hard tasks. The individuals who left a well-implemented primary program to go into a straight-grade intermediate program reported that they continued to use the skills they gained in the new setting.

Many participants admitted that they put bad habits in place during their primary years, including avoidance of tasks that they thought might be hard, daydreaming, resisting repetitive or review tasks, misbehaving, and just shutting down. When asked about the reasons for the development of those behaviors, lack of challenge, low teacher expectations, and the need for stimulation were identified as causes. When asked about whether they were aware of these behaviors at the time or whether that was adult 
perspective, the participants admitted that they were aware of making conscious choices about their performance even as 6 and 7 year-olds.

All of the participants reported that they basically enjoyed coming to school through their primary years, but especially looked forward to their day at gifted. Parent expectations and gifted participation were the two factors credited with preventing or reversing underachievement at the primary level. Two participants also credited sibling influences with "keeping them straight" when they began to cut-up or shut-down as primary students.

Gifted services were credited with exemplifying what the primary program was supposed to be according the participants. They identified the multi-age groupings, the flexible groupings, the hands-on activities, the thematic instruction, the individualized projects, and emphasis on literacy (listening, speaking, reading, \& writing) as factors that they "wished school could be like every day."

\section{KERA Component-KIRIS/CATS Assessment}

I wanted to perform well on everything I did, but the tests [KIRIS] themselves were rather irrelevant to my instruction. I remember thinking the questions were very easy and not particularly challenging. Shutting down instruction in high school for test preparation was a true loss of instructional time and I resented it. I remember that there were errors in the KIRIS test booklets. The bar was too low to test what I could do.--Angie

As KERA was signed into law, the mantra was that all students would be Proficient by the year 2014 (KDE, 1990). As the high-stakes accountability system linked to the Kentucky Education Reform Act, the KIRIS system was designed to blend multiple 
choice testing, criterion-referenced written responses, and student performance events to establish a broad-based picture of school success toward reaching that goal. The KIRIS assessment, built around the Kentucky Core Content, was administered to students in "accountability grades" in order to gauge student achievement levels with each assessment area three times during a student's school career (KDE, 1990). The performance events were dropped from the assessment and the CATS assessment system replaced KIRIS in 1998, but CATS was very similar and was also administered each spring to the accountability grades identified for the specific content areas (KDE, 2000). As criterion-referenced assessments, the KIRIS or CATS performance of each student was rated Novice, Apprentice, Proficient, or Distinguished based on the number of multiple choice items correct and on the scoring of the content-related open-response items (KDE, 1990). Each performance rating was used in combination with other accountability indicators to develop a school accountability index between 1 and 140 . The accountability indices were used to rank schools, to determine growth trajectories toward the goal of 100 by the year 2014, and to determine rewards or sanctions for individual schools.

Getting all students to Proficiency continues to be the goal on the assessments in Kentucky and in response to state mandates surrounding novice reduction and performance gaps reductions, schools focus their energy on reducing the number of students who perform at a Novice level and target at-risk populations. Schools are required to submit plans to improve the performance of populations for whom a performance gap is identified. Those groups include students identified as English Language Learners, minority students, students eligible for free and reduced lunch, 
students with disabilities, and students who received extended school services (KDE, 2000; KDE, 2006; Pankratz \& Petrosko, 2000).

High stakes accountability was a dominating feature of KERA and its related instructional initiatives intended to improve student achievement. Identification of the perceptions of individuals who experienced the impact of KIRIS/CATS on student achievement is a critical element in gauging the effectiveness of this universally applied reform element.

Participants were interviewed to determine the impact of the KIRIS/CATS assessments on their achievement using the following structured interview questions:

1.3a. How did the state assessment program impact the instructional program during your school career?

1.3b. What impact did the KIRIS/CATS assessment have on your achievement as a student?

1.3c. What impact did the KIRIS/CATS assessment have on your achievements as an adult?

1.3d. How would you describe your performance on the state assessment?

1.3e. What factors influenced that performance?

The testing process was a combination of boring and stressful. I expected a lot of myself, but the school seemed to have an expectation that I would do well, even if they hadn't really paid any attention to my progress before that time. I often felt like the tests didn't match up with what we were studying or what was important for me to learn. Things were always at full tilt in the spring and the tests destroyed the momentum. It was like stopping learning and it proved nothing-nothing about the quality of my instruction and nothing about my capability.--Kierra A consistent theme that emerged in discussion of the KIRIS/CATS assessments was lack of educational relevance. Participants reported that "The tests were rather irrelevant to my instruction," and that "The tests didn't match up to what was taught." 
The perception that the expectations were low was echoed repeatedly. James stated that "The questions and content measured on the CATS was never challenging. I was able to score distinguished without much effort."

As students, the participants maintained high expectations of themselves, while reflecting themes of resentment about the school's attitudes toward their abilities. Sam reflected that "I always did my best on any task I was given, including the state assessment, but it was as though the school expected me to put out this great effort when, up to that point, they had treated me like a pariah." The feelings of resentment toward the system influenced effort and achievement on the assessments. Participants expressed frustration that they experienced as students as a result of the perceived difficulty in getting acknowledgement and recognition for academic excellence. Anne recalled, "If you had a pattern of good work in the classroom, it was just expected. Your consistently good performance was not noticed unless you made a mistake. Then you heard 'I thought you were gifted!"”

All participants reported that they made a good effort on the assessments at various phases in their education careers, but that their motivations came from within-"I expected the best of myself on everything that I did." They relied on setting a personal level of challenge or reported that they competed with significant peers to do well on the testing. Many participants reported that they were also motivated by wanting to make their parents or other significant adults proud. Stephen summarized the theme well when he stated that "The success I experienced on the CATS assessment was the result of the fact that I'm a good test taker, had a high level of internal motivation (while it lasted), and had the desire to make my parents proud." 
Key themes-KIRIS/CATS assessments. The themes that emerged based upon the perceptions of the participants related to the impact of KIRIS/CATS assessments were:

1. Conflict occurred when teacher expectations were lower than student expectations regarding academic performance.

2. Inadequate instructional relevance negatively impacted motivation.

3. Fidelity of implementation impacted effectiveness.

4. Students resented expectation that they would automatically be Proficient without instructional attention.

5. Students resented expectation that Proficient was good enough.

6. Assessments were poor reflections of student capabilities.

7. Students relied on internal motivation and/or parents/significant adults in making good effort on assessments.

8. Testing interfered with learning.

9. KIRIS/CATS had no impact on student achievement.

10. KIRIS/CATS had no impact on adult achievement.

KIRIS/CATS assessment themes are represented in Figure 4 as a visual representation of the clustering done through aggregation and comparison. Key themes that could be subsumed were clustered within the major themes and related themes were linked in order to provide a picture of the phenomenon of the experience of KIRIS/CATS testing on study participants (Miles \& Huberman, 1994). 
Figure 4. KIRIS/CATS Themes-Links and Relationships

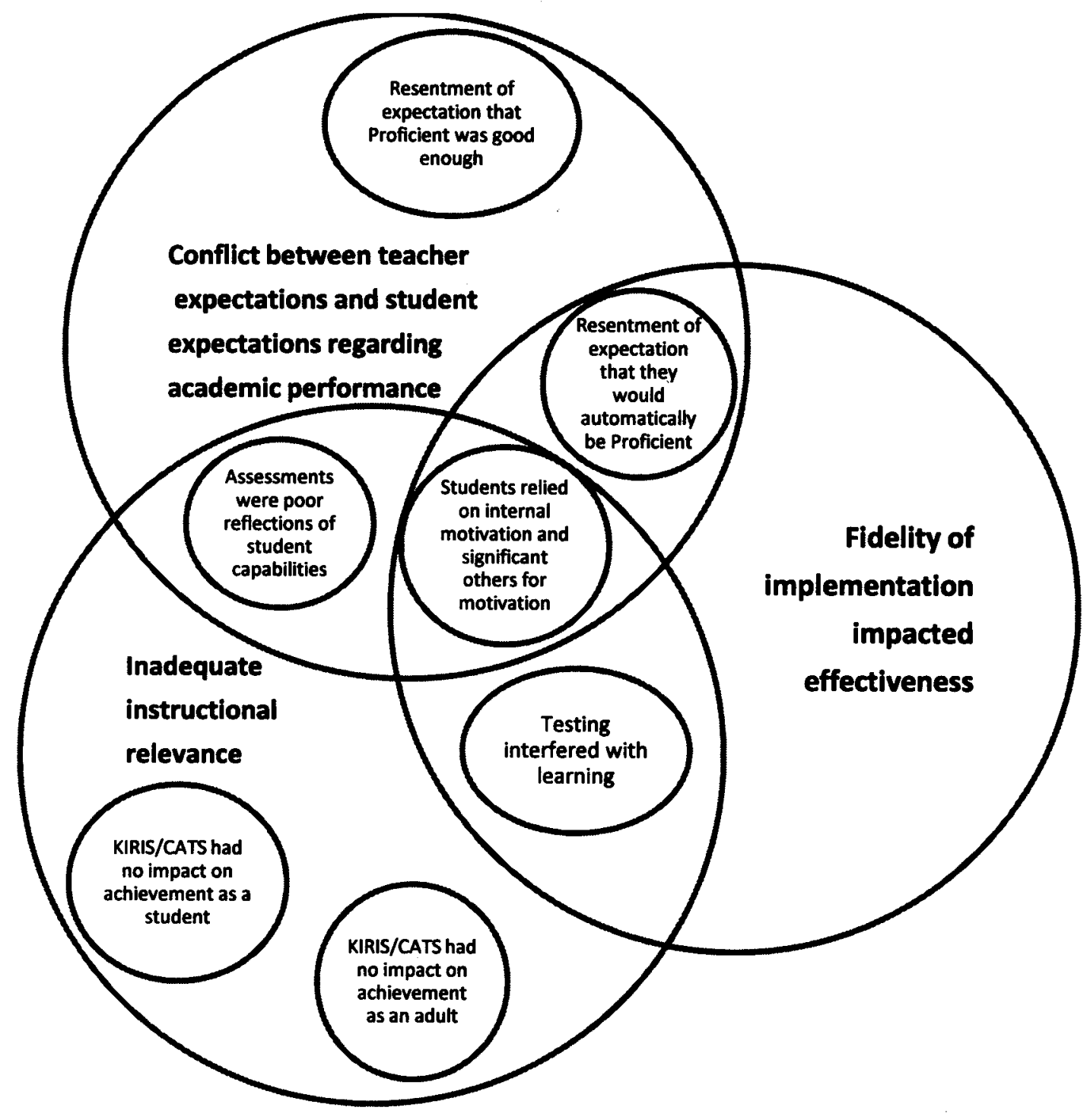

Findings summary. Figure 4 provides a visual representation of the

interrelationships among the key themes that emerged around the topic of KIRIS/CATS assessments. By clustering the key themes, the three major themes that emerged are (a) Inadequate instructional relevance; (b)Lack of fidelity of implementation; and (c) Conflicts between teacher and student expectations regarding academic performance.

According to the participants in the study, the KIRIS/CATS assessment was not instrumental in improving student or adult achievement. Conflicts between teacher 
expectations of student performance and the expectations that the students held for themselves were at the heart of the lack of confidence in the assessments. Participants reported that as students, they resented the implied and overt messages the Proficient was good enough and the implication that they should be Proficient without any attention. Participants repeatedly articulated the perception that there was a disconnect between what was tested and what they were learning, as well as a disconnect with what they needed to know. The fact that participants could identify errors that they had found in the test booklets further damaged the perception of credibility of the test.

As students, the participants expected that they would perform well and they were willing to work hard to do so, but the majority of participants expressed the concern that the KIRIS or CATS assessment was a poor measure of their capabilities. Many reported that they were good test-takers and that the questions were very easy, so they questioned that the test was actually measuring the quality of the instructional program, while some reported that they were not great test-takers, but were confident that they had good mastery of the skills and content that the KIRIS test was measuring. Most participants expressed the sentiment that the testing process interfered with learning as instruction ceased for test preparation and then for test administration. They resented the loss of instructional time.

Every participant indicated that the assessment had no positive impact on achievement for them as a student. Similarly, every participant indicated that the assessment had no positive impact on their achievement as an adult. 


\section{KERA Component-Proficiency as a Performance Goal}

I felt that I was usually beyond Proficient before I started and my personal goal was mastery and excellence. To me, Proficiency seemed a little lazy and I rarely felt like I was being pushed to reach my potential. --Monty

Based on the state goal that all schools reach an academic index of 100 by the year 2014, Proficiency became the target performance goal across Kentucky. Proficiency reflects basic competency with the skills and concepts within a content area and that target became a powerful instructional focus for curriculum planning and delivery. Consequently, those students who were not yet reaching Proficient performance were heavily targeted for instruction. After all, everyone had to be at Proficient by 2014 (KDE, 1990).

This KERA component was examined for its impact on student achievement or underachievement by using the following structured interview questions:

1.4a How did you see yourself in relation to the school goal of Proficiency? 1.4b How did the school goal influence your achievement?

Proficiency was never my personal goal. I expected myself to learn and improve and since I saw myself as starting at Proficient, I expected to get to Distinguished and was frustrated when the opportunities to build those skills weren't readily available. My peers and I were competitive and tried to reach higher and higher, but it was through one another that we improved, not usually because of classroom instruction.-Rena Every participant expressed concerns about the school expectation of Proficiency as a goal. According to Stephen, "I started at Proficient, yet I was expected to practice being Proficient. Why was I even in the room?" The personal goals of the participants 
reflected high performance expectations and a need to improve and achieve. In the perspective of the participants, school expectations regarding learning were too low. This occurred because "They never bothered to find out that I already knew it before they plunged in teaching."

Participants expressed internal conflicts regarding the school expectations compared to their own capabilities. Stephen voiced the feelings of the majority of the participants when he explained, "I thought that Proficient might be something for someone else to shoot for, because I was a 'Distinguished' student ... We always wondered why the school thought it best to shoot for mediocrity."

The participants viewed their time as a valuable commodity and sought to fill it in ways that were meaningful and stimulating for them. Anne reported that she "... could get Proficient without too much effort. That was good enough for someone else, but I wanted more. I would double-task—reading another text or reading ahead—while the teacher went over what I had learned long ago."

Filling the class time with meaningful and stimulating activities took different forms for some students, resulting in withdrawal or behavior issues that impacted classroom performance and attitude toward school. James admitted that he craved mental stimulation:

By middle school I was always into something because I 'got it' the first time and I put my mind to creating, diverting, or disrupting the discussion. Seems like it would have been so much easier for the teachers to have planned something for me than to have to constantly react to my antics. 
This sentiment was echoed by many participants who struggled with sustaining high achievement levels.

I was a Distinguished student. Everybody knew it and seemed to dread that I might open my mouth to participate in the discussion, unless things were at a standstill and then it was okay to put me on the spot to expect me to answer the question no one else could answer. I loved learning, but except for gifted, I grew to hate school. The one place where my passions should have been honored was the place it was most difficult to be myself. I learned to escape inside my head and wait for movement around me to let me know that the lecture was over and that I was supposed to be doing something. I was kind of like Charlie Brown and the teacher's voice was 'waa, waa, waa, waa.....' What a royal waste of my time when I could have been learning something!--Marcus

Participants universally reported some degree of underachievement when faced with the consistent message of Proficiency as the performance goal. They reported the need to disconnect from school in some way in order to sustain their own achievement goals in the face of school expectations that were lower than their own. Mandy admitted that "I performed well on tests but it was regurgitation. It felt hollow and became one more part of the game that was school. School was parallel to my real passion for learning and creativity."

Participants reported that classes were structured to emphasize Proficiency and those courses without a direct link to CATS assessment seemed to be taught as though they were not important. Sue noted that "The rigor seemed to evaporate from the classes that were not directly tested on the CATS test. There were classes (like biology and 
physics) in which I didn't open the book until the night before the exam, yet I could ace the test, and not open the book until the next exam." Those patterns of low expectations and lack of rigor contributed to habits of underachievement reported by the participants.

Many participants recalled that there was intensive test preparation before the KIRIS and CATS testing at the high school level. They remembered preparing to take tests that were totally unrelated to the courses on their high school schedules and the motivators offered were T-shirts and plaques that touted Proficiency as the goal.

As the participants reflected on the impact of an emphasis on Proficiency on their achievement as adults, many reported that they were unprepared to be competitive in college because the professors' expectations were higher than Proficiency. James admitted that "It was a culture shock to walk into a setting where the expectation was high and I hadn't had any practice performing at that level for years."

Proficiency was never my goal. By focusing on Proficiency, it sends a message that true excellence is not necessary. What a sad message for our society and for the individuals with the capacity to truly reach excellence.--Beth The goal of Proficiency by 2014 dominated decision-making and instructional delivery throughout the time the participants were students.

Key themes-Proficiency as a performance goal. The following themes emerged based upon the perceptions of the participants related to the goal of Proficiency:

1. Conflict occurred when teacher expectations were lower than student expectations regarding academic performance.

2. Inadequate instructional relevance negatively impacted motivation.

3. Students relied on internal standards to continue to achieve at high levels. 
4. Low expectations were viewed by students as a waste of their time.

5. Emphasis on Proficiency contributed to patterns of underachievement.

6. Students felt unprepared to compete in college and in the workforce.

Every participant expressed strong perceptions about their KERA experiences related to Proficiency as a performance goal and Figure 5 provides a visual representation of the clustering of themes that emerged. By clustering the key themes, the relationships were linked and the related themes are subsumed within the major theme in order to create a visual display of the participants' perceptions of the phenomenon of Proficiency as a performance goal under KERA initiatives (Creswell, 1998; Miles \& Huberman, 1994).

Figure 5. Proficiency as a Performance Goal Themes-Links and Relationships

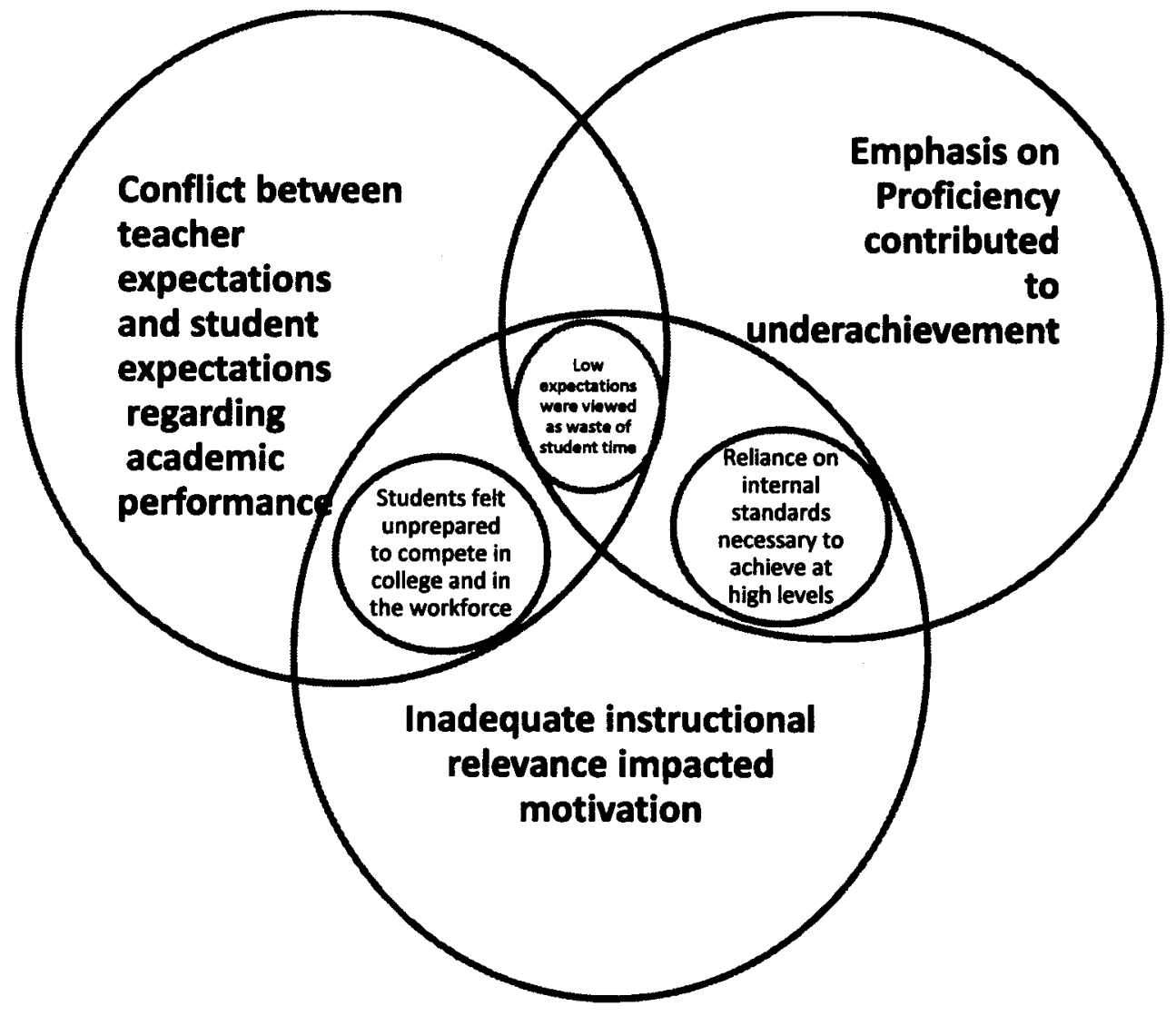


Findings summary. Figure 5 provides a graphic representation of the interrelationships among the key themes that emerged around the topic, Proficiency as a performance goal. Those themes were organized into three major themes: (a) Conflicts arose between teacher and student expectations regarding academic performance; (b) Inadequate instructional relevance impacted achievement; and (c) Emphasis on Proficiency contributed to underachievement.

The perceptions of the participants indicate that Proficiency as a performance goal was inadequate to foster achievement. Not one participant reported that Proficient was their personal goal as a student, yet this reflected a conflict between their expectations and the expectations held by teachers. As students, the participants held high expectations of themselves and they held the belief that Proficient performance was a minimum standard. Because they wanted to achieve at the highest possible levels, conflict between the personal expectations of the students and the expectations of those teachers who reflected that Proficient was good enough was a source of concern for each participant.

As a result, every participant reported a conscious choice to underachieve when faced with the consistent message that what they did with minimal effort was good enough. This created a dynamic in which the course content was not relevant to the needs of the students, leaving many feeling unprepared for the rigor of college coursework or the career paths they had chosen. One participant summed up the perceptions of all:

Every time there was a certain goal established, I expected myself to be Distinguished. I never saw myself as Proficient. I was frustrated that the school 
expectation was Proficient. Proficient was adequate and my peers and I saw ourselves as more than adequate academically.--Shelley

Participation in gifted services was reported as integral to sustaining an emphasis on high personal standards in the face of lower expectations in other settings. Bonnie recalled that "In gifted, our goal was never Proficiency. Therefore, I would have never accepted anything less for myself, and neither would my gifted teachers." Gifted participation was reported to provide clear rubrics, checklists, and other strategies to allow students to internalize standards of excellence. Participants reported that they used the standards they had internalized in the face of lower expectations across other settings.

Resentment was a term used frequently by participants when reflecting on both Proficiency as a performance goal and the use of class time. As students, the participants felt that there was insufficient effort put into identifying what they already knew and too much time spent reviewing what had already been mastered. These individuals reported that they wanted to learn, wanted to be challenged, and wanted to be valued and the emphasis on Proficiency as the goal was a barrier to all three of those objectives.

None of the participants reported that Proficiency as a performance goal positively impacted their achievement as a student, while 27 reported periods of sustained or pervasive underachievement that they attributed at least partially to the impact of the emphasis on Proficiency as the goal on their classroom instruction.

Participants also reported an adverse impact on adult achievement as a result of Proficiency as a performance goal. Though the participants were all students who knew they had the capacity to perform well academically, the majority reported that the 
emphasis on Proficiency did not adequately prepare them for performing competitively at the college level.

My family didn't have much money and I knew that I HAD to have scholarships if I was going to go to college. I knew that good grades were very important, but I found that grades didn't prove learning and that frustrated me. I found that when I got to college, I was at a disadvantage because I had not had to work at the same levels of rigor as the students sitting next to me in my college classes. I was already behind and I shouldn't have been. --Marla

\section{KERA Component—School Based Decision Making Council (SBDM)}

The SBDM council seemed to make policies with the struggling students in mind while creating obstacles for high ability students. With block scheduling, I took the high level courses that were available, but there weren't enough available or they were scheduled on top of each other so you had to choose. Then I had to take 'bunny' classes to fill up the time. Again, a waste of my time. --Kierra

The Kentucky Education Reform Act authorized the establishment of School Based Decision-Making Councils (SBDM) who were charged with the authority to establish policies related to curriculum and instruction. The SBDM council structure was comprised of three teachers (elected by the teachers), two parents (elected by the parents), and the school principal (KDE, 1990). The purpose of the SBDM council in the shared governance model was to improve student achievement through local decisionmaking that was responsive to the unique needs of each school (School-based Decision Making, 2006). 
The decision to establish a SBDM council was optional as long as the school's test scores were showing sufficient improvement and that decision was made by a vote of the teachers (KDE, 1990). As a result, during the time period of the study, the district high school, both middle schools, and two of the four elementary schools had SBDM councils.

A key SBDM initiative during the focus time period was the implementation of $4 \times 4$ block scheduling at the high school. Under $4 \times 4$ block scheduling, each student took four 90-minute classes a day, allowing student to earn a credit for most courses in one semester (Queen, 2000). Advanced Placement courses and band each met for both semesters of the school year for the credit at the target district high school.

In order to determine the perceptions of the study participants regarding the impact of SBDM policies on achievement or underachievement, the following structured interview questions were used:

1.5a Describe your awareness of the SBDM Council and its actions while you were a student.

1.5b Tell me about actions of the SBDM Council that influenced your achievement as a student.

SBDM council put block scheduling in place and block scheduling adversely impacted my achievement as I could not take the courses I needed to stay on my chosen path and to stay busy. I had to choose between AP classes. I had to choose between taking band and AP French. No one in the school saw this as a problem.-Shelley

Participants reported no awareness of SBDM activities or policies at the elementary level. A few participants reported awareness of the SBDM council at the middle school level when they attempted to take advanced classes for high school credit 
while in middle school. However, the majority of students were very aware of the SBDM council and those policies that impacted their educational program or options as students at the high school level.

A recurring theme in the feedback of the participants was the negative impact of block scheduling and the participants identified three primary areas considered negative. Block scheduling created obstacles around access to courses for many of the gifted students. The fact that Advanced Placement courses were taught across two semesters and that they were scheduled against each other meant that students could not readily access the advanced curriculum offerings that they felt they should be entitled to take. Stephen explained that "I was pursuing the Commonwealth Diploma and had a passion for art. The way that the AP classes were scheduled, it was impossible to take the courses I needed without taking correspondence courses and KVHS classes. They didn't even want to approve that."

Arbitrary interpretation of the policies created additional potential for underachievement. Kierra recalled that "Because block scheduling came in during my junior year, I was told I had to graduate under the old system, leaving me an open block each semester. They wouldn't LET me take extra classes!" Other participants attributed similar policy interpretations to a "well-meaning, but ill-advised desire to 'protect us from ourselves' by not asking us to work too hard." Jay remarked, "Because the adults had coasted during their senior years, that was supposed to be what was best for me."

Two participants reported situations where they were able to use a policy designed to support non-college bound students to their benefit. 
The SBDM council approved a school-to-work program that was really geared to students who wanted to leave school early to get jobs, and was not geared to students who wanted a more rigorous schedule. Though they assured me it would be 'too hard,' I was able to use the policy to allow me to take an extra class early in the morning every day, giving me that chance to take required classes and still have band. Once I did it, a couple of others joined me and we were able to take a 7:30 anatomy class together. Otherwise, we never would have been able to take it.--Monty Another set of SBDM policies that adversely impacted many of the participants related to the number of credits that could be brought in from middle school and the number of credits that could be taken through correspondence courses or through KVHS. Though the participants acknowledged that the policies were established in response to address credit recovery issues for students, the councils seemed unwilling to look at their unique situations or the requests of the students in order to foster higher achievement. For example, Todd recalled,

I lost credits coming out of middle school because of an arbitrary limit on how many you can bring in. Then they 'offered' me the chance to retake those same classes that I had A's in already, in order to get the credits. My parents had to do battle to get me the opportunity to take independent study, correspondence courses, and KVHS courses because of SBDM policies. I wasn't trying to get out of anything - I wanted more. I wanted to take AP classes that weren't offered at my high school, and that was seen as a bad thing by the council. 
The importance of parents or teachers as advocates when facing the SBDM council was a recurring theme. Jenny recalled that "my parents seemed to have to fight the school all the time just to get the classes I needed. I always worried about those arbitrary policies that put limits on what we could achieve." Todd concurred, but added, "When my parents tried to get a change in the policy for me to take a KVHS course, they reminded the principal that I could just go on to college without the diploma and they'd hate for me to count as a drop out, the principal indicated that would be 'okay'!"

The instructional impact of block scheduling was an additional feature that participants universally discussed as having the potential to negatively impact achievement. Lack of fidelity to best practice in implementing the instructional adjustments required in block scheduling was a consistent issue. The 90-minute period adversely effected student study skills and time management because for many teachers, the extra class time became a study hall. Kelly recalled that "I knew teachers loved it because they talked about the fact that they had only three classes and 90 minutes of planning, but they [SBDM council] didn't step back and look at whether it was really good for students."

Block scheduling was a real detriment to me because I always got my homework done in class. Teachers didn't adjust their teaching - they still taught about 45 minutes, then gave us the rest of the time to do our homework or entertain ourselves. What a waste of time and a poor preparation for college!--Matt Participants reported difficulty transitioning to college. Anne reflected that the difficulties arose "because time management and study skills were not part of the high school training." Even students who had taken the most rigorous courses available at the 
high school found that they had not had the experiences necessary to really know how to study and manage their time. Marla reported, "I felt like I was done a disservice. I took the hardest courses that were offered and graduated in the top 10 of my class, yet when I went to college and sat next to kids from across the country, I was behind."

A recurring comment was that the SBDM council ignored the issues their policies created--the difficulty in transition that was created by an absence of homework or an expectation that the work would actually be done outside of class time.

Block scheduling was a negative impact on my achievement. I didn't ever have much homework (because it was not assigned), but if it was we always had time to do it in class ... Totally unrealistic preparation for college.--Allan Discussion of the School-based Decision Making council, intended to provide responsive school governance to meet the needs of the students at the school level, generated heart-felt commentary regarding the degree to which council policies were non-responsive to the needs of the study participants.

Key themes_SBDM council. The themes that emerged from participant perceptions regarding the impact of the SBDM council were:

1. Conflict occurred when teacher expectations were lower than student expectations regarding academic performance.

2. Council policies were often obstacles to achievement.

3. Policy interpretation was narrow and didn't address individual needs.

4. Lack of fidelity impacted instructional effectiveness.

5. Block scheduling impeded access to rigorous schedules.

6. Block scheduling and other SBDM policies fostered underachievement. 
7. Parent advocacy was vital in addressing policy obstacles.

Themes related to the SBDM Council are represented in Figure 6 as a visual model of the clustering done to establish the links and relationships among the themes articulated by the participants. By using aggregation and comparison of the themes, the figure shows key themes that could be subsumed by major themes and the numerous key themes related to SBDM councils that can be categorized under the major themes of 1) Fidelity of implementation impacted instructional effectiveness and 2) Conflict occurred when teacher expectations were lower than student expectations regarding academic performance. Every participant articulated experiences related to those themes and their perceptions help provide a phenomenological understanding of their experiences with SBDM councils as rural gifted student in Kentucky.

Figure 6. School Based Decision-making Council Themes_Links and Relationships

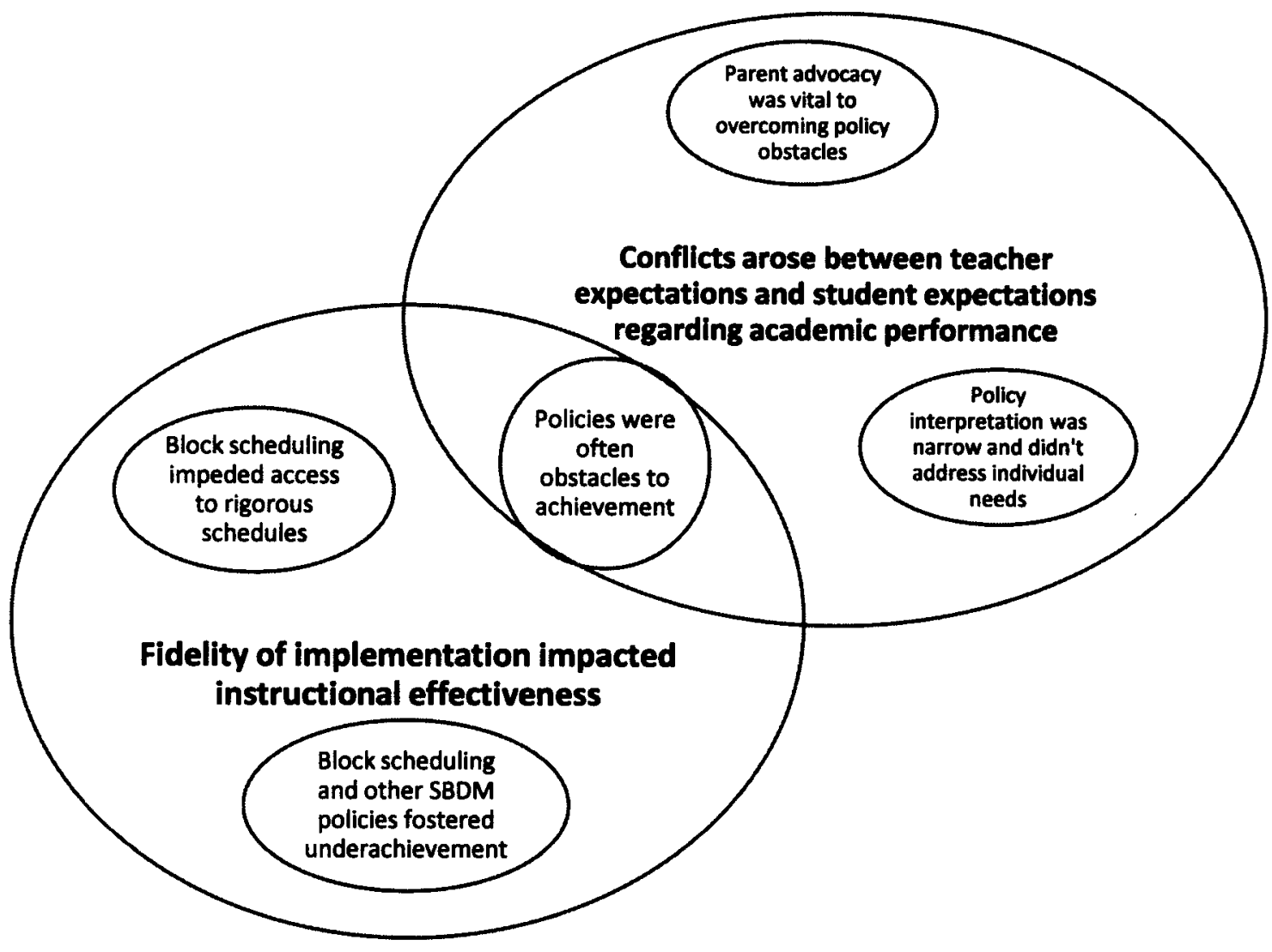


Findings summary. The actions and policies of the SBDM council were perceived by the participants as obstacles to achievement with the potential to foster underachievement at the secondary level. Participants either had no awareness or no concerns regarding policies and actions at the elementary or middle school level.

Figure 6 provides a graphic representation of the interrelationships among the key themes that emerged around the topic, SBDM Councils. Those themes were organized to yield two major themes: (a) Fidelity of implementation impacted effectiveness and (b) Conflicts arose between teacher and student expectations regarding academic performance.

All participants reported issues relating to block scheduling as they worked to access Advanced Placement courses, fine arts curriculum, college preparation foreign language sequence, and other course offerings needed to successfully complete their secondary program. Over half of the participants reported a conflict with SBDM council policies relating to (a) access to KVHS, (b) access correspondence or dual credit courses, or (c) bringing in credits from middle school. Participants recognized that the majority of policies were initially implemented to address either credit recovery or vocational education issues, but expressed frustration that limits were imposed unilaterally when it was evident that the requests were made to access more rigorous coursework, rather than to get out of work.

Participants reported multiple incidents in which the obstacles to access to higher level courses or additional rigor were left in place in fear that it would be "too hard," denying the student access to their instructional need. As adults, the participants were 
frustrated by the irony articulated by Joel. "It's ironic than an entity in existence to improve academic achievement is the source of barriers to achievement for bright kids."

\section{Findings Related to KERA initiatives.}

In an effort to identify the impact of KERA reform initiatives on individuals who were gifted students in a rural Kentucky district, it was important to use the data to develop a phenomenological picture of the experience for the study participants. In the process of creating that picture, a synthesis of the findings for all of the KERA initiatives examined in the study reveals a number of recurring themes. As indicated in the Table 3 , the conflict between teacher expectations and student expectations regarding academic performance impacted every strand of the KERA initiatives. Participants reported a misalignment between the expectations that they held for themselves and their school experiences and the expectations that they perceived were held by many teachers and the schools. The poor alignment among expectations was discussed in the context of teacher attitudes, teacher competency, and student responses. Students were universally frustrated as teachers' expectations were too low, expecting students to remain wholly engaged through a steady diet of repetition or unrealistically high, expecting students to "get it on their own." This conflict was closely related to the themes of lack of instructional relevance and the impact of fidelity of implementation on instructional effectiveness.

Participants discussed poor connections between what they were ready for and what they were taught in the context of every KERA initiative. As students worked to sustain high levels of achievement and to maintain motivation to learn, the participants universally reported that aspects of their instructional setting related to the KERA 
initiatives seemed to be (a) irrelevant to the instruction of the course, (b) at levels that were too low, or (c) unrelated to the needs of the students. This lack of instructional relevance represented a struggle for many of the participants as they worked to maintain motivation within the classroom setting.

A closely related issue for the majority of the participants was the lack of fidelity as many of the KERA initiatives were put into place. As students, the participants had experienced quality writing instruction through their gifted services and reported a wide variation among the strategies used to generate both the writing and math portfolios in the general education classroom. They reported awareness of the difference in instructional impact of the components, depending on the fidelity with which the portfolios were taught and assessed.

Similarly, participants reflected on the importance of fidelity of implementation for all other KERA initiatives. As students, they recognized that some teachers had more enthusiasm or a greater commitment to an initiative so the success or impact of that KERA strand was also greater for those teachers. Joel reported that "Mrs. made us believe that writing and the writing portfolio were important and wonderful.

She believed, so we believed." Participants reflected that their perceptions regarding the KERA initiatives varied from year to year in their school experiences and that many of the differences among their perceptions regarding KERA initiatives-KIRIS/CATS assessments, Proficiency as a performance goal, Ungraded Primary, and SBDM councils-depended on the attitudes projected by individual teachers and the school itself. 
For example, participants shared an understanding that the Ungraded Primary

program should have been similar to their experiences in their multi-age gifted pull-out.

Those individuals who had teachers who implemented the critical attributes of multi-age, flexible groupings, continuous progress, authentic projects and assessments, and developmentally appropriate instruction reported that their primary experiences did have positive impact on their achievement. However, those participants whose teachers did not implement the Ungraded Primary program with fidelity, reported underachievement and loss of motivation.

Table 4

Common Themes Across KERA Initiatives

\begin{tabular}{|c|c|c|c|c|c|c|c|c|c|c|}
\hline KERA Initiatives & 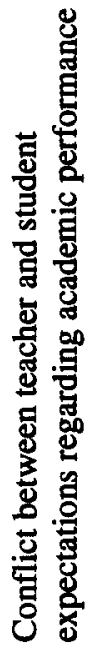 & 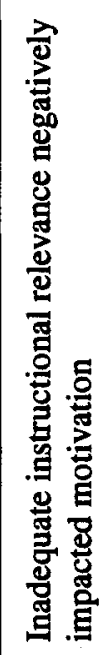 & 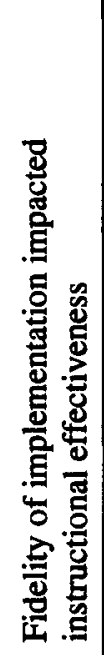 & 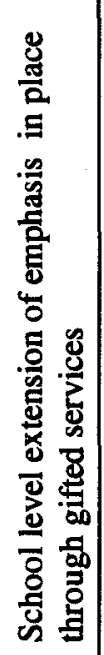 & 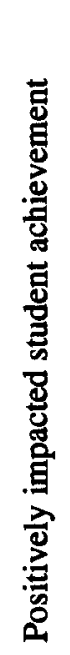 & 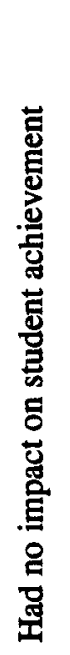 & 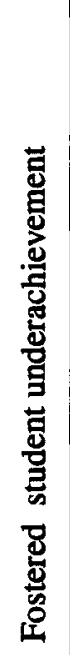 & 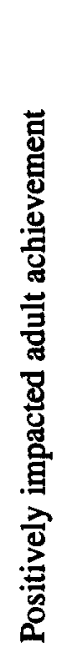 & 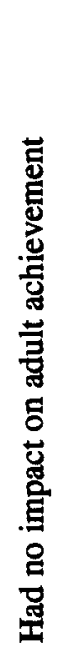 & 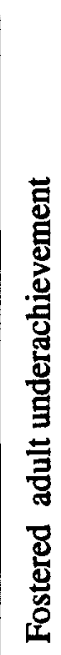 \\
\hline Writing Portfolio & $\overline{\mathbf{X}}$ & $\mathbf{X}$ & $\overline{\mathbf{X}}$ & $\mathbf{X}$ & $\mathbf{X}$ & & & $\mathbf{X}$ & & \\
\hline Math Portfolio & $\mathbf{X}$ & $\mathbf{X}$ & $\overline{\mathbf{X}}$ & & & 9 & 21 & & 26 & 4 \\
\hline Primary Program & $\overline{\mathbf{X}}$ & $\mathbf{X}$ & $\mathbf{X}$ & $\mathbf{X}$ & 3 & & 27 & & $\mathbf{X}$ & \\
\hline $\begin{array}{l}\text { KIRIS/CATS } \\
\text { Assessments }\end{array}$ & $\mathbf{X}$ & $\mathbf{X}$ & $\mathbf{x}$ & & & $\mathbf{X}$ & & & $\mathbf{X}$ & \\
\hline $\begin{array}{c}\text { Proficiency as } \\
\text { Performance Goal }\end{array}$ & $\mathbf{X}$ & $\mathbf{X}$ & $\mathbf{X}$ & & & & $\mathbf{X}$ & & & $\mathbf{X}$ \\
\hline SBDM Councils & $\mathbf{X}$ & $\mathbf{X}$ & $\mathbf{X}$ & & & 2 & 27 & & & $\mathbf{x}$ \\
\hline
\end{tabular}


Table 4 compares each of the KERA initiatives and the participants' perceptions regarding impact on achievement. As a part of the interview process, participants were asked about the impact of each of the KERA initiatives on their achievement as students and as adults. As the themes emerged, the participants were asked about their perceptions related to the major themes in a follow-up interview. The table represents those themes and the participants' perceptions of the impact of the initiatives. Numbers indicate the actual responses of the study participants. Themes or initiatives marked with an $\mathrm{X}$ reflect those reported by 30 out of 30 participants.

Based upon the perceptions of the study participants, the writing portfolio had positive impact on student achievement and positively impacted adult achievement among students who were gifted students in a rural district. All other KERA initiatives were perceived by those participants as having had no impact on achievement or were perceived as have fostered underachievement.

The math portfolio was reported as having no appreciable impact on student achievement. However, over half of the participants reflected that the math portfolio negatively impacted their adult achievement for a number of reasons. Some felt the process detracted from time they needed to build genuine mathematics competency. Others felt that the types of writing required in the math portfolio left them unprepared to do real mathematics or scientific writing. For those with lower confidence levels in math, they felt that the math portfolio process undermined their belief that they "could do math" at high levels and caused them to avoid high level math in college. As Collin reported, "After the math portfolio, once I got to college, I never took another math course." 
The Kentucky Education Reform Act was intended to represent a significant, systemic change in the educational expectations and instructional delivery across Kentucky (KDE, 1990). Based upon the perceptions of the study participants, with the exception of the writing portfolio, the initiatives that reflected those educational expectations and instructional delivery systems did not positively impact achievement among these high ability students.

\section{Summary}

The first research question of the study was the basis for this chapter. Thirty adults who were products of KERA reform initiatives were asked to reflect on the impact of those initiatives on their achievement and underachievement as individuals who had been gifted students in rural Kentucky. The chapter synthesized the responses of the participants to the research question:

1. What are the perceptions of former gifted students regarding the roles of each of the instructional Kentucky Education Reform Act initiatives (Portfolios [writing and mathematics], Ungraded Primary, KIRIS/CATS assessment, Proficiency as a performance goal, SBDM council policies) in fostering or impeding self-reported student and adult achievement?

The participants reported that the writing portfolio had positive impact on their achievement as students and as adults. The other KERA initiatives-math portfolios, Ungraded Primary, KIRIS/CATS assessments, Proficiency as a performance goal, and SBDM council policies-were all perceived as having no impact on achievement or as having fostered underachievement among the participants. 
Chapter 5 provides synthesis of the participant responses to the two remaining research questions in order to structure the most accurate description of the phenomenon of impact of KERA initiatives on the achievement and underachievement of gifted students in a rural Kentucky district between 1994 and 2004 the era of the Kentucky Education Reform Act.

In order to structure the results the two remaining research questions, comments or quotes related to the questions, preliminary findings, and findings summaries are used. Findings are synthesized into topic-specific key themes that reflect universally occurring themes within the topics discussed by participants and provide depth of description for the phenomenon of the rural Kentucky gifted student experience during KERA. Those key themes are then further synthesized to develop the major themes of the study. 


\section{CHAPTER 5}

\section{RESEARCH FINDINGS-RURAL GIFTED AND UNDERACHIEVEMENT Introduction}

This phenomenological study linked insights about the impact of initiatives of the Kentucky Education Reform Act on student and adult achievement with perceptions regarding the impact of related educational programming and structures on achievement and underachievement of individuals as students and as adults. The participants were adults who had been served as gifted students in a rural Kentucky school district between 1994 and 2004. Two research questions are the basis for this chapter:

Research Question \#2. What related educational experiences and structures in a rural setting are perceived by the former gifted students as fostering or impeding selfreported student and adult achievement?

Research Question \#3. What are the similarities and differences in perceptions between those adults who self-reported sustained achievement and those who reported underachievement?

Using the results of face-to-face interviews and telephone interviews, analysis of the transcribed responses of 30 adults who were identified and served as gifted students between 1994 and 2004 was used to develop accurate descriptions of their experiences as rural gifted students and their perceptions regarding the impact of their educational experiences on their achievement and underachievement as students and as adults. 
Chapter 5 is organized around the two research questions. Through the use of the interview questions, comments or quotes related to the questions, preliminary findings, and findings summaries, the research findings are presented.

\section{Findings Related to Research Question Number Two}

Research Question \#2-- What related educational experiences and structures in a rural setting are perceived by the former gifted students as fostering or impeding selfreported student and adult achievement?

Being in the gifted program is the single most influential part of my education career. It impacted my achievement more than anything else. As a gifted student in a rural school, I could easily have gone through my whole career as the 'top dog' in my little school, thinking that whatever I did was excellent because I usually was first, fastest, and accurate. However, when I went to the gifted classes and got to be a in a group of students just like me, it was both humbling and invigorating because it gave me confidence in my abilities based on true standards of excellence.--Stan

Gifted students in Kentucky are identified as a category of exception children as a part of the Kentucky Education Reform Act, KRS 157.200 (1990). They are defined as those student identified possessing demonstrated or potential ability to perform at an exceptionally high level in general intellectual aptitude, specific academic aptitude, creative or divergent thinking, psychosocial or leadership skills, or in the visual or performing arts (KDE, 1990). The participants in this study were 30 individuals who had been identified as gifted according to the Kentucky Gifted Regulation, 704 KAR 3:285 (KDE, 1994), in the area of general intellectual ability and at least one other area. All 
participants received services as a part of the Primary Talent Pool between grade K-3 and as a part of the Gifted Education Module beginning at grade 4 (KDE, 2004).

In accordance with the Kentucky Gifted Regulation, 704 KAR 3:285 (KDE, 1994), multiple service delivery options must be available for students $\mathrm{K}-12$, and services for the students in the study were provided by gifted-endorsed teachers through: (a) oneday-per-week pull-out services at a central location for elementary students K-6 at a central location, (b) half-day or full-day pull-out services for grades 7-8 provided at the high school or in the middle school, and (c) gifted English classes for grade 9-12. Resource services were also provided through leadership seminars, travel study, elementary instrumental music offerings, youth chorus, and once-a-week talent pool activities. Gifted and talented teachers also provided monitoring of student instructional programs through collaboration with regular classroom teachers (KDE, 2004).

Research Question \#2 was explored through the following interview questions:

2.1 Tell me about what it was like to be a gifted student in your rural Kentucky school district.

2.2 Tell me what it was like to be a gifted student in your regular classroom.

2.3 Tell me how your peers influenced you.

2.4 Tell me about the relationship between your gifted services and the KERA initiatives during your school career.

\section{Gifted in Rural Kentucky}

In order to place the experiences of the participants in context, they were asked to reflect on their experiences as rural gifted students by answering the question:

2.1 Tell me about what it was like to be a gifted student in your rural Kentucky school district.

As a rural student, I lived an isolated life. My family didn't have money, so the trips we took through gifted were the only opportunity I would have had to those 
exposures beyond the county line. Being gifted in a rural setting makes you different and gifted was the only place where high achievement on an intellectual level was fostered. Gifted truly save my life.--Sandy

Participants identified factors in their rural educational experiences that were barriers to achievement. The barrier of limited resources was articulated by every participant. Participants extended their definitions of resources to include human resources as they discussed the phenomenon of being a rural gifted student with an adversarial teacher. Monty explained that "Sometimes there was one person in a grade level or department, so when that person didn't know their content or was a negative presence, there was no way around them." Discussion of individual teachers in the rural setting also included the difficulties many students encountered with teacher attitudes. John reported that "Because some teachers felt threatened, they found ways to persecute us. Some teachers were subtle, some very blatant. At times it seemed like more than I could handle."

Resource limitations also included items such as inadequate materials, books, technology, science equipment, and cultural opportunities. The participants identified the difficulty in accessing print resources as a painful barrier. Stephen recalled that "Rural school libraries were very limited and the books, especially in science, were very outdated. Even the public library was a limited resource for research or just to pursue an interest." Thirst for exposure in the sciences and in the arts was another barrier created by lack of resources. Jon stated that "In rural Kentucky, there weren't many opportunities for kids to see the upside of being artistic or creative. As a creative, artistic kid, I was 
truly an outsider in my own community." Liza summarized the perceptions articulated by every participant:

There weren't enough resources and at times I felt like many of the adults were not equipped to deal with my questions. There's not a lot of surplus of population-you have what you have. We had one school with the same people for twelve years. There's no real science. There's not any art or theatre-there's none. If you don't happen come from a family who has the resources or knows where to get them, you just have to go without. Access to resources makes such a difference!

An additional barrier identified by participants was the small community size. Though they acknowledged the potential benefits of a support system that extended beyond the classroom, most identified situations in their educational career when the fact that there is little privacy in a rural community presented difficulty. Andy recalled, "We rode the bus together for 12 years and everyone along the bus route thought they were entitled to voice their opinions about what I did. Anything that deviated from the status quo was suspect." Marcus concurred, "Norms were so deeply ingrained. Not doing what everyone expected you to do or doing too well set you apart in a negative way. You quickly had to choose-give in or give up."

Participants who expressed less distress were found to have compensatory factors in place that lessened the conflict with the rural norms. Those students who participated in school sponsored sports reported greater ease with being identified as a rural gifted student. Kierra admitted that "It would have been very different if I hadn't been an athlete. Because I played sports, I was accepted in both worlds." Those participants who 
were on sports teams, cheerleaders, or who were members of the high school marching band reported levels of social acceptance and satisfaction with their school experiences that were more positive than their peers who did not participate in those activities that were part of the community norm. Monty recalled that "Participation in band gave me an automatic peer group that was focused on a common goal that was working toward high standards, but was not seen as too different."

A second compensatory factor that participants identified was participation in church activities with an active youth organization. This membership provided a similar link to the community beyond the school setting and was closely linked to community norms. Participants reported that their strengths were appreciated when they were focused on an event that brought recognition to the church. Milly recalled that "Some of the same kids who gave me a very hard time at school for being a good student were my 'best friends' at church when I won a regional Bible Bee. Suddenly my good memory was in favor!"

Geographic isolation was a factor that participants identified as a powerful factor in their rural education experience. "We were isolated!" recalled Lana. "I had a teacher who was proud of the fact that she never had driven outside of the county and many people in the community were content NOT to know about anything beyond the county line." Many students reported living in remote areas in the county and having no close neighbors and limited access to other children besides family members. They did not have cable television and definitely did not have Internet access. Todd reflected, "I had nature and books!" 
Participants related the geographic isolation to social isolation. They viewed the community was close-knit and slow to acknowledge an interest or need for anything that was different from what had come before. Cara remarked, "That mindset of being content with what you know and who you know carried over into all layers of social grouping. As someone who moved to the county in $3^{\text {rd }}$ grade, I spent my entire school career as being from 'away from here."”

Key themes-Rural gifted. The key themes the emerged from participant perceptions regarding their experiences as Rural Gifted were:

1. Limited human resources impact educational opportunities.

2. Limited material resources impact educational opportunities.

3. Geographic isolation impacts educational opportunities.

4. Close-knit community groups impact acceptance or rejection.

5. Participation in socially-acceptable non-gifted activities increase social acceptance.

6. Gifted students feel different and isolated.

Figure 7 provides a visual display of the clustering to show the interrelationship among the themes that dominated the description of the rural gifted experiences of the participants. The themes were aggregated and represented as linked within the major themes in which they are subsumed. This display shows the connections among the themes that are the basis for understanding the perceptions of the participants regarding their experiences as gifted students in rural Kentucky (Creswell, 1998; Miles \& Huberman, 1994). 
Figure 7. Rural Gifted Themes-Links and Relationships

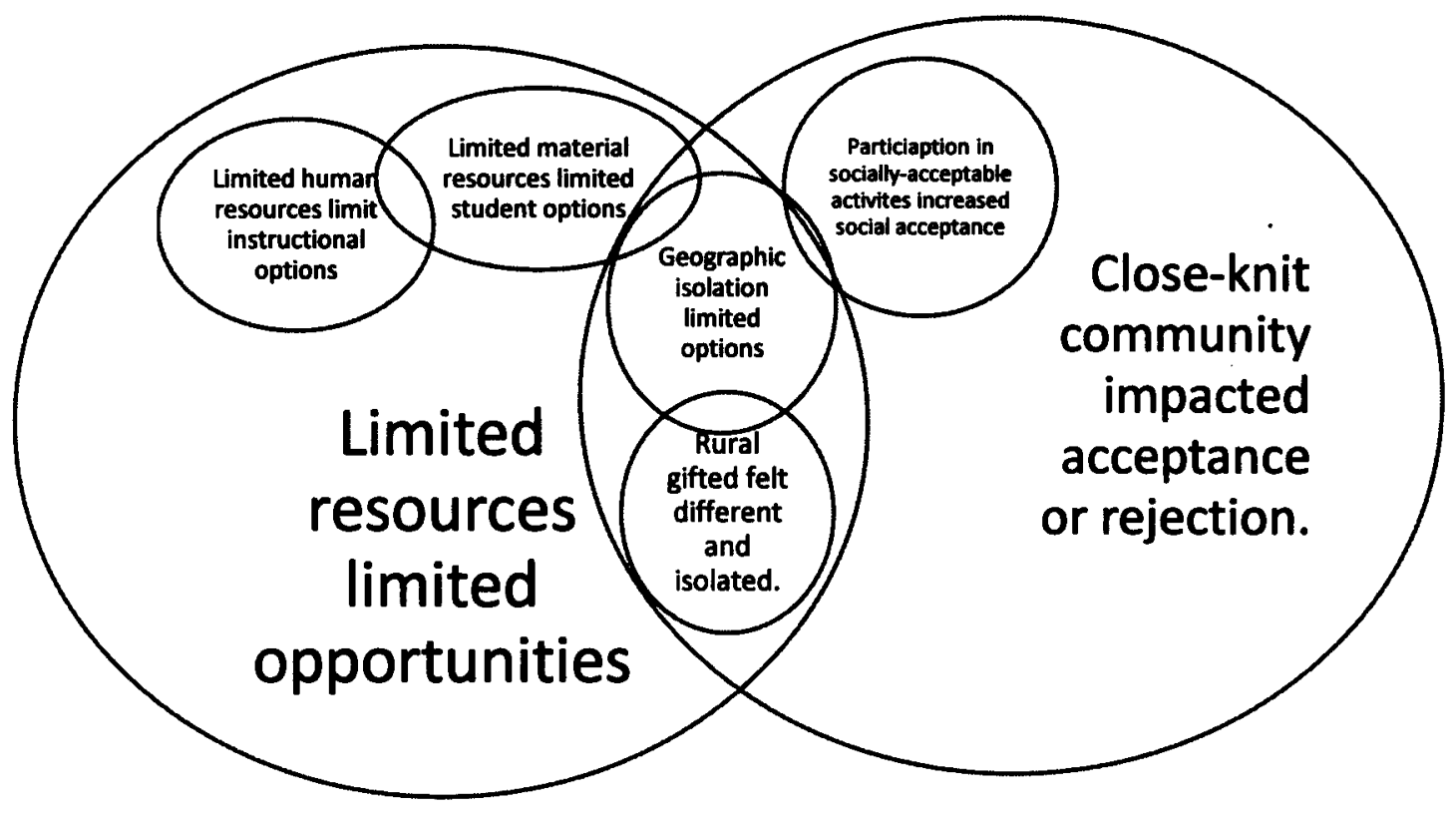

\section{Summary findings.}

The dynamics of being a gifted student in a rural district were identified by the participants as complex and closely linked to feeling different, to being perceived as different by peers and teachers, and to experiencing appropriate educational opportunities. Geographic isolation and limited resources, both human and material, have the potential to impact the educational experiences of rural gifted students and were identified as the major themes around rural gifted. These themes were subsumed into two major themes: 1) Limited resources limited opportunities and 2) Close-knit rural community impacted acceptance or rejection of gifted students.

\section{Gifted in the Regular Classroom}

An important perspective in addressing the phenomenon of being a rural gifted student was the dynamic of the regular classroom. Participants were asked to address the following question: 
2.2 Tell me what it was like to be a gifted student in your regular classroom. There is an anti-intellectualism that is part of the rural experience. If you try to have a conversation that is outside the realm of what the teacher knows about, rather than get excited about the opportunity to learn about it, they would try to shut you down or make you feel bad. You'd get 'THE LOOK.' That scathing look you get when you have a question or idea that is different. Adults treated me that way all the time. Of course kids are going to do that, but the grown-ups did it, and we weren't supposed to care.--Lana

Though the participants were asked to address the question of regular classroom dynamics at the elementary, middle, and high school level, all participants either answered the questions in terms of specific teachers and specific experiences or generalized about their entire school experience when answering this question. The majority of participants were positive about the majority of their teachers as people, but were very candid about the quality of instruction and the classroom climates that they experienced.

Participants reported that they struggled with a lack of acceptance by teachers that was difficult to understand as elementary students. Liza remarked that "It was kind of like walking around with the scarlet "G" on your forehead. They [teachers] had a problem with the very idea of gifted and that was hard for me to deal with as a nine-year old." Sandy recalled that "I knew the answers to all the questions, but I learned not to answer because of the teacher's reactions." Teacher acceptance was important to the majority of the participants and they reported conflicted feelings when they realized that 
a teacher did not like them for being smart, but they could not figure out why intelligence would be threatening.

Struggling with conflicted feelings toward individual teachers was reported by all participants. They characterized their feelings as "hurt," "confused," "puzzled," "disappointed," "surprised," and "baffled" as they struggled to reconcile the admiration and confidence that they initially held toward all of their teachers with the actions and attitudes of individual teachers toward the gifted students. Allen pondered, "I could never figure out why someone who was in the business of encouraging learning would be threatened by kids who were excited to learn."

Teacher attitude played a powerful role in establishing classroom climate and the level of acceptance within the regular classroom. Shelley recalled that "I had teachers who wouldn't tolerate any kind of name-calling or picking on someone because they struggled to learn or looked different, but calling me a 'geek' and a 'nerd' every day was perfectly okay." Participants universally reported that teacher attitude was the single most important factor in determining the level of peer acceptance. Joe noticed that "Because the teacher was cool with it [picking on you], there were kids who were pretty friendly outside of class, but once you walked into the classroom, you were fair game." According to the participants, as students they learned to check out or misbehave to try to gain peer approval or to just "stay under the radar." Anne remembered,

I learned that I could make people laugh. It was the first time I had been aware of any level of peer approval and I began to get in trouble because I developed an attitude. In a strange way, the teacher seemed to like me better because, I guess, that made me seem more normal. 
Participants reported that teachers deliberately covered critical material when they were gone to gifted class and that many teachers "wielded your intelligence against you as a weapon." Todd recalled that "I never felt like my presence in the room wasn't noticed. I felt under extreme scrutiny because the teacher was going to delight in my mistakes."

Pleasing teachers and trying not to disappoint was a common goal reported by the participants. Because adults were the initial intellectual peers sought out by the gifted students, they expected to cherish the relationships with their teachers and most reported that they worked hard to foster those relationships. That dynamic made it especially painful when teachers didn't seem to value what the students could do or what they know and Todd explained that "It was hurtful when teachers over-reacted."

When asked about the regular classroom, every participant listed descriptors that supported the theme-lack of challenge. "Boredom," "wasted time," "waiting," "too slow," "discouraging," and "disconnected" are just some of the terms that participants offered when asked to tell what it was like in the regular classroom. Participants reported that they were able to only partially engage and still perform well on tests. Sandy commented that "I learned to take a book and hide it in my desk. I could read my book during class and not miss out on anything happening in the room." A recurring theme was that the participants were able to keep up with classroom instruction with very low levels of engagement and accountability. As Stephen said, "I could listen with one ear and still keep up. I would slip away and no one cared."

Frustration with lack of acknowledgement of what students knew and eagerness to be appropriately challenged created significant conflicts for participants within the 
regular classroom. When asked specifically about levels of challenge, every participant replied that the levels of challenge at elementary levels and at middle school levels were very low. Responses for high school were more varied, based on the courses that students were able to access. Participants reported that, though there were a few specific courses in high school that provided opportunity for challenge, as a total secondary program, it was definitely not challenging. Danny summarized the secondary experience by recalling:

There were some AP classes and dual credit classes available, but even those were not consistently challenging. Because there was no push to take the AP exams, the courses were not structured to assure mastery of the content at high levels. It was still very possible to just 'get by.'

Participants reported that the implementation of KERA initiatives did not have a positive impact on the level of challenge within the classroom or the teacher's likelihood to differentiate. Boredom, frustration, and impatience were commonly expressed sentiments as participants reflected on the curriculum and instruction within their KERAbased school experiences. Perceptions about classroom instruction emerged as primarily whole-group instruction at all grade levels and teachers were reported to be very unlikely to group or provide differentiated instruction for students who needed to go faster. Callie reflected the comments of the participants when she reported,

I don't ever remember working in a small group for reading or for math.

Everyone in the class read out of the same book, even if you told that teacher you had already read that book. I was expected to diligently do my work, act 
interested, and plan to quietly keep myself occupied while I waited for the rest of the class to catch on.

The regular classroom was not consistently a nurturing or challenging place for the participants. The influence of the teacher's attitude, the classroom climate that was established, and the level of challenge presented were identified as the most significant factors in influencing the impact of the regular classroom for the participants. All participants linked the classroom experiences to their struggles to maintain motivation and the impact on their achievement. Connections and relationships among the themes are illustrated in Figure 8.

Key themes—Gifted in regular classroom. The key themes that emerged based on the participant perceptions related to their experiences as gifted students in the regular classroom were:

1. Conflict occurred when teacher expectations were lower than student expectations regarding academic performance.

2. Gifted students wanted teacher approval and were distressed when they could not achieve it.

3. Teacher attitude impacted classroom climate related to acceptance by other students.

4. Inadequate instructional relevance--The level of challenge in the regular classroom created boredom and disengagement.

5. Students were able to keep up in classes where they made minimal effort.

6. High levels of student frustration resulted from lack of challenge. 
7. Students developed a variety of coping strategies to deal with lack of challenge and issue of peer and teacher acceptance.

8. Reform initiatives did not reduce boredom or increase teacher capacity to address student needs.

Through clustering of the key themes, a visual representation of the relationships among those themes was developed in Figure 8. Student perceptions of their regular classroom experiences centered on the major themes of 1) Lack of instructional relevance impacted achievement and 2) Conflict occurred when teacher expectations were lower than student expectations regarding academic performance. Those two factors were linked in the classroom dynamic and every participant reported both interpersonal and academic performance issues that related to those themes. Key themes were linked to show relationships and subsumed within the major themes in order to reflect the perceptions of the participants regarding their experiences as rural gifted students in the regular classroom (Creswell, 1995; Miles \& Huberman, 1994). 
Figure 8. Gifted in the Regular Classroom Themes-Links and Relationships

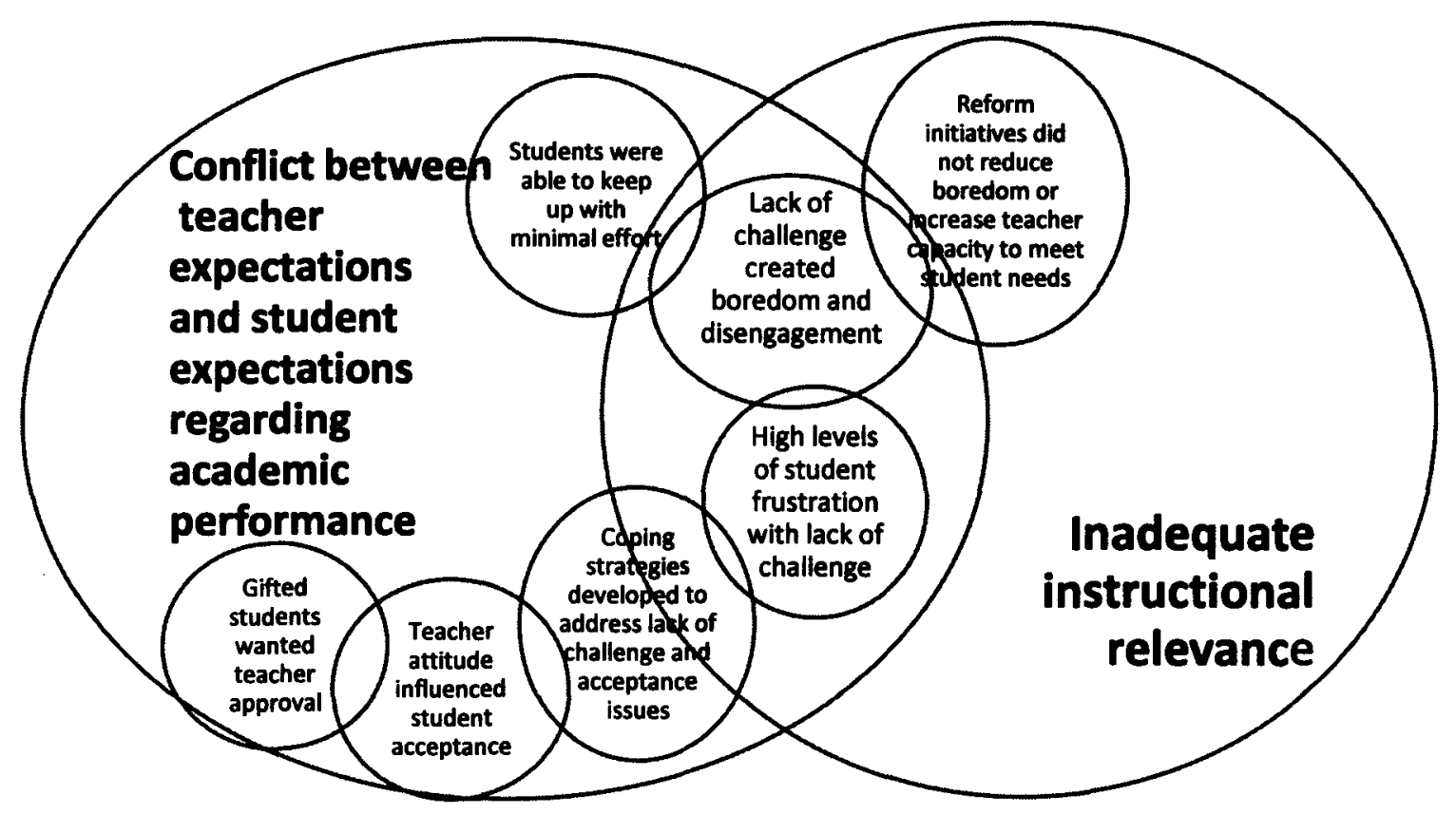

\section{Summary findings.}

The educational experience of the participants in the study, as rural gifted students, reflected a heavy dose of whole-group instruction delivered by teachers who did little to create a classroom environment that supported the unique needs of gifted students or that supported acceptance by other students. Instructional delivery was at a level and pace that did not offer high levels of challenge so that students were able to maintain acceptable levels of performance with minimal effort. The regular classroom was a source of frustration for gifted students and that dynamic was consistent in spite of KERA reform initiatives. Figure 8 illustrates the relationships among the key themes that emerged around the experiences of gifted students in the regular classroom and shows that the two major themes- (a) Conflicts between teacher and student expectations 
regarding academic performance impacted achievement; and (b) Inadequate instructional relevance impacted achievement.

\section{Impact of Peers}

Peers were not identified in the most significant factors when reflecting on the regular classroom, but the role of peers was examined through a specific question:

2.3 Tell me how your peers influenced you.

Getting made fun of for being smart became a daily occurrence at about $3^{\text {rd }}$ grade. The only attention I got was negative attention. It started on the bus and continued through the school day, and that ridicule became my daily companion.--Joel

Participants universally identified the impact of like-minded peers in fostering and sustaining high levels of achievement and satisfaction toward school. All participants reflected that the peer dynamic created through their gifted services allowed them to meet and know gifted students from across the county very early in their school careers. That dynamic created a stable group of intellectual peers with a body of common experiences and similar goals who proved beneficial in maintaining motivation and competition.

The peer influence exhibited by gifted peers was reflected in the comments of participants across every grade level. Mandy recalled that "The gifted students were really the allies for one another. We learned from each other and added rigor where it might not exist by personally raising the bar." The participants identified competition and lasting friendships as recurring themes related to the peer influence of gifted peers.

Peer influence across settings was less positive. "I learned not to answer any questions and not to look eager when the teacher was talking so that the other kids would think I was more like them," confessed Sandy. Others reported that they totally 
disengaged by daydreaming or reading or doing something disruptive. Participants reflect that teacher antagonism provided a powerful role model in some classrooms. Chase admitted that "after a few well-placed comments by the teacher, the gifted kids were fair game."

Participants who faced lack of acceptance by peers recalled that they responded by either trying to change how they came off in the classroom to try to gain acceptance, by going underground so that the peers wouldn't notice, or by just pushing forward and ignoring them. Most participants reported that they used all three strategies in different situations. Todd reported that "I just didn't really care what peers were doing. I used another gifted individual that I respected as a reference point for my trajectory."

"Loneliness" and "isolation" were descriptors that participants applied to their lives as rural gifted students and their feedback linked these indicators to a combination of teacher and peer influences. While teachers were most significant in creating a dynamic of isolation, participants reported that even in an accepting environment, they frequently had no intellectual peers in their rural classrooms and instructional delivery did nothing to provide opportunities for students with similar interests and abilities to work together.

Participants acknowledged that the interests of many of their age-mates were very different from theirs and the successes that were celebrated through the schools such as athletics and Future Farmers of America were not matched by celebrations of the successes of Academic Team or Mock Trial. Participants learned to rely on personal goal-setting and support within their gifted peer group. Personal goal-setting helped to 
focus students on future achievements and helped to put the day-to-day occurrences in perspective.

The fact that school was a bad match with what I wanted for myself made middle school a miserable existence for me. I was able to 'play the game' only because I had goals outside of school that I wanted to accomplish and I realized that if I shut down completely, I would never be able to reach them. I set personal goals and made it a personal mission to endure it the best that I could. --Thomas

Key themes-Impact of peers. Key themes that emerged from the perceptions of the participants related to impact of peers were:

1. Intellectual peers were a significant factor in sustaining achievement and satisfaction.

2. Intellectual peers provided affirmation and competition.

3. Gifted students employed non-performance, misbehavior, or ignoring when faced by peer rejection.

4. Teacher attitude was significant in influencing how gifted students handled peer rejection.

5. Loneliness and isolation occurred frequently in the regular classroom.

6. Personal goal-setting was an important factor in maintaining achievement.

7. Vulnerability to teacher/peer rejection was pervasive during middle school years. In order to aggregate and compare the themes, related ideas were clustered in Figure 9. By linking the themes as they overlapped or were subsumed by a major theme, it was possible to create a visual representation of the relationships between and among 
the perceptions of the participants in order to create a picture of the phenomenon of peer impact (Creswell, 1995; Miles \& Huberman, 1994).

Figure 9. Impact of Peers Themes-Links and Relationships

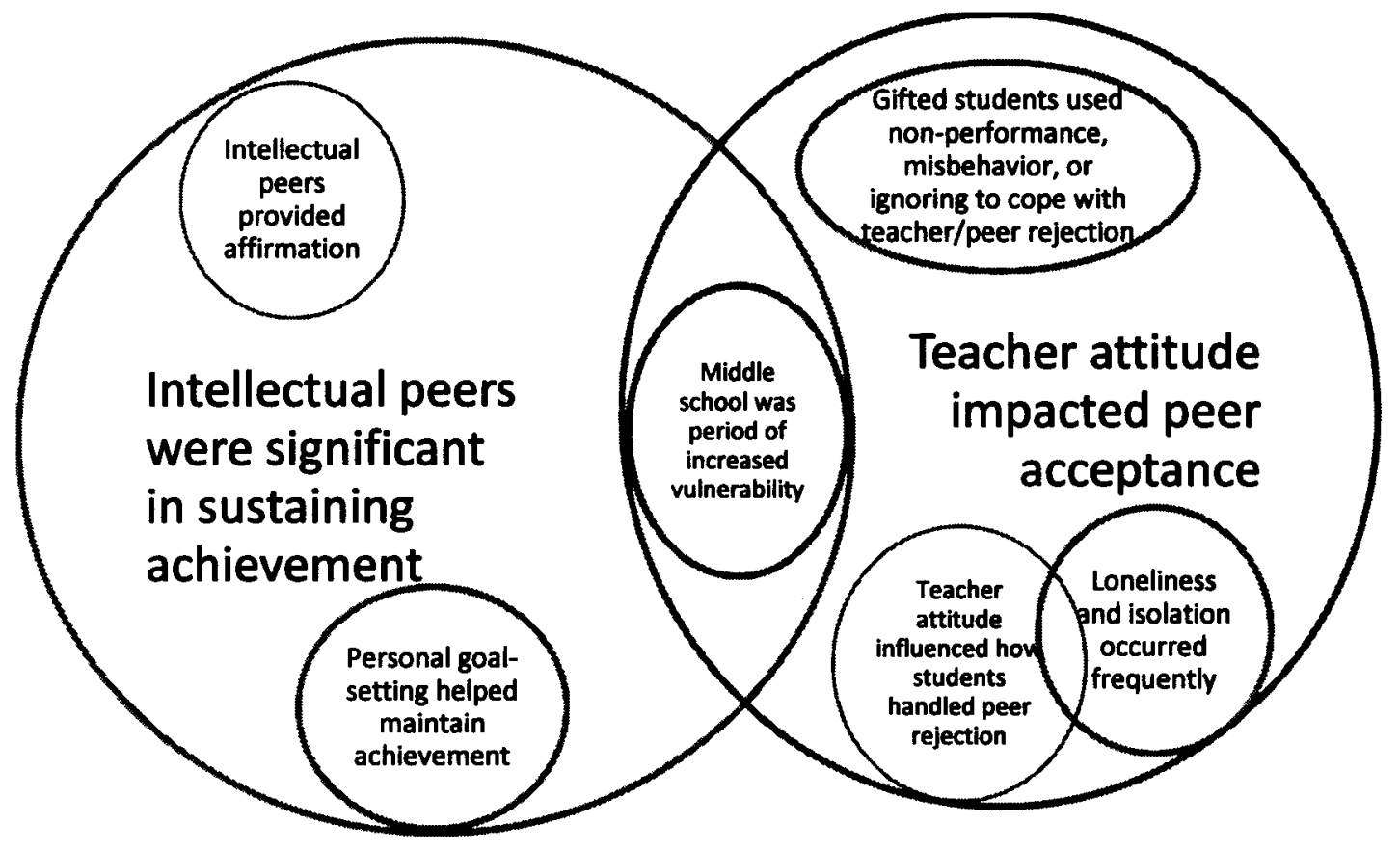

Summary findings. The impact of peers on the achievement and satisfaction of rural gifted students was an important dynamic. As seen in Figure 9, the two major themes that emerged around Impact of Peers were 1) Intellectual peers were significant in sustaining achievement; and 2) Teacher attitudes impacted peer acceptance or rejection.

Intellectual peers who formed a group with common interests and goals were the most influential group in helping to sustain high achievement and high levels of satisfaction. Todd reported that "Intellectual peers provided a reference point for how we should feel about ourselves" and, because they shared common goals, intellectual peers were identified as a natural group for healthy competition. 
Gifted students who faced peer rejection in the regular classroom reported that they frequently adjusted their behavior to appear less prepared, less capable, or less interested in order to gain peer approval. Participants admitted that the longer they disengaged, the more likely they were to lose ground. Thomas recalled that "The habit of checking out of class was so deeply engrained that by the time the class got to new material, I had skill gaps that haunt me to this day." The middle school years were universally reported as a period of vulnerability to teacher and student rejection for gifted students and gifted behaviors.

Teacher attitude was the key determining factor in establishing the classroom climate that made peer rejection acceptable. Participants reported that teachers frequently established the tone that made gifted students easy targets. As a result, loneliness and isolation were common descriptions that participants applied to their regular classroom experiences.

Participants reported that they used personal goal-setting and interests outside of school to help sustain an interest in learning and even achievement in class because they tried to see school as a means to an end. The role of gifted services in addressing the dynamics of being a gifted student in a rural school district and in reflecting on the impact of KERA initiatives was examined through questioning the relationships among gifted services and reform initiatives.

\section{Relationship Between Gifted Services and KERA Initiatives}

In order to gain insight into the perceptions of participants regarding the relationships between KERA initiatives and their gifted services, they were asked the following question: 
2.4 Tell me about the relationship between your gifted services and the KERA initiatives during your school career.

To me, KERA was just an attempt to take all of the good things that were happening through gifted services and move them into the regular classroom. As the reform initiatives went into place in our classrooms, they were a big change for some teachers and for some students, but for most of the gifted kids, it was what we'd been doing all along.--Todd

The impacts of the Kentucky Education Reform Initiatives were analyzed through specific questions and the related participant perceptions in Chapter 4. To gain a full description of the experiences of the rural gifted students in the era of reform, it was important to analyze the relationships among the KERA initiatives and the gifted services provided to the participants. Each KERA initiative was examined in order to determine its connections with the philosophy and practices of gifted services delivered to students in the target school district and the impact on achievement or underachievement.

\section{Writing portfolio}

Participants identified writing as a seminal component of their gifted services $\mathrm{K}$ 12. The gifted teachers used writing as a powerful strategy to teach and practice critical and creative thinking, and students reported writing regularly as a part of their gifted classes. Laurie recalled that "We worked on portfolio pieces in gifted, but we had been using peer review and had been maintaining a portfolio of our writing long before it was gathered for KERA." Joel concurred, "I was already accustomed to writing and using critical thinking in gifted, so writing pieces for the portfolio were just no big deal."

Another aspect of the writing portfolio that participants reported was closely linked to gifted services was the use of rubrics and checklists. Lana recalled that "Self- 
reflection was a part of everything we did. I was constantly in self-reflection on where I stood on the progression toward the skills and mastery. Everything had a continuum. The writing scoring guide was just one more."

Participants reported that the enthusiasm and commitment of the gifted teachers toward the writing process and toward high levels of student writing was contagious. Marcus admitted, “I didn't want to disappoint Mrs. . She expected me to be

Distinguished and I was willing to work to get there. I was very proud of my portfolio!" Lana recalled that,

When we went to gifted, Mrs. __ told us we were going to GET to write and then she'd walk us through all of these steps to generate ideas and then narrow them and then expand them and then share them ... We really were so primed that we were finally asking when we could finally GET to write it. We produced amazing writing and didn't even realize that it was anything exceptional.

\section{Math Portfolio}

Participants reported that the gifted teachers challenged them with more rigorous math, but the math writing they did in gifted did not get incorporated into the math portfolio.

We had to write analytical math responses for Mrs. but the regular classroom teacher wouldn't let us use those for our portfolios because they didn't know how to score them. They were too complex. All we were allowed to use for our math portfolios were the common prompts.-Jason 


\section{Ungraded Primary}

Critical attributes of the Ungraded Primary program—continuous progress, developmentally appropriate instruction, multi-age groupings, and authentic assessments-were reported by participants as attributes of their gifted education experiences at the elementary and middle school levels. The fact that gifted classes were multi-age and pulled together students from all over the county was reported to provide both social and intellectual stimulation. Participants expressed strong feelings about the value of their gifted experiences through their primary years to add rigor and differentiation to their educational program. Kierra remembered, "We were always working on something that was just a little bit harder than what we'd done before." The use of checklists and the opportunity to self-assess their projects and written work was another attribute that made the gifted services important to the participants' primary years. Lana recalled,

My experiences at the 'Little Yellow House' were what Ungraded Primary was supposed to be. We had three grades all together on our gifted day. We worked in small groups and independently on projects that were matched to what we were ready for. We had rubrics and checklists for every presentation, book project, or research project so that we could assess ourselves and assess each other. I can still hear Mrs. saying, 'What would make it EVEN BETTER next time?"

Participants emphasized the importance of their gifted services while they were students in the primary grades. The majority of participants reported that even in the multi-age setting of the Ungraded Primary, they spent significant amounts of time waiting or working to help younger students. Shelley recalled, "I was the best teacher 
helper! I finished my work quickly and was always busy helping other students. I can't remember working on anything in my regular class that was challenging.:

Their opportunity to come to gifted one day each week was a vital part of their primary years. Sandy recalled that "We were never challenged at our level in my regular school. Then I got to come to gifted. At gifted we were challenged, we had unlimited performance opportunities, and a teacher who never, ever said 'That's too hard for you." Shelley added, "I always had the feeling that my primary teachers just weren't quite sure what to do with me. At gifted, everyone was glad to see me and there was a definite plan in place to nurture my talents."

\section{KIRIS/CATS Assessment}

Participants reported that they knew their gifted teachers believed that they had the ability to be Distinguished on the assessments and that the gifted teachers provided direct instruction on how to analyze a question and how to write a Distinguished openresponse. The expectation that they would perform well was always paired with instruction that put the skills in place to achieve at high levels, according to the participants. Allan remembered,

The gifted teachers always seemed to be excited about possibilities! They would 'sell' the open-response process as this great opportunity to be reflective and evaluative, then they'd give us a little practice with the process, and then it was easy.

Participants recalled that specific test-taking strategies, especially related to openresponses and on-demand writing were a part of their gifted experiences. "We were 
specifically taught how to craft a written response to a Socratic question, then we used the same type of process to answer a basic OR question," according to Matt.

\section{Proficiency as the performance goal}

According to participants, their gifted education classes were the one place that the expectations didn't focus on Proficiency. According to Marcus,

It didn't matter where we started. The gifted teachers presented us with a continuum that always ended with guiding us to think about what we would do next time to make our performance EVEN BETTER. There was never an endpoint. We internalized that belief that we could (and should) keep on learning and growing and getting better. Now I approach everything that way. Participants were unanimous in their perception that Proficiency was not their personal goal or the performance goal of the gifted education teachers as they projected an expectation that those students could achieve Distinguished performance. They reported that the scoring guides and rubrics used in gifted always represented a focus on the top indicator and that the teachers and their peers projected an expectation that they would all do whatever it took to get to that top rating. Because they had opportunities to self-assess and use the rubrics, participants reported that they internalized the standards and applied them in other settings besides gifted.

Kierra recollected that "at the 'Little Yellow House', we heard that we absolutely could be successful at higher levels. We knew it would be hard work, but the steps were laid out for us and then we plunged in together to get there." Danny added that

Being in the gifted program impacted my achievement more than anything else. Every place else, Proficient was the goal, but at gifted we heard 'The sky is the 
limit! Let's see just how far you can go.' And we all knew we could go much farther than Proficient.

\section{SBDM Council policies}

Participants were not aware of any connection between SBDM policies and gifted at the elementary or middle school level. They recalled that gifted teachers did work with the council at the high school level to address the issue of weighted grades for Advanced Placement classes, but the participants were not aware of any other specific connection between gifted education or gifted services and the SBDM council.

The issues identified by the participants related to the SBDM council policies were related to curriculum access, scheduling, and barriers to achievement as a result of council policies. Participants reflected on the issues surrounding Block Scheduling and policies restricting access to correspondence courses, restricting the credits that could be brought in from middle school, and restricting access to KVHS courses, but they were not aware of specific actions of the gifted teachers or the gifted program relative to those policies. Participants reported that parent advocates were most influential in addressing the issues surrounding SBDM policies.

\section{Key themes-Relationship between KERA initiatives and Gifted Education.}

Key themes that emerged around the participants' perceptions of the relationship between KERA initiatives and gifted education were:

1. Gifted services reflected fidelity of implementation of KERA initiatives, especially writing portfolios, Ungraded Primary, and high performance expectations. 
2. Gifted services reflected alignment among student and teacher performance expectations.

3. Gifted services reflected instructional relevance.

4. Gifted education provided strong writing background and support of students to write across all content areas and to write at high levels.

5. Gifted education provided ongoing use of rubrics and authentic scoring to internalize quality standards.

6. Gifted education teachers projected a positive attitude toward the portfolios and the belief that students could perform at high levels.

7. Gifted education exemplified critical attributes of the Ungraded Primary Program even when they were not in place in regular classrooms.

8. Students had opportunities to practice high level skills with open-response through gifted services.

9. Gifted education projected an expectation of Distinguished performance as the goal.

10. Gifted education practices supported the development of personal goals and student self-assessment.

11. Continuous progress was the expectation for all participants in the gifted program. The interrelationships among the themes are illustrated in Figure 10 as a visual display of the perceptions of the participants regarding the relationships between KERA initiatives and their gifted services. This figure was developed as the participant perceptions were analyzed for emerging themes and those themes were clustered using comparisons and aggregation (Miles \& Huberman, 1994). 
Figure 10. Relationships Between KERA and Gifted Education Themes-Links and Relationships.

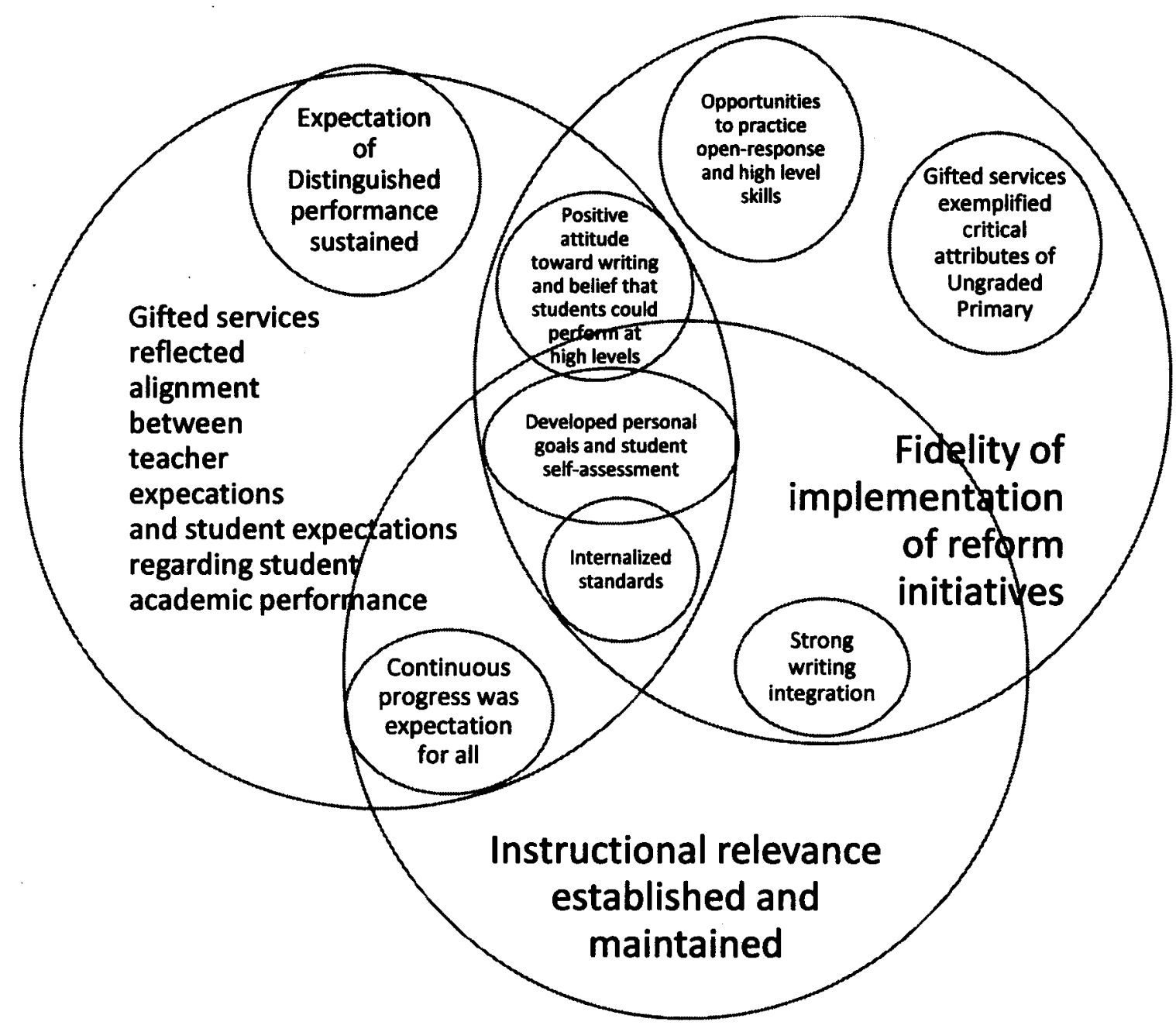

Summary findings.

As seen in Figure 10, the key themes that emerged around relationships between KERA initiatives and gifted education centered around fidelity of implementation of reform initiatives, alignment between student and teacher expectations, and instructional relevance. According to the participants in the study, the gifted education services they received were structured around attributes of the KERA initiatives that were fundamental to their gifted program. Emphasis on critical thinking and writing integrations made the 
transition to portfolio development a natural outgrowth of continuous writing, while providing ongoing practice with the use of rubrics that supported the practice of identifying and internalizing mastery criteria for quality writing and for open-responses. Participants credited gifted education teachers' enthusiasm for writing and high level expectations with causing the gifted students to share both that enthusiasm and the confidence that they could achieve at high levels. Students had opportunities to develop math products that represented high level writing through their gifted classes, but they were not used as a part of math portfolios.

The elementary gifted services reflected critical attributes of the Ungraded Primary program even before the KERA initiative was passed in 1990 through the use of multi-age groupings, continuous progress, authentic assessments, and developmentally appropriate instructional strategies. Participants reported that each of those facets of their gifted experience positively impacted their achievement and that those attributes provided appropriate challenge and affirmation even when the implementation of the Ungraded Primary program in the regular classroom had not implemented the attributes with fidelity.

Participants did not reflect a significant relationship between their gifted education services and SBDM policies. They had limited awareness of gifted education teachers' work to assure weighting for Advanced Placement grades, but were not aware of any other connection with the policies of the SBDM.

The relationship among the KERA initiatives and gifted education was a positive, proactive relationship in those areas that reflected direct instruction. According to the participants, the gifted education teachers played an important role in making the 
connections between the KERA initiatives, daily instruction, and their gifted services. According to Joel, "When the KERA initiatives came to pass, many of us who participated in gifted felt like we were back in familiar territory. The only difference was that now we were expected to perform those tasks in our regular coursework."

Figure 10 illustrates the three major themes that emerged around the relationships between gifted education services and the KERA educational initiatives. The three themes identified were (a) Clear alignment between the expectations of the gifted teachers and the students fostered academic achievement; (b) Attributes of KERA initiatives were implemented with fidelity through gifted services; and (c) Gifted services established and maintained instructional relevance.

\section{Impact on Student and Adult Achievement and Underachievement}

The final question in the study addresses the impact of KERA initiatives, factors in rural education, and all other related educational structures and programs on the selfreported achievement and underachievement of the participants. These factors are addressed through Research Question \#3.

\section{Findings Related to Research Question Number Three}

Research Question \#3. What are the similarities and differences in perceptions between those adults who self-reported sustained achievement and those who reported underachievement?

I got good at being lazy. I developed a way to look like I was doing something or a way to look like I didn't understand it already in order to be non-threatening. Years of lackluster experiences at regular school were only offset by the 
counterpoint of my experiences in gifted. Without those experiences, years of my school experience would have been almost a total loss.--Jon

The purpose of all educational initiatives and programs is to improve the educational achievement of students, making it vital to identify the qualities of instructional programming and other features of educational systems that support high achievement in order to replicate them. It is equally important to identify the factors that impede achievement so that those factors can be minimized or eliminated. Research Question \#3 explores the factors the support and impede high levels of achievement through the following interview questions:

Interview Questions:

3.1 How do you define achievement?

3.2a Tell me about your perceptions of your achievement throughout your school career.

3.2b Explain the relationship between your grades and your underachievement.

3.3a Were there points where you experienced situational underachievement?

3.3b Were there points where you experienced sustained or pervasive underachievement?

3.4a What factors most influenced your achievement levels?

3.4b What factors supported reversal of underachievement for you?

\section{Achievement}

A critical step in examining self-reported achievement and underachievement is using the perceptions of the participants to identify critical attributes of personal achievement. That process was initiated through a specific interview question:

3.1 How do you define achievement?

Achievement is a measure of growth that comes from overcoming an obstacle or mastering something challenging. True achievement is succeeding at something 
that you weren't necessarily confident that you could already do before you began.--Ciara

Participants universally reflected the theme that true achievement reflected succeeding at something that was perceived as difficult or challenging. Though every participant also acknowledged that grades were important and that they usually expected themselves to get good grades, most did not include grades in their conversations about achievement. Most participants consistently made good grades, but reported that they were aware of sustained or pervasive periods of underachievement:

Achievement is personal excellence. That may be partially defined by an external standard, but it is also defined by growth, success in the face of challenge, and that true sense of accomplishment that comes from doing something at a level that you haven't reached before or something that you know you worked hard to accomplish.--Sam

The participants reported multiple situations where they knew they had not worked hard and that the product reflected mediocre quality by their standards, but they received verbal or written feedback that indicated superior quality. They reflected that the external evaluation was not a measure of achievement. Marla commented that "Those external measures are not achievement to me, especially if the bar is too low. Having the bar too low fosters underachievement, because I look for connections and importance to me."

An additional quality of achievement identified by the participants was task persistence. According to Joel, "The biggest factor that contributed to my achievement was simply the desire not be a quitter. Peer pressure, as well as Mrs. ___'s relentless 
confidence in us pushed us to achieve at tasks that would have daunted someone else." Some individuals indicated that the temptation to quit because a task seems difficult was a good indicator that actually completing that task was going to be an achievement. Carla echoed that sentiment by adding that "the process is usually a better indicator of achievement that the product. If you start a task and think 'This is hard,' then persevering to finish is achievement."

\section{Underachievement}

For purposes of this study, it was also important to establish working definitions of underachievement as the participants self-reported. Participants defined underachievement as consciously choosing to diminish performance quality. Tim, a selfreported sustained underachiever, articulated a definition that included all of the attributes identified by others.

Underachievement is a choice. When we choose to do less than we are capable of, that's underachievement, but for me there is an added element of motivation. Sometimes we underachieve to try to avoid scrutiny of teachers or peers in an effort to fit in. Sometimes we underachieve because something outside of school takes precedence over working hard. But mostly we underachieve because the constant diet of mediocrity just wears you down. Teachers accept, or even expect, mediocre work and there is absolutely no payoff for working hard and bucking the system to try to make them let me learn.

Participants were asked the following questions regarding their perceptions of their achievement throughout their school career:

3.2a Tell me about your perceptions of your achievement throughout your school career. 
3.2b Explain the relationship between your grades and your achievement.

In the design of the study, the expectation was that out of the randomly selected group of gifted students who attended school within the target school district over a 10year period, the majority of the students would be achievers, but that there would be enough underachievers among the 30 participants to be able to compare responses. The findings were not as expected. Among the 30 participants, 27 self-reported sustained or pervasive underachievement. Because the participants reported those incidents of sustained (negative discrepancy between potential and performance in one or more area sustained for more than one semester) or pervasive underachievement (a significant negative discrepancy between potential and performance across all settings for an identifiable period) in the context of clearly identifiable settings and time periods, it was possible to compare perceptions regarding achievement and underachievement (Heacox, 1991; Peterson \& Colangelo, 1996; Speirs-Neumester \& Hébert, 2003). However, the differences in perception were often between circumstances experienced by the same individuals, rather than contrasts between two distinct sets of individuals.

Because underachievement was self-reported, it was important to identify the context in which the participants considered themselves underachieving. When asked about the relationship between their grades and their underachievement, all participants explained that they were able to make A's and B's in most courses with little or no effort, especially in middle school, and according to Allan, "If I just showed up and was breathing, I could get a C." Participants who reported underachievement were purposeful about the nature and degree of their failure to perform at expected levels. According to Anne, "I knew how many questions I could miss, how many assignments I could skip, 
and exactly how many participation points I had to get to stay under the radar. My grades looked good enough, but I knew how little I actually did."

When asked about their perceptions regarding the level of awareness of teachers and parents relative to their underachievement, most reported that only their parents seemed to be aware. Nineteen participants reported situations in which teachers seemed relieved or vindicated when their work was less than perfect and very few teachers seemed concerned or even aware as students lowered their performance standards.

Lana explained,

When my mother tried to talk to the teacher about the change in my performance and motivation, the teacher let my mom know that I was doing fine and that she shouldn't PUSH ME so hard. My gifted teacher was in my face about the quality of my work and I always worked hard for her, but regular school was a disappointment.

Though none of the participants sustained low grades (D's and F's) over more than two consecutive semesters, a pattern of A's and B's changing to a pattern of B's and C's as a result of conscious changes in classroom participation and performance reflected underachievement with the potential for far-reaching impact. Almost every individual (24) reported that they made conscious choices not to perform at the level of their ability for sustained periods of time in school. It seemed important to the participants that the researcher understand the dilemma that underachievement presented to the students.

The following interview questions were used to investigate the achievement perceptions of the participants.

3.3a. Were there points where you experienced situational underachievement? Tell me about that. 
3.3b. Were there points where you experienced sustained or pervasive underachievement? Tell me about that.

\section{Situational underachievement}

I could read the teachers and the students very well. I remained patently aware of the degree to which I participated from class to class. This caused a tendency to shut down as I was very aware that people, even teachers, don't seem to like it when you know the answers.--Paul

Every participant reported experiencing situational underachievement in at least one class for a number of reasons. Based on participant reflections, situational achievement occurred in settings where these gifted individuals wrote off a subject or content area because it did not come easily to them. For many it was in the area of math, for some it was in the area of science, and for some it was history. None of the participants reported situational underachievement in reading or writing. As adults, many participants reported that this underachievement and avoidance has sustained and most expressed regret that they lost out on building the skills needed to fully access that content or skill set as adults. Danny admitted that "I never made the effort in history. That didn't come easily to me the same way math did, so I didn't really try very hard. Now I wish that I had worked at it because it's information that I see others using and I am deficient."

Situational underachievement was also reported as a reaction to a negative adult interaction. When the participants clashed with a teacher or didn't like the teacher or the teacher's style, they reported that they tended to make a conscious choice to make no effort in that class. 
Once I realized that the teacher didn't like me, I felt like I didn't have anything to prove. I'd sit through class, do enough problems to get an understanding, and nail that test without doing any homework or participating in class. I knew it made her mad, but I knew that I knew and that was what mattered to me. I didn't really learn anything, but she didn't make me want to learn.-Sandy Negative peer interaction was a third trigger for situational underachievement identified by the participants. Two participants identified settings where they chose not to respond or not to perform in class in order to avoid negative peer interaction. According to Joel, "In middle school I became very aware of the low expectations all around me. I deliberately feigned disinterest or pretended I hadn't studied to keep out of the spotlight."

Other participants recounted situations where they adjusted the frequency of responses or other in-class interactions based on peer feedback, but did not change their behaviors enough to adversely affect their performance. Monty admitted, I was deliberately selective about the frequency of my answers, even if I knew the answer every time, because everyone seemed intimidated. I did what it would take to sustain my high average, but felt like I had to be clandestine about it.

\section{Sustained underachievement}

Between grades 4 and 8, I experienced sustained underachievement. The lack of challenge and the extreme levels of repetition caused me to just zone out. I'd read a lot and I'd mentally leave the room. That process began to be linked to selfloathing because I used to be a 'good' student and now I was a fake. I was in a total downward spiral through my whole middle school experience, and nobody noticed.--Marla 
Sustained underachievement was reported by 22 of the participants and all of them reported a period of underachievement that included at least one class during their middle school years. Sustained underachievement was reported as a result of lack of connection with teachers, the perception that the instructional content was irrelevant, or lack of confidence that the individual possessed the skills to succeed.

Jon reported,

Fifth and sixth grade were low points for me. There was a gaping absence of teachers who showed that they cared about me and my success. The fact that nobody at the school seemed to care about academic success made it hard to sustain when praise was lavished on other types of achievements. It was easiest to just quit trying so hard.

Participants identified a set of key contributing factors to their sustained underachievement. Lack of relevance was a primary cause. Participants reported that teachers made no effort to find out what they already knew or to address their interests, while failing to make it clear why students should spend hours practicing what they already knew. As students, they could not see a connection with what they were being asked to do and their instructional readiness. "I had spent the end of second grade learning my multiplication facts, then spent the beginning of every school year after that learning them again. I learned that I could just go away for a big chunk of the year and I wouldn't get at all behind." --Anne

For many participants (13 of 30), sustained underachievement often followed a series of situational underachievement periods, especially if they were in the same content area. Lana recalled that she had experienced a pattern of "checking out" during 
math when she wasn't sure she had the confidence to do the task easily. Because those periods were frequent and significant in duration, the result was sustained underachievement in math that continued into the following year. Even though she liked the teacher and wanted to succeed, the periods of underachievement from the year before left her with specific skill deficits that added to her spiral of unwillingness to attempt. I just went away through most of my seventh grade year. In eighth grade, when a wonderful teacher determined to give me some appropriate challenge, I chose to act disinterested and not attempt it because I simply didn't have the skills in place from the year before. -Ciara

\section{Pervasive underachievement}

I became terrified of adult interactions in the regular classroom because of a series of very negative teacher attitudes. I would deliberately slow down or shut down. I felt embarrassed and ashamed about the things that I loved-art, science, writing, passion for learning — because I assumed that they were the cause of my social discomfort. From fourth grade to eighth grade, I went completely inside myself and that seemed to suit the teachers just fine. They had no idea of what to do when I performed beyond their expectations, but they had a pattern of behaviors they could fall back on if I did not perform. I just gave them what they seemed to want.--Thomas

Pervasive underachievement was reported by nine of the participants. (Several participants reported experiencing all types of underachievement--situational, sustained, and pervasive underachievement—depending on the setting.) Pervasive underachievement reflected a failure to perform up to potential across all settings and 
participants referred to this as their "total shut-down." All nine participants reported that some part of their pervasive underachievement included at least one middle school year. When questioned about the timing of their underachievement experiences, participants reflected on what they characterized as "the very poor match" between what they were ready for and what they experienced at the middle school level. Marcus recalled that, So much of every day was review of something I had learned and mastered years before. The content and the skills that were the core of instruction represented absolutely nothing new in middle school. Teachers seemed to be the most antagonistic at that level and it was just easier to just get by and try to disappear than to make myself a target for teachers' frustrations.

Lack of challenge and failure to connect with significant adults were the primary contributing factors to pervasive underachievement. All participants reported that they loved to learn and that they were excited by new information, but those who reported underachievement felt that the personalities in authority or the structures in the classroom seemed at odds with accomplishing learning. Stephen shared that "The classroom structure sucked, but I could look out the window and see science, math, and art—all that comforted me. I felt there was nothing in that room for me."

Excessive repetition and review, teacher ridicule, and failure to connect with a significant adult were each identified as causative factors in pervasive underachievement. Some individuals also reflected on school climate, especially the lack of social benefit of high academic performance, as an influence on underachievement. However, every participant identified lack of challenge as the most significant factor that led to underachievement. 
I experienced pervasive underachievement throughout middle school. I was not challenged. I experienced a significant withdrawal from all aspects of school, both academically and socially, because the program and expectations of the school were not connections for me. I really stagnated.--Ronnie

Key themes-Underachievement. Key themes that emerged around participant perceptions of their underachievement were:

1. Achievement was succeeding at something that was personally significant and that reflected challenge.

2. Grades did not necessarily reflect achievement.

3. Teacher attitudes played a key role in student underachievement.

4. Some level of underachievement was common among gifted students.

5. Students chose to underachieve in an effort to fit in or to avoid negative interactions.

6. Students chose to underachieve as a result of lack of connection with the content or the teacher.

7. Situational underachievement contributed to long-term underachievement through failure to master requisite skills or concepts.

8. Conflict that contributed to underachievement occurred when teacher expectations were lower than student expectations regarding academic performance.

Figure 11 provides a graphic representation of the relationships and links among the themes that emerged around underachievement. As participants' perceptions were analyzed and themes emerged, those themes were clustered to provide a graphic that shows how themes were linked with or subsumed by related themes (Miles \& Huberman, 
1994). Those themes were aggregated to establish the major themes related to underachievement.

Figure 11. Underachievement Themes-Links and Relationships

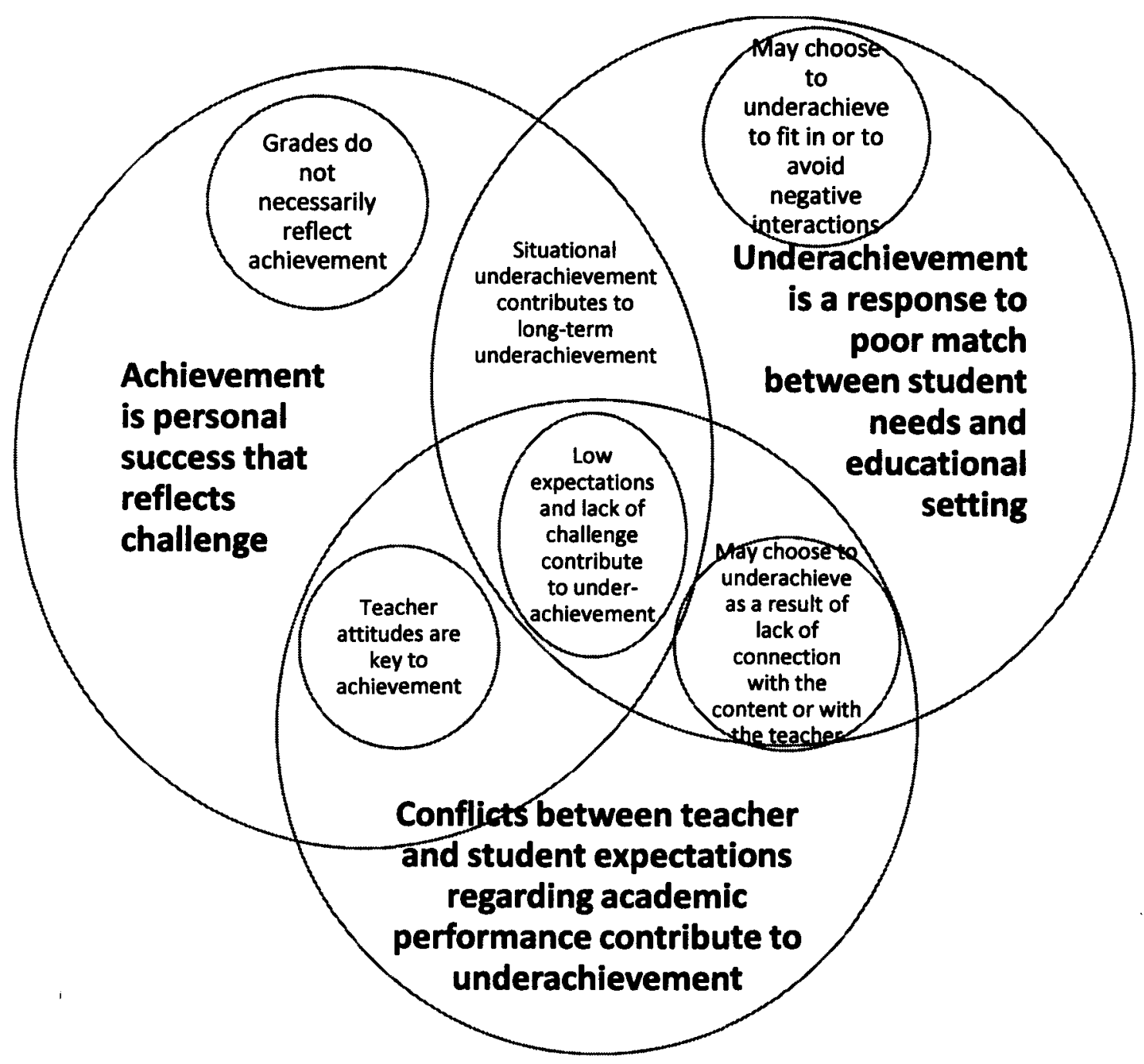

Summary findings. Underachievement was systemic among the participants,

with 27 out of 30 reporting sustained and/or pervasive underachievement. In addition, every participant reported situational underachievement at some point in their school careers. According to the participants, achievement was succeeding at tasks that reflected personal significance and challenge. The participants did sustain good grades, but did not equate their grades with achievement. The importance of grades was identified by the 
participants as external in order to meet the expectations of others or as a means to an external goal, but their personal achievement was measured by the participants as meeting or exceeding personal standards and reflecting growth.

Every participant reflected that the attitudes of teachers were important student achievement. Teachers who held low expectations or who established an adversarial classroom climate were credited with fostering underachievement, while teachers who held high expectations and who created a climate that valued what students knew and contributed helped to foster high levels of achievement. Participants reported that, as students, they choose to underachieve in an effort to fit in or to avoid negative interactions with the teacher or peers. This set of behaviors was exacerbated when there was a result of lack of connection with the content or the teacher.

The perceptions of the participants reflected awareness that the length of time and the settings in which it occurred was cumulative. Situational underachievement contributed to long-term underachievement as students failed to master requisite skills or concepts, making them likely to demonstrate sustained underachievement when faced with challenging tasks they felt ill-equipped to address skill deficits.

The most common factors identified as contributing to underachievement were low expectations and lack of challenge. Participants reflected that when faced with a steady dose of low expectations and inappropriate challenge, their will to achieve at high levels diminished and they adopted patterns of behavior they identified as underachievement.

Though I never honestly disliked school, I was often made to feel uncomfortable or apologetic because of my interests and my abilities. I learned a whole set of 
behaviors that would allow me to go 'under cover' as I adjusted to a regular diet of easy work, low expectations, and a sense of penalty for needing more. How sad that I had so many teachers who never really knew what I could have accomplished!--Liza

Participants reflected on the impact of underachievement patterns as students and adults and indicated that the issues of "fitting in" continue as adults. Monty explained, In the workplace there is a level of either chronic underachievement vs. hiding achievement or sharing it only with a very specific group of people who are secure enough with themselves not to worry about it. As someone who is expected to go to the next step of working on a systems issue or is expected to assume a leadership role, I am depended on to make things happen. However, because I see solutions clearly and remember things after only one reading, I always have to proceed with the awareness that people don't like the person who knows it first.

Underachievement represented an important factor in the educational experience of the study participants. Conversations regarding their school careers yielded key themes that emerged around the topic of Underachievement. Those key themes are synthesized in Figure 11 showing the connections and relationships among the themes to generate three major underachievement themes. Those themes are: (a) Achievement is personal success that reflects challenge; (b) Underachievement results from poor match between student needs and the educational setting; and (c) Conflicts between teacher expectations and student expectations regarding academic performance contribute to underachievement. 


\section{Fostering achievement and reversing underachievement.}

Having identified factors that participants perceived as influential in impacting their underachievement, the next step was to investigate the factors that fostered achievement and reversed patterns of underachievement. The following interview questions were used to investigate achievement:

3.4a. What factors most influenced your achievement levels?

3.4b. What factors supported reversal of underachievement for you? Tell me about that. When people that you trust and respect tell you that you are doing well and why, and you believe you are capable and that you are willing to take a chance, you achieve. At gifted, I was made to feel good about my achievements and I felt supported. When I was supported, I was willing to go out on a limb and when I experienced success it built confidence. It was a beautiful cycle!--Ciara According to the participants, personal achievement for them reflected success with tasks that reflected growth or were perceived as challenging. Levels of personal interest and task persistence were all listed as recurring elements as a part of achievement. Participants did hold themselves accountable for achieving acceptable grades as determined by their personal expectations, but they all made a distinction between grades and achievement.

Grades were always important to me. I got good grades, but my true achievements weren't grades. I knew when I had a good project and I really didn't need a grade to validate it. The feedback - that was the important part.--Kierra

\section{Teacher Expectations}

Participants universally reported that significant adults and high personal standards played powerful roles in sustaining achievement. Mandy recalled, "I didn't 
want to disappoint-not Mrs. and not my parents. I knew they believed in me and I told myself that if they thought I could do it, I surely could.” Just as adults played an influential role in fostering underachievement, parents, gifted teachers, individual classroom teachers, relatives, and older siblings were all identified as influential in helping participants maintain their motivation to achieve at high levels. According to the participants, those adults achieved significance by being perceived as caring about the students personally, by being positive, by being content knowledgeable, by being honest, and by having a sense of humor.

Teachers who impacted me were those who genuinely knew the content and cared enough about me to try to help me know it, too. They saw me as a person first and realized that how I felt had an influence on how I learned. Those teachers could make me laugh and were able to laugh at themselves.--Lana

Teachers who were perceived to be passionate about their content and excited by possibilities were frequently named as pivotal in sustaining achievement or reversing underachievement. Because participants were passionate about learning, they indicated that they were drawn to those teachers or other adults who displayed similar passion and excitement about what they taught. Joel recalled, "The energy and excitement Mrs. displayed as we started a new topic was contagious. She never shut me down or seemed threatened if I already knew something or asked unexpected questions. She acted like she wanted to know, too!"

The fact that individual teachers maintained high expectations and held students individually accountable was another key factor identified by participants. "She took the time to find out what I knew," recalled Jon. "She wouldn't let me hide and she conveyed 
a positive belief that I could always do a little better or a little more. It was evident that my progress was her personal challenge." Those teachers used clear expectations and personalized feedback, according to the participants. Teachers who reversed underachievement used self-assessments and goal-setting to personalize the instruction and to establish clear standards for excellence. Mandy explained that "In gifted, for every project or presentation there was a checklist or a rubric and we had to evaluate ourselves and each other. We were expected to identify the strengths and point out what would make it even better the next time." In addition, Joel recalled,

Sometimes she'd take me aside and grin and ask me how hard I worked on this. As we talked about the relationship between effort and success, I'd walk away with plans for improvement and a renewed commitment not to try to fool her.

As participants reflected on achievement and reversal of underachievement, it was difficult to separate the impact of teachers from the level of challenge and high expectations. However, participants consistently identified high expectations as important to maintaining achievement. Those high expectations were often linked to personal relevance for the students. Mandy clarified the connection by recalling that "Mrs. ___ expected us to internalize the standards that reflected that our writing was publication ready, while constantly using examples and providing real-world opportunities to publish so we'd see why it was important to aim high."

\section{Parent Expectations}

Parent expectations and involvement were identified as important to sustained achievement and underachievement reversal. Participants perceived that their parents and gifted teachers maintained the most accurate awareness of their abilities and many 
indicated that the vigilant oversight of their parents helped to prevent or reverse underachievement. Laura reported, "My mom was my biggest fan, so she was always looking over my shoulder. She knew what I could do and kept the bar high for me, even when I was tempted to let it slip." Many participants acknowledged the importance of parent advocacy in removing barriers to achievement, such as school or SBDM policies or issues with classroom dynamics, and with maintaining stable expectations of achievement. According to Jon, "Without my parents doing battle with the school over policies about taking in credits from the middle school and access to Virtual High School classes, I think the school would have let me just coast."

Though participants defined underachievement as a conscious decision not to perform up to potential, participant feedback indicated that achievement was sometimes the default behavior rather than a conscious choice. Chris, one of the participants who reported sustained achievement recalled, "I certainly didn't like school, especially in middle school, and I certainly didn't behave well when I was there, but I guess underachievement just didn't occur to me."

\section{Opportunity for Choice}

Opportunity for student choice and leveled courses in high school were identified as important to student achievement. According to Danny, "Most of the differentiation I experienced was just through the choices available at high school. We were lucky to get a diet of some high level classes." Secondary choices also provided opportunities to pursue specific interests, a factor that increased motivation for some participants. 


\section{Gifted Services}

Those who overcame underachievement credited their success to their gifted services, their ability to sustain their intrinsic motivation, and the ability to align themselves with others with similar goals. Allen described his personal "Battle against Proficiency" by relying on "being challenged by my peers. When my friends and colleagues upped their game, I felt I had to do the same." Those students who were able to sustain achievement or reverse underachievement credited a balance of internal motivation and external goals. As Monty explained, "Internal competition in competing against myself, working to please the adults who were important to me, and external competition were the most powerful influences on my achievement."

Study participants repeatedly articulated the importance of their participation in gifted services as the most important factor in overcoming the potential barriers presented by rural education and were influential in preventing or reversing underachievement.

Several features of gifted services that were identified as crucial were:

1) Opportunity for gifted students to spend time together,

2) Differentiation and access to variety of high level resources,

3) High expectations and exposure to content beyond the core curriculum,

4) Travel opportunities,

5) Research and project opportunities,

6) Performance opportunities,

7) Acceleration, and

8) Positive teacher relationships. 
Each feature of gifted services identified by the participants was articulated as influential in fostering achievement and as important in reversing underachievement.

Opportunity for gifted students to spend time together. Every participant articulated the importance of an intellectual peer group that validated and challenged them. The fact that gifted services pulled students together from across the county to establish that peer group was identified as a lasting impact on the individual self-concepts of the students and on their ability to continue to maintain high personal expectations and achievement across settings.

Gifted was a Godsend. I came from my little tiny school once a week to be with other students like me and I realized that I wasn't aberrant. The peer group established when I was little sustained through my senior year and we supported, challenged, and validated each other throughout our school career. I don't know if I could have sustained without it.--Liz

The participants reported that the opportunity for the gifted students from across the county to come together to a central location once a week for gifted services provided powerful emotional, social, and academic support. The weekly grouping was identified as a powerful component in overcoming the perceived cliques of rural communities. Participants reflected that as classes in their home schools traveled together from kindergarten through twelfth grade, "The pecking order was quickly established and gifted students rarely had a favorable place in that pecking order." The peer group established through the gifted service pull-out was perceived to provide an important counterbalance to the individual school peer groups. 
My family wasn't from __ County and when we moved in, I was totally ostracized within my classroom. Those kids had been together since birth. When I came to gifted, I had an automatic peer group and I was immediately included and validated and finally felt like I belonged.--Lana

Participants recalled that their gifted peer group was essential to provide personal validation, to provide opportunity to come together to pursue common interests and goals, and to establish a natural group for healthy competition. That competition, identified by participants as lasting and brutally honest, emerged as a critical lifeline for many participants in sustaining achievement or reversing underachievement through their school careers. It allowed them to maintain high personal standards in the face of low expectations. Sandy summarized the sentiments of the participants. "My G/T peer group, served as motivators and supporters for years. We were in similar situations, setting goals for ourselves and challenging one another. Together, we were able to maintain our high achievement in spite of the school."

\section{Differentiation and access to a variety of high level resources. Study} participants listed a wide range of specific activities and projects that were part of their gifted services as examples of differentiation and access to high level resources. As rural students, the participants were aware of differences between their day-to-day instruction and gifted. They commented on the degree to which their experiences were personalized and leveled resources were matched to the interests and readiness of the students. James described his perception as "the awareness that Mrs. knew where each of us started and took pains to match us up to just the right challenging activities that would keep us moving forward." 
Participants recalled the library at gifted and Marla commented that "There was not another like it anywhere in the county." Liz added, "Mrs. could put her hand on just the right resource matched to what I needed and she never avoided a question or topic because it might be too hard for us."

High expectations and exposure to content beyond the core curriculum. Gifted was my salvation. My regular classes were like leaving the table hungry, but when I got to gifted, I was fed. Everything was so influential一the research projects, the French, the dissection, the cooking, the book projects, the presentations, the musicals, the literature, the writing, ... We were expected to question and connect and grow every time we were together, and it was all within an environment of infinite faith that we could do amazing things. We learned things that extended the core content into the real world.--Liz

Participants reflected on their initial culture shock when things were not graded at gifted and they got feedback instead. "I learned that I could take feedback without bursting into tears," recalled Marla. "The expectations were clearly established and modeled, then our products were measured against the standards." Those high expectations were identified as important to sustaining achievement and reversing underachievement. Shelley reported that "I had strong perfectionist tendencies and frequently shut down in the regular classroom because I was afraid I couldn't be perfect. Using clear standards and setting personal goals helped me move away from that impossible 'perfect' product so that I could see my own progress."

The high expectations of the gifted teachers were also identified as having impact on classroom achievement. Matt recalled, "Mrs. gave us a hard time about our 
work habits and the choices we made. She made it clear that grades were a means to an end and that we needed to have high expectations of ourselves to get to those things we wanted to do as adults." As the expectations were articulated, participants reported awareness of the importance of internalizing them. Danny explained,

The high expectations that were established in gifted were couched in this undying confidence that if Mrs. __ believed we could do it, we could do it. As our relationships with her and with one another evolved, we internalized those high expectations and tried to hold to them across all school settings.

Travel opportunities. Every participant identified the field trips and extended trips that were part of the gifted program as important to sustaining achievement or reversing underachievement. Joel recalled that "It was easy to get caught up in the injustice and lack of logic in the classroom and decide to take a stand. Somehow, she managed to get us out of the county just often enough to help us put things in perspective." Trips to cultural events and historical locations, exchange trips with other schools, and extended trips to locations in the United States and Canada were all identified as key factors in maintaining motivation and seeing real-world connections that helped overcome the barriers the participants faced within the school district.

Participants identified the leadership opportunities, communication skills, social skills, and expanded world view as essentials that came from the travel opportunities. Every participant recalled specific travel experiences as evidence when discussing the impact of gifted services on their achievement.

My mother didn't have a driver's license and we didn't have the money to travel anywhere. No one in my family had graduated from high school or from college. 
Mrs. __ started taking us places and helping us see what was out there. It made a huge difference as I set goals for myself. I discovered possibilities for myself that I had never dreamed of.--Marla

Research and project opportunities. "I learned research skills in gifted that I have continued to use throughout my life."--Sandy.

The participants ( 30 out of 30 ) identified research opportunities and other types of gifted projects as powerful strategies for supporting achievement and reversing underachievement. Because the projects involved high degrees of choice, participants perceived them as personally relevant and tailored to the interests and needs of the students.

Even though the task was highly structured to assure our success, we could choose how we'd present it and how we'd test the understanding of our audience and even how it would be evaluated. As a first grader, I was beginning to be in charge of my own learning and it was intoxicating.--Matt.

Participants reflected on the impacts of the research projects and presentations and the impact on their achievement. They identified the skills as important in empowering them to select and pursue personal interests and the whole process as a set of high standards that they practiced repeatedly until they were internalized. Many participants reported that, even as adults, they still have some of the products created as a result of their gifted research. The process was one that the participants identified as having lasting impact on achievement and the research skills were reported to be useful to the participants, even as adults. Monty explained, 
Only in gifted did I get to identify an interest and pursue it to great depth. I learned how to access resources, identify research questions, outline, take notes, distill information, synthesize, report out, create visuals, and measure the effectiveness of my presentation by creating questions my audience should be able to answer. It was so totally different from the regular classroom assignment of 'write a report about squirrels' where the expectation was that we'd open the encyclopedia and copy. By learning these skills as a young student, there was no interest that I could not pursue and I use those skills even today.

Performance opportunities. Performance opportunities were identified as a critical attribute of gifted services with impact on achievement and underachievement by every participant. According to the participants, the performance opportunities represented a set of skills that deviated from the standard pencil-and-paper skills as a true integration of a massive body of content and skills into a content-related musical, skit, video, etc.

Every participant reflected on specific content-related songs or performance experiences that had positively impacted their achievement motivation and their ability to apply content beyond the textbook. The performance tasks were described as having linked their research skills, their leadership skills, their organizational skills, and their ability to honestly evaluate their own performances and the performances or products of others. "Performance of the skit or the presentation 'as' Paul Revere or as a jellyfish linked skills from every content area in a genuine way that made us all want to work a little harder," according to Marla. 
Many participants recounted situations where the lyrics to a song from one of the musicals they performed in over a decade ago was the trigger for an answer on an exam or helpful in a political discussion.

I still remember my lines and lyrics from songs that tie back to content that I will never forget and continue to use. In a recent conversation that resonated with accusations about socialist programs, I remembered the song we learned about FDR ‘. . Let me tell you about the NEW DEAL, NEW DEAL, Everybody's talking 'bout the NEW DEAL. Hitch you wagon to the star, "cause FDR is givin' us all the brand NEW DEAL ... It was not a great leap to the other things I learned that informed my conversation as an adult. . . All from my gifted experiences.--Sam

Participants also articulated the importance of the actual performance skills relative to adult public-speaking, personal self-expression, organizational skills, and increased confidence. Mia recalled that,

Participation in the musical productions not only helped me come out of my shell, but the experiences actually made learning history or science come to life. I learned organizational skills as a stage manager, while I internalized the concepts from the songs and dialogue at a level that I will never forget. The ability to speak in front of a group came directly from those experiences.

Participants reported increased levels of motivation and willingness to do what they perceived as mundane schoolwork in exchange for the opportunity to participate in the gifted productions. 
Acceleration. Acceleration—subject level and grade level acceleration—was identified as a feature of gifted services that extended across settings for all participants. Through gifted services, students who were identified as good candidates for various forms of acceleration were supported through collaboration with classroom teachers and principals in order to improve the match between the instructional setting and the needs of the students. Gifted collaboration facilitated subject level accelerations for a large number of the participants and grade level accelerations for 6 of the participants.

Acceleration was a factor credited with a profound impact on sustaining high achievement and reversing underachievement. According to the participants, by placing students in instructional settings where they faced appropriate levels of challenge, acceleration improved instructional relevance and validated what students already knew or were able to do. The words of those participants are most effective in explaining the impacts. "I had gone far underground. When I was accelerated, it validated what I knew and suddenly it made a difference that I worked hard and showed what I could do."Ciara.

As a student who reported only situational underachievement, Monty reflected on the impact of acceleration on his achievement:

The ability to advance at my own pace through the graded structure truly enhanced my achievement. Because there was no grouping in the regular classroom, there was always repetition of things that I had already heard or already knew, but at least by allowing me to accelerate, the system did tend to get out of my way. Allowing me to progress rapidly through skills and concepts I 
already knew was vital to sustaining my high achievement and sent an important message that my learning was important to the school.

As a student who reported situational underachievement, sustained underachievement, and pervasive underachievement, Sam's perspective on acceleration echoes the thoughts of other participants, but includes unique insights.

I was always thirsty for the intellectual stimulation of high level instruction and it didn't occur. I thrived on the opportunity to be with older students who were more likely to be my intellectual peers. As I went farther and farther underground between fourth and eighth grades, I was at risk of crashing and burning because I couldn't find anything or anyone in my regular school setting that provided a connection for me. Acceleration was a life saver. By moving me up, the school did two things that made all the difference. First, they moved me up with older students, making it easier for me to access peers with similar interests and outlooks. Most important, though, they validated what I knew and could do. I had been working so hard to be invisible because I felt socially compromised and irrelevant to the school setting. When someone noticed that I could do more and adjusted my instructional setting to better match my needs, it was the validation I needed and caused me to adjust my belief that it was not necessary for me to share what I knew with anyone else.

Validation of what students know and can do was important to reversing underachievement. Participants repeatedly expressed justifications for underachievement that related to their responses to low expectations, to the lack of educational relevance, and to their lack of connection with the teachers or educational setting. Acceleration was 
a factor that was used to help address those justifications by adjusting the educational environment to raise expectations, to increase the degree of educational relevance, and to forge stronger connections between the needs and readiness of the students within the educational setting (Colangelo, Assouline, \& Gross, 2004).

Teacher relationships. Just as teacher attitudes and poor teacher relationships were identified as powerful in fostering underachievement, positive teacher relationships were critical in sustaining achievement or reversing underachievement. Through every interview, participants linked educational practices with the teacher as they rated educational impact.

Teachers who treated the students with respect and who valued the skills and talents the participants presented were identified as important in breaking down the barriers that all participants reported that they put into place through their educational careers. Teacher enthusiasm for learning, competence, sense of humor, compassion, and honesty were among the important qualities identified by the participants. Participants expressed particular admiration for those teachers who saw through the "games" and held the student to high expectations while demonstrating an understanding of why those barriers were in place. Joel explained about an inspirational teacher, "She would call our bluff, but she was a realist. We'd have heart-to-heart conversations about learning how to "play the game" and problem-solve so that we could get to the goals beyond school that were really important to us." Shelley emphatically stated, "Teachers who valued us as individuals and expected us to soar made all the difference."

\section{Key themes_Sustaining achievement and reversing underachievement.} Multiple key themes emerged around the topic of sustaining achievement and reversing 
underachievement. The themes reflected classroom practices, gifted education practices, and philosophical themes that emerged from the perceptions of the participants.

Based upon the perceptions of the participants, the themes that emerged around the topic of sustaining achievement and reversing underachievement were:

1. Relationships with significant adults were critical.

2. Grades did not equate with achievement.

3. Effective teachers were caring, positive, knowledgeable, honest, and have a sense of humor.

4. Effective teachers were passionate about learning and their content.

5. Effective teachers held high expectations and a belief in student capability.

6. Clear standards provided basis for self-assessment and reverse underachievement.

7. Relationship between effort and success were established.

8. Parent expectations and involvement were influential.

9. Opportunity for student choice was influential.

10. Intrinsic motivation was maintained.

11. A peer group with similar goals provided needed support.

12. Gifted education services provided multiple educational components that influenced motivation and achievement. (peer group, differentiation, exposure to rich curriculum, travel opportunities, research opportunities, performance opportunities, acceleration)

13. Validation of student knowledge and abilities was essential.

14. Acceleration was important to improve the match between the educational setting and the needs of the student. 
Based upon the perceptions of the participants, themes were clustered using comparison and aggregation in order to identify relationships between and among the themes. Figure 12 provides a visual model of themes identified by every participant and the levels at which those themes were linked to and/or subsumed by the major themes. Figure 12. Sustaining Achievement and Reversing Underachievement Themes-Links and Relationships

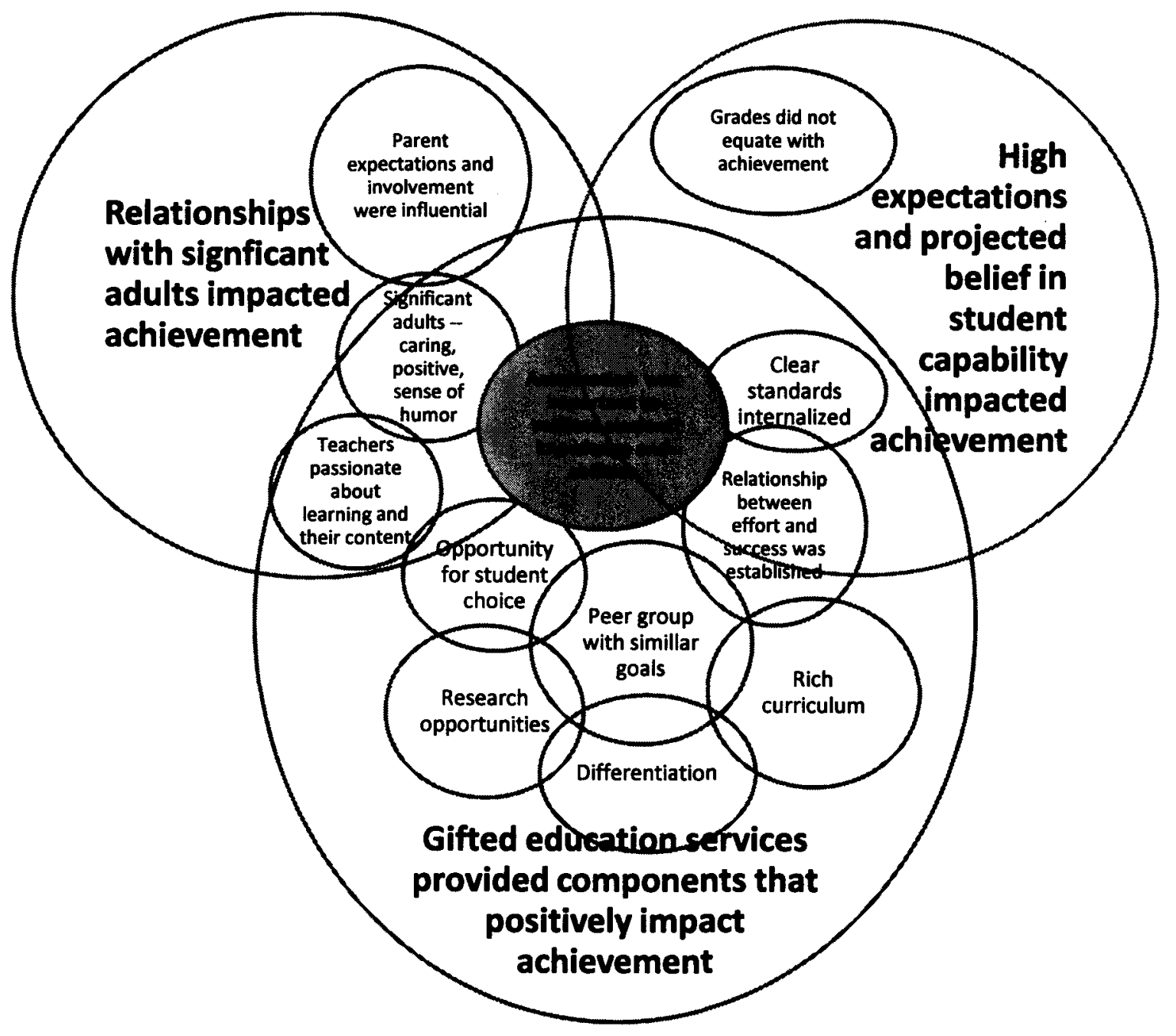


Summary findings. The perceptions of the participants in the study provided insights into the factors that helped them foster achievement and reverse underachievement. Figure 12 shows the interrelationships among the key themes that emerged around sustaining and reversing underachievement and shows the three major themes that emerged. Based on the perceptions of the participants, the three major themes derived from this study were: (a) Gifted education services provided components that positively impact achievement; (b) Relationships with significant adults positively impacted achievement; and (c) High expectations and projected belief in student capability impacted achievement.

Of primary significance to every participant were the relationships between the students and significant adults, especially teachers. The participants who reported high levels of achievement concurred with the individuals who described those factors that reversed their underachievement relative to the role of significant adults. Important to the relationships were the qualities projected by the teacher and participants identified effective teachers as those who appeared to genuinely care about the student as a person.

Participants described the ways that the teachers demonstrated that they cared by expressing personal interest in the student's progress, interests, and success. A positive attitude, passion for their content and learning, a sense of humor, and honesty were also identified as important qualities in teachers who effectively sustained high levels of achievement or reversed underachievement. Effective teachers were identified by 18 participants as those who held high expectations for their students and used their knowledge of the content to establish strategies and structures that reflect their belief in the capabilities of the students. 
Parents were also identified by the participants as having played significant roles in sustaining high achievement and reversing underachievement. Parents were credited with knowing the abilities of their students and advocating for supports or changes that would impact the performance of their child. The fact that parents held high expectations was influential in helping students sustain effort as parents reported that they did not want to disappoint their parents. Allen recalled, "My parents were always there as a support or a prod. They knew what I could do and part of my motivation was pleasing them."

Because the participants articulated a distinction between grades and achievement, they identified the importance of helping students see the relationship between effort and success in order to sustain or improve motivation. In order to establish that relationship between effort and achievement, all participants identified the importance of working with clearly defined standards, though most added that the standards of excellence were often personal if the classroom standards were low.

As students (and adults) internalized standards for quality performance, the participants reflected that intrinsic motivation was difficult to maintain when faced with lack of challenge or low performance expectations of teachers. Marla recalled that, "I had a teacher who told me I was going to have be hospitalized because I wasn't satisfied with a 95. I wasn't freaking out about it, but I wanted to know what I missed so I could learn from my mistakes."

All participants reflected on the motivating impact of opportunities for student choice. They expressed the belief that through choices of topics, products, and even course selection, intrinsic motivation increased and underachievement decreased. Kierra 
reported that, "The opportunity to select topics for research and the opportunity to choose how to present made all the difference for me."

All participants identified aspects of their gifted services as significant in sustaining high achievement and in helping to reverse underachievement. Fundamental to the gifted services was the fact that it created a peer group with similar interests and goals. All participants reflected on the importance of those peers, as individuals and as a group, in helping to maintain motivation in the face of low expectations in the classroom, in providing competition toward high expectations, and in providing validation of the unique abilities and strengths within the group.

Through gifted services, participants reported that they had opportunities to work with differentiated tasks that were matched to their strengths and needs. By increasing the level of instructional relevance, the tendency for students to disconnect was decreased and achievement increased. Gifted education services were reported to have provided increased exposure to rich curriculum, increasing student opportunities to demonstrate strengths beyond the regular curriculum and establishing connections at high levels for those students. Participants reported that when they approached tasks in gifted that were different from what they had experienced in the regular classroom, it was okay to fail because the tasks did not represent the types of products or processes that they had done before. Joel explained,

The novelty and rigor sort of put everyone on the same footing ... nobody knew French ... nobody had dissected a frog ... and it was suddenly okay to take a risk and even okay to fail. In gifted, we didn't have anything to prove ... except to ourselves. 
For those students who saw themselves as underachievers, fear of failure or the need to maintain a certain image in the regular classroom was identified as a contributing factor. "Those obstacles to trying a task or to exposing my true abilities were diminished in gifted."--Shelley

Every participant reported the positive impact of the travel opportunities, research opportunities, and performance opportunities provided through gifted services. Each of these was identified as positively impacting student achievement and as having the potential to reverse underachievement.

Acceleration opportunities, both subject level acceleration and grade level acceleration, were also identified by 30 out of 30 participants as influential in the processes of sustaining high achievement and reversing underachievement. By providing appropriate resources or by physically moving the student to a setting where there was ready access to appropriately challenging instruction, participants reported experiencing higher levels of motivation and achievement.

Participants gave multiple examples of the use of subject level acceleration to provide validation of student knowledge and abilities. That validation was a powerful tool in maintaining or increasing motivation which helped to reverse underachievement. Subject level acceleration also improved the match between the educational setting for the student and the needs of the student. Participants reported increased achievement and motivation as the match was improved. An interesting finding was the apparent potency of acceleration. Few participants reported acceleration that was sustained across multiple school years or across multiple subjects, but even teacher efforts to accelerate short-term were identified as powerful in validating student skill. 
Joel reflected that "None of us expected teachers to make accommodations for us every day, but the few opportunities to move at a level and pace that was appropriate were like an inoculation against the daily routine." Participants reported that they were more tolerant of a poor curriculum match after a period of acceleration because they felt they had been acknowledged and they were better able to handle the "mundane" assignments in hopes that acceleration opportunities would be offered again.

Participants who had experienced grade level acceleration(s) reflected on the positive impact of the experiences on their achievement.

By placing me in a setting where the level the content and the pace was a better match for my ability, and by placing me with older students who were a better match for my intellectual interests, I automatically came closer to having a peer group and daily experiences that were challenging. I still needed to be accelerated in math, so I got to move faster in that subject and that became a lifeline for me.-Monty

Participants who reported sustained achievement and participants who reported sustained and/or pervasive underachievement shared the perspective that the grade level accelerations, when paired with appropriate additional subject-level accelerations, had profound impact on helping them sustain achievement or reverse underachievement. Stephen reflected that "When somebody looked at me and said 'I believe you could go faster,' it fostered an amazing turn around in my self-image. I was interested in making an effort again." The grade level acceleration provided validation of the skills and knowledge that the students had mastered, reduced the time spent in unnecessary 
repetitions, and improved the alignment between the educational setting provided in the school and the instruction needs of the students.

Table 5

Perceptions of Impact on Achievement and Underachievement of KERA Initiatives and the Dynamics of Rural Gifted Education

\begin{tabular}{|c|c|c|c|c|c|c|}
\hline & $\begin{array}{l}\text { Positi } \\
\text { Impac } \\
\text { Achie }\end{array}$ & & $\begin{array}{l}\text { Had } \\
\text { Impa } \\
\text { Achi }\end{array}$ & $\begin{array}{l}\text { on } \\
\text { ement }\end{array}$ & $\begin{array}{l}\text { Foster } \\
\text { Under }\end{array}$ & vement \\
\hline KERA Initiative/Educational Feature & A & UA & $\mathbf{A}$ & UA & $\overrightarrow{\mathrm{A}}$ & UA \\
\hline 1. Writing Portfolio & 3 & 27 & & & & \\
\hline 2. Math Portfolio & & & 3 & 14 & & 10 \\
\hline 3. Ungraded Primary Program & 1 & & 2 & 14 & & 13 \\
\hline 4. KIRIS/CATS Assessment & & & 3 & 27 & & \\
\hline 5. Proficiency as a Performance Goal & & & & & 3 & 27 \\
\hline 6. SBDM Council Policies & & & 1 & 3 & 2 & 24 \\
\hline 7. Limited resources of rural setting & & & & & 3 & 27 \\
\hline 8. Acceptance or rejection of close-knit rural community & & & 2 & 4 & 1 & 23 \\
\hline $\begin{array}{l}\text { 9. Conflict between low teacher and high student } \\
\text { performance expectations }\end{array}$ & & & & & 3 & 27 \\
\hline 10. Lack of instructional relevance in regular classroom & & & & & 3 & 27 \\
\hline 11. Intellectual peer group & 3 & 27 & & & & \\
\hline 12. Negative teacher attitude impacted peer acceptance & & & 1 & 2 & 2 & 25 \\
\hline 13. Instructional relevance through gifted services & 3 & 27 & & & & \\
\hline $\begin{array}{l}\text { 14. Alignment between teacher and student performance } \\
\text { expectations through gifted services }\end{array}$ & 3 & 27 & & & & \\
\hline $\begin{array}{l}\text { 15. Fidelity of implementation of reform initiatives through } \\
\text { gifted services }\end{array}$ & 3 & 27 & & & & \\
\hline 16. Opportunity to demonstrate genuine achievement & 3 & 27 & & & & \\
\hline $\begin{array}{l}\text { 17. Poor match between student needs and educational } \\
\text { setting }\end{array}$ & & & & & 3 & 27 \\
\hline 18. Differentiation and access to high level resources & 3 & 27 & & & & \\
\hline 19. Exposure to content beyond core curriculum & 3 & 27 & & & & \\
\hline 20. Travel opportunities & 3 & 27 & & & & \\
\hline 21. Research and project opportunities & 3 & 27 & & & & \\
\hline 22. Performance opportunities & 3 & 27 & & & & \\
\hline 23. Acceleration-subject and/or grade & 3 & 27 & & & & \\
\hline 24. Relationship with significant adults & 3 & 27 & & & & \\
\hline 25. High expectations and belief in student capability & 3 & 27 & & & & \\
\hline
\end{tabular}


Table 5 provides a comparison of the perceptions of the impact on achievement and underachievement among the KERA initiatives and the dynamics of gifted education in a rural setting as reported by those individuals who self-reported underachievement and those who reported achievement. The perceptions of the individuals who reported achievement and the perceptions of those individuals who reported underachievement showed very few differences in the assessment of impact of the KERA initiatives or of the related educational structures in their educational careers. Those factors credited with fostering achievement were the same for both groups. Genuine opportunities for achievement, instructional relevance, features that reflected high expectations, acceleration, features made available through gifted services, positive relationships with significant adults, writing portfolios, and an intellectual peer group were all identified by both achievers and underachievers and features that fostered achievement.

KIRIS/CATS assessments were identified as an initiative that had no impact on achievement by both groups, while those who self-reported achievement and 14 who selfreported underachievement identified the math portfolio as another feature exhibiting no impact. Ten individuals who characterized themselves as underachievers reported that the math portfolio did foster underachievement for them.

KERA initiatives reported to foster underachievement by both groups were: Proficiency as a performance goal, SBDM Council policies, and Ungraded Primary. Both achievers and underachievers were at risk of underachievement when faced with lack of instructional relevance, teacher attitudes that impacted peer acceptance, poor match between student needs and instructional setting, and conflict between teacher expectations and student expectation regarding academic performance. 
Both groups, achievers and underachievers, reported that acceleration, instructional relevance, differentiation, and alignment of teacher and student expectations regarding academic performance were powerful factors in fostering achievement and reversing underachievement. Both groups also concurred regarding the impact of features offered through gifted services. Especially important in the rural setting were the opportunity to find an intellectual peer group and the travel opportunities. Research and projects, exposure to content beyond the core curriculum, and performance opportunities provided both academic motivation and exposure to fields of endeavor that were not available anywhere else in their school program. Those exposures were reported as critical to the achievement of many of participants, especially those who reported underachievement, as they provided a connection they needed to sustain motivation. Joel summarized the opinions of the underachievers:

I was one of those kids who hovered on the fringe, making as little commitment to my school work as I possibly could; but when I came to gifted, I was immersed in experiences that were not found anywhere else in my world. The research skill and presentations skills I learned in gifted came from the plays and projects and now I use those skills every day. Looking back, I must say that gifted made me who I am today.

\section{Summary}

Through the use of interview questions, quotes and comments of the participants related to the questions, theme identification, and summary findings, Chapter 4 and Chapter 5 identified the perceptions of the study participants related to the KERA initiatives, significant factors relating to the phenomenon of being a rural gifted student in 
the regular classroom, and significant factors relating to sustained achievement or underachievement. Chapter 6 provides the summary of the research findings and discussion of the impact and implications for further study. 


\section{CHAPTER 6 \\ CONCLUSION AND DISCUSSION}

The Kentucky Education Reform Act (KERA) of 1990 included a number of systemic initiatives intended to improve student achievement and to eliminate performance gaps throughout the educational system (KDE, 1990). Many of those same initiatives continue to dominate discussion about effective educational improvement. The purpose of this study was to answer the broad question-How do adults who were rural Kentucky gifted students see the impact of the KERA initiatives on their achievement and underachievement? In other words, "Did KERA and the related educational structures work?"

\section{The Study}

As a phenomenological study exploring the impact of reform initiatives on the achievement and underachievement of rural gifted students, this study investigated the perceptions of young adults regarding the impact of the components of the Kentucky Education Reform Act on their achievement as students and as adults. As the study was designed, the amount of time that had passed since the participants had been in school was considered as a potential limitation of the study. Concerns were raised about whether the young adults would remember their school experiences with enough awareness of the KERA initiatives to be able to reflect on the impact on their achievement. With the exception of the activities of the SBDM councils at elementary 
and middle school levels, every participant demonstrated high levels of awareness of the KERA initiatives and had vivid recollections about their school experiences and the experiences of their peers. Questions triggered student memories that reflect strong emotional investment and the use of repeat interviews provided rich description of the experiences of the participants.

Qualitative methods were used to gain insights into the cultural and social norms of the target group—rural gifted students (Creswell, 2006; Spradley, 1979). A series of interviews and conversations yielded narrative data that allowed the researcher to use an iterative process between data collection and data analysis (Teddlie \& Tashakkori, 2009).

The language and perceptions of the participants were used to produce a description of the educational culture during the implementation of reform initiatives and a description of the impact of those cultural elements that informed the description of the phenomenon being studied (Creswell, 2006; Spradley, 1979; Teddlie \& Tashakkori, 2009). The wealth of data generated through multiple interviews provided opportunity for both in-depth analysis of specific reform elements and opportunity to identify relationships among those elements and the rural gifted experiences of the participants (Creswell, 1998; Creswell, 2006; Miles \& Huberman, 1994; Seidman, 2006; Spradley, 1979).

The varied topics examined in this study initially produced over 200 preliminary themes through the process of transcribing the interviews, reading them repeatedly, identifying key words and phrases, and categorizing them (Creswell, 2006; Miles \& Huberman; Seidman, 2006). Beginning with a set of structured interview questions, clarification questions and probing questions were also asked at the first interview. Two 
additional semi-structured interviews followed using questions derived from earlier responses and emerging themes through the interview process. As themes emerged and the iterative process was used, the researcher went back to participants with interpretations to verify that the interpretations or derivations from the comments were accurate (Creswell, 2006; Kvale \& Brinkmann, 2009).

Identification of connections and attention to the nuances of detail finally provided the depth of understanding that allowed for the development of key themes and sufficient information to craft a description of the experiences of the participants (Biklen \& Casella, 2007). Built around the major themes derived from the key themes, this chapter is a summary of the findings with discussion of the implications for further study.

\section{Findings and Discussion}

Three questions framed the study. The questions and the related themes organize the research findings:

Question 1. What are the perceptions of former students regarding the roles of each of the instructional Kentucky Education Reform Act initiatives (Portfolios [writing and mathematics], Ungraded Primary, KIRIS/CATS assessment, Proficiency as a performance goal, SBDM council policies) in fostering or impeding self-reported student and adult achievement?

To address this question, participants reflected on each of the KERA initiatives in the context of their personal experiences using each phase of their educational career (primary grades, intermediate grades, middle school, high school, and post-secondary education) as points of comparison. Structured interview questions asked participants to 
tell about each of the initiatives and asked them to describe the impact of each initiative on their achievement at each educational level.

Among the instructional initiatives of the Kentucky Education Reform Act, only the writing portfolio was perceived to have had positive impact on achievement. The portfolio was credited with impacting achievement for the participants as students and as adults as a foundation for strong communication and critical-thinking skills. Participants linked the clear performance standards, high expectations and enthusiasm of their gifted education teachers, the differentiated nature of the writing tasks, and the frequent application of the writing strategies to the effectiveness of the process. Though some participants reported that the actual portfolio products were not always motivational, the portfolio was universally a source of pride and was identified as an educational practice that had lasting positive impact.

The math portfolio was perceived to have had no impact on achievement. The math portfolio was characterized as a product with vague standards and low expectations. Many participants regretted the time spent on the math portfolio when they could have been acquiring higher level math skills. Though some participants did appreciate the potential benefit of writing about math, they felt the process as it was implemented did not reflect high level work and that it was difficult for a student to create an outstanding portfolio based on the existing criteria.

Based upon the perceptions of the participants KIRIS/CATS assessments were not found to positively impact achievement. They reported that it was not relevant to their classroom instruction and that there was little attention to moving their performance to the Distinguished level. Those students who performed well on the assessments reflected 
that their performance was not due to instruction, but felt it was due to the fact that the test was not difficult and that the tested material reflected prior knowledge. The emphasis on Proficient performance undermined the ability of some participants to maintain motivation, but the majority of participants felt that, though the testing reflected loss of instructional time and a loss of momentum in their AP classes, the state assessments were a negligible part of their school program.

The Ungraded Primary Program, SBDM Council policies, and Proficiency as a performance goal were all considered to be initiatives that fostered underachievement. At the heart of the negative impact of these three components were the low expectations of teachers or "the school." Participants expressed frustration that Proficiency was not their goal and that the school's focus on Proficiency ignored the fact that there was a group of students who were already performing at the Proficient level prior to instruction.

A few of the participants reported that their Ungraded Primary Program did reflect some degree of continuous progress and opportunities to move faster at some point during their primary years. However, the majority of the participants reported that their primary experiences were dominated by whole group, age-graded instruction, with the exception of their primary experiences within their gifted services.

During the elementary and middle school years, study participants had no practical knowledge of the SBDM policies. At the secondary level, however, participants voiced strong recollections about the impact of SBDM in the development of policies related to block scheduling, access to correspondence courses and KVHS courses, credits brought in from middle school, and atypical course loads. The SBDM council policies were characterized as impediments to achievement as they were perceived to be narrowly 
interpreted and frequently applied to prevent the student from taking more challenging work.

Based on the perceptions of the study participants, the major themes related to KERA initiatives that emerged from the study were:

1. Conflict that impacted achievement occurred when teacher expectations were lower than student expectations regarding academic performance. (Kolb \& Jussim, 1994; Liu, Chen, Chen, \& Wu, 2009).

2. Lack of instructional relevance fostered underachievement (Kanevsky \& Keighley, 2003).

3. Fidelity of implementation impacted effectiveness (Borman, Hewes, Overman, \& Brown, 2003).

4. Gifted education services provided essential support (Clark, 2008; Renzulli, Reid, Gubbins, 1992).

5. Emphasis on Proficiency contributed to underachievement (Moon, Brighton, \& Callahan, 2003; Stanley \& Baines, 2002).

Question 2. What related educational experiences and structures in a rural setting are perceived by the former students as fostering or impeding self-reported student and adult achievement?

To address this question, participants were asked structured interview questions intended to cause them to reflect on their experiences as a gifted student in rural Kentucky, their experiences as gifted student in the regular education setting, their experiences with gifted education services, the impact of peers on their educational experiences, and the impact of gifted education services on the KERA initiatives. These 
questions were also addressed through a series of contacts in which semi-structured interviews were based on questions developed for clarification, expansion of responses, or in response to themes that began to emerge out of analysis of interview transcripts.

Answers to these questions created a description of the educational lives of the participants as rural gifted students. Important factors in their rural experiences were identified with the impact on their achievement. Participants identified lack of resources, geographic isolation, small critical mass of adults and students within the county, lack of fine arts opportunities, cliques established at very young ages, and anti-intellectual cultural norms as features of the rural setting that present potential obstacles to achievement.

The participants' perceptions of regular class experiences as rural gifted students were frequently characterized by boredom, frustration, waiting, or antagonism from the teacher. Many participants (28 out of 30) reported negativity of a teacher toward high performing students or a classroom climate that accepted harassment of the bright students as a matter of course. Regular classroom experiences were described as primarily whole-group instruction with few opportunities to move more rapidly or to explore a topic at greater depth. Most participants (27 out of 30) reported sustained and/or pervasive underachievement as they discussed their regular classroom experiences. All 30 students reported that they experienced some form of underachievement (sustained, pervasive, or situational) during their middle school years. The impact of gifted education services was consistently articulated as a counterpoint to the barriers and negativity in the regular classroom settings of the participants. Features of the gifted services that participants identified as most significant 
in sustaining achievement included the provision of an intellectual peer group. Because the students were gathered once a week at a central location, even students from very small schools had the opportunity to establish intellectual bonds with students with similar abilities and interests. Participants reported that those peer groups were sustained throughout their school careers, providing a consistent set of peers for goal-setting and intellectual competition that helped to prevent underachievement.

Other features of gifted services identified by every participant as having positive impact on achievement were travel opportunities, research and project opportunities, performance opportunities, multi-age groupings, emphasis on writing, differentiation, and acceleration.

Analysis of the perceptions of the participants yielded the following major themes in response to question 2:

1. Limited resources in the rural setting impacted instructional options at all levelshuman resources, material resources, and narrow resources of geographic isolation (Cross \& Burney, 2005; Howley, Rhodes, \& Beall, 2009).

2. The close-knit rural community impacted acceptance or rejection of gifted students as they face feelings of isolation and being different (Howley, Pendarvis, \& Howley, 1998).

3. Conflict that impacted achievement occurred when teacher expectations were lower than student expectations regarding academic performance. (Kolb \& Jussim, 1994; Liu, Chen, Chen, \& Wu, 2009).

4. Inadequate instructional relevance impacted achievement (Rimm, 1995).

5. Intellectual peers were significant in sustaining achievement (Berlin, 2009). 
6. Teacher attitudes impacted peer acceptance or rejection (Cross, Coleman, \& Stewart, 1993).

7. Clear alignment between the expectations of the gifted teachers and the students fostered academic achievement (Davalos \& Griffin, 1999; Emerick, 1992).

8. Attributes of KERA initiatives were perceived to have been implemented with fidelity through gifted services.

9. Gifted services established and maintained instructional relevance (Fredricks, Alfeld, \& Eccles, 2010; Kaplan, 2004).

Question 3. What are the similarities and differences in perceptions between those adults who self-reported sustained achievement and those who reported underachievement?

In order to answer this question, participants were asked semi-structured interview questions that addressed their perceptions about their levels of achievement and underachievement, their definition of achievement, and the factors that influenced their ability to sustain high levels of achievement. Participants were asked to describe periods and circumstances that fostered achievement or impeded their achievement. Using the semi-structured format based on prior answers and emerging themes, participants were asked to expand or clarify previous answers and interpretations of earlier responses were shared for verification.

Participants reflected that all students were at risk of underachievement. All 30 participants reported that they could identify times or locations of academic situational underachievement in their own educational careers, and 27 out of 30 reported that they had experienced pervasive and/or sustained underachievement. All participants reported that they had experienced some form of underachievement at the middle school level. 
Participants made a distinction between grades and achievement. Though they all reported making good grades and setting high personal expectations regarding grades, they defined personal achievement as succeeding at something that represented a true challenge. All participants discussed the importance of feeling a sense of achievement in order to sustain motivation.

According to the participants, their achievement was fostered through clearly established standards related to tasks that are educationally relevant. The role of the relationships with significant adults was articulated repeatedly with effective teachers defined as those who were knowledgeable, were passionate about their content and about student learning, were honest, were caring about students as individuals, and had a sense of humor. Many participants expressed distress over the lack of connection between many teachers and the gifted students, recalling specific situations in which their teachers deliberately established an antagonistic relationship that, as young students, the participants could not understand.

Participants discussed the circumstances around underachievement and reversal of underachievement with great passion. Most reported situations of shutting down or choosing not to participate as a form of self-preservation. Many reported situations where they chose to underperform in an effort to fit in with other students or to try to gain teacher approval. All participants reported strategies they used to find intellectual stimulation during class time when it was not present within the classroom structure.

Acceleration practices, differentiation, opportunity for student choice, and personal relationships with teachers were the most consistently reported factors in reversing underachievement. 
Based on the perceptions of the participants, the major themes that emerged around question 3 follow:

1. Achievement was personal success that reflected challenge (Grant \& Dweck, 2003; Neihart, 2006).

2. Underachievement resulted from a poor match between student needs and the educational setting (Davalos \& Griffin, 1999; Winner, 1996; ).

3. Conflicts between teacher expectations and student expectations regarding academic performance contributed to underachievement (Gentry, 2006; Johnsen, Haensly, Ryser, \& Ford, 2002; Liu, Cheng, Chen, \& Wu, 2009).

4. Gifted education services provided components that positively impacted achievement (Clark, 2008; Fredricks, Alfeld, \& Eccles, 2010).

5. Relationships with significant adults positively impacted achievement (Hoekman, McCormick, \& Gross, 1999).

6. High expectations and projected belief in student capability impacted achievement (Kanevsky \& Keighley, 2003).

7. Underachievement was prevalent (Emerick, 1992; Moon \& Reis, 2004).

The researcher, as an advocate for many of the KERA initiatives, entered into this project expecting to discover a range of perceptions, but believing that the majority would be positive and that the positive impacts of reform would be reflected in a number of the KERA initiatives. The researcher also held the expectation that within a given sample of gifted individuals, the numbers who self-reported achievement and those who self-reported underachievement would be about even. 
The results of this study showed that the perceptions of individuals who were identified and served as gifted students in a rural Kentucky county between 1994 and 2004 painted a vivid picture of the experiences they faced as students. The participants provided clear recollections of their school experiences and were able to relate the impact of various reform initiatives at multiple points through their school careers. The results were surprisingly consistent.

With the exception of the writing portfolio, the other KERA initiatives were universally found to be ineffective or detrimental to achievement and all individuals reported experiencing periods of underachievement, with 27 out of 30 reporting sustained or pervasive underachievement. Many participants who initially projected a positive demeanor regarding their educational experiences would then offer a heartfelt narrative about their levels of discontent or lack of connection within their school career. Incidents of harassment and bullying were commonplace among the participants, while teacher advocates were not.

\section{Implications for Further Research}

Expanding this study of a single rural district to investigate the perceptions of rural gifted students from several school districts in Kentucky or rural districts where other reform initiatives have been implemented could be valuable in examining their impact on achievement and on attitudes toward school. Additional study of the perceptions of school reform initiatives and achievement levels of gifted students while they are in school could also be valuable in understanding the dynamics of underachieving students and the role of reform, and in using the findings in a timely manner to adjust instructional practices that are not effective. 
Because students consistently identified a significant teacher as the most important factor in sustaining achievement or reversing underachievement, and because that finding is consistent with other research on underachievement (Baum, Renzulli, \& Hébert, 2004; Heacox, 1991; Hébert \& Beardsley, 2001; Siegle \& Schuler, 2000), the results of this study can serve as a source to inform self-reflection among educators seeking to identify teacher behaviors that support student achievement. Teacher Efficacy Through Change Initiatives--What practices support/undermine classroom teachers' ability to foster high levels of student achievement while implementing curricular or philosophical changes in the classroom?

Of particular importance might be research into the teacher behaviors that sustain high achievement through periods of reform. As each state faces the challenges of NCLB (USDOE, 2002), Race to the Top (USDOE, 2009b), and the processes of the adoption and implementation of national Common Core Standards (USDOE, 2009a), teacher efficacy in implementing change while providing instruction that supports high levels of achievement will be important to monitor through quality research that extends the current body of research.

Related research on teacher attitudes toward change and the impact of those attitudes on interpersonal relationships with students; research on strategies to build capacity to implement required changes, and research on strategies to monitor the effectiveness of those changes could all be important in improving the continuous process of educational reform in American education (Easton, 2008; Lieberman \& Pointer-Mace, 2008; Wolf, Borko, Elliott, \& McIver, 2000). 
Additional studies on the consistency and quality of implementation of reform initiatives could expand upon the current body of research and to support future reform initiatives (Beach \& Lindahl, 2004; Chen, 2010; Suchsland \& Schneider, 2006; Supovitz \& Weinbaum, 2008; Weinbaum \& Supovitz, 2010). Using the findings of the body of research around school effectiveness research, studies relating reform initiatives, and impact on gifted students could inform current practice (Teddlie \& Reynolds, 2000).

Closely related will be research on effectiveness of teacher training models with diverse populations, including gifted students, to add to the current body of research and to inform decisions about educational reform (Darling-Hammond, 2010; Lieberman \& Pointer-Mace, 2008; Vaiyda \& Zaslavsky, 2002). Additional studies to expand the body of research related to administrative leadership and expectations regarding teacher accountability to meeting the needs of gifted students could expand upon systemic research into the dynamics that create positive, neutral, or adversarial learning climates for gifted students (Hertberg-Davis \& Brighton, 2006; Tucker \& Stronge, 2005). Implementation is Key--What strategies are most effective in fostering educational change that is implemented with fidelity?

The difference in implementation of KERA initiatives such as the Ungraded Primary and the writing portfolio was significant from teacher to teacher. Participants repeatedly articulated the distinction between their perceptions of the reform initiatives when implemented with fidelity and when the classroom represented no change or a negative attitude toward the KERA strand. Research to add to the body of expertise on reform implementation could increase fidelity of change initiatives (Fullan, 2010). 
Participants identified the teacher qualities that made the difference in implementation (Emerick, 1992; Wendel \& Heiser, 1989) and most were careful to distinguish between the failure of the initiative as an idea and the failure because of implementation. Teachers did not implement reform initiatives with fidelity. Research to identify effective strategies for changing teacher practices will be important to break the cycle of failed reforms and to add to the existing body of research on educational change implementation (Borman, Hewes, Overman, \& Brown, 2003; Lieberman \& PointerMace, 2008; Supovitz \& Weinbaum, 2008).

\section{The Role of the Teacher in Impacting Peer Interactions--What do classroom} teachers do to support or undermine acceptance of high ability learners?

The teacher's influence on peer attitude toward the participants in the study was universally identified as the key to the classroom climate and level of acceptance. Multiple research implications result from that finding. Research regarding the difference between teacher-reported attitudes and student perceptions of their attitudes toward high ability students could inform the existing body of research (Cashion \& Sullenger, 2000; Grant \& Dweck, 2003). Research on classroom dynamics and the impact of teacher's verbal and nonverbal communication on peer interaction could be important in identifying features that can be addressed through awareness or training (Easton, 2008; Kolb \& Jussim, 1994; Rayneri, Gerber, \& Wiley, 2006). Additional studies on the beliefs and attitudes classroom teachers have regarding gifted as a category of exceptional children, regarding gifted students, gifted services (Gentry, Rizza, \& Owen, 2002; Hertberg-Davis \& Brighton, 2006), and differentiation could be very 
important in expanding the body of research examining strategies for improving teacher training, professional development, and advocacy.

Middle School Motivation and Expectations-What are we doing or not doing at the middle school level that makes it a poor match with the needs of gifted students?

The degree to which the participants reported underachievement and lack of motivation, especially at the middle school level, has implications for educators in the process of improving classroom instruction. Lack of instructional relevance and conflict between teacher and student expectations regarding academic performance were consistently identified as causes by research participants (Easton, 2008; Gentry, Rizza, \& Gable, 2001; Megay-Nespoli, 2001). Research to add to the existing body of research will be important to identify additional strategies to improve instructional relevance. Improving the match between student expectations regarding academic performance and the expectations of their teachers could have powerful implications for the achievement of students (Besser, 2008; Liu, Cheng, Chen, \& Wu, 2009; Mann, 2006).

Research to compare the dynamics of the middle school learning environment with the environments at the elementary and secondary level could be implemented to help identify the causative factors surrounding $100 \%$ of the study participants reporting some form of underachievement at the middle school level (Moon, Callahan, Tomlinson, \& Miller, 2002; Pepperell \& Rubel, 2009).

Unidentified Underachievement-How can schools be more responsive to students who are not performing at levels commensurate with their abilities?

The fact that all of the participants in the study reported some form of underachievement, coupled with the fact that they reported that their parents were usually 
aware, leads to a number of important research questions. Research on the strategies that schools and teachers are using to formulate their expectations about students' abilities and performance levels could be important in addressing the fact that so many students were able to spend extended periods of time significantly underperforming without being challenged (Gentry, Rizza, \& Owen, 2002; Johnsen, Haensly, Ryser, \& Ford, 2002). Research measuring achievement of students when preassessments for content are used to match students to instruction could be valuable and timely as common core standards go into place across the country. Research on student self-assessment strategies could be important in finding and addressing underachievement.

Research on the specific behaviors students report as coping strategies that impact underachievement-daydreaming, inattention, choosing not to complete work or underperforming, disruptive behaviors-could be important in identifying the functions of those behaviors and effective interventions to change those behaviors to more prosocial or more productive behaviors in the classroom and to enhance existing research in the field of gifted underachievement (Kanevksy \& Keighley, 2003; Neihart, 2006).

Gifted Services/Practices and Achievement-What regular classroom practices can be added/changed to increase the implementation of gifted/talented best practice strategies? What differentiation strategies do/can regular classroom teachers use to increase student achievement?

The results of the study have multiple implications in informing discussion about the role of gifted services in meeting the needs of students. Participants identified those features that helped to sustain achievement or reverse underachievement and those reflected instructional best practice for gifted and talented students (Berlin, 2009; Clark, 
2008). Those attributes, predicated on matching instruction to the needs and abilities of the students, have implications for addressing differentiation strategies within the regular classroom (Cross \& Burney, 2005; Davalos \& Griffin, 1999). Additional research could expand the existing body of research regarding strategies to infuse the attributes identified by students as positively impacting achievement into all classrooms.

\section{Long-term Impact of Reform Initiatives}

It will also be important to examine the perceptions of individuals representing all ability levels in order to study the impact of reform initiatives and attitudes toward school experiences for all students. Examining the adult perceptions of more students could be important in identifying the similarities and differences regarding the impact of educational practices across the school population.

There are multiple factors in this study that could be expanded upon through further research to provide data that would allow for broad applications in the field of education.

\section{Conclusion}

Educational reform movements abound and the prevalence of initiatives that are similar to those found in KERA is a constant factor in the world of education (Cissell, 2010; Fullan, 2010; Hawley, 2007; KDE, 2010). The Kentucky Education Reform Act was a systemic reform initiative designed to promote significant improvement in student achievement. Based on the perceptions of the study participants, adults who were identified as gifted students in a rural Kentucky school district between 1994 and 2004, the instructional components of KERA did not meet that objective for them. With the exception of the writing portfolio, each of the KERA initiatives examined was found to 
have no impact on achievement (math portfolios and KIRIS/CATS testing) or was found to foster underachievement (Ungraded Primary, Proficiency as a performance goal, SBDM council policies). Only the writing portfolio was identified as a component that had positive impact on achievement of the participants while they were students and that impact extended into their college and adult lives.

Every study participant reported experiencing underachievement during their school career, with 27 of the 30 participants reporting sustained underachievement at a point that included at least one year of their middle school experience. The conflict between teacher expectations and student expectations regarding academic performance, with the emphasis on Proficient as a performance goal, infiltrated every KERA component and negatively impacted student performance. While the participants reported positive feelings towards aspects of their school experience and most participants liked most of their teachers, they struggled with the lack of connection between their high personal standards and the expectations in the classroom.

Though the majority of the KERA components are no longer implemented consistently, the findings of the study have current implications. The constant need to improve education for students generates ongoing discussion of reform initiatives to better address student needs. Many critical attributes of those discussions are centered around reform initiatives that look very much like the components of KERA.

Even today, the "new" motto of the Kentucky Department of Education is "Every Student Proficient and Prepared for Success." As the new accountability system in Kentucky is developed to fulfill the requirements of Kentucky's Senate Bill 1 (KDE, 2010) and as new assessments around the country are developed to incorporate the new 
common core standards and address the requirements of Race to the Top (USDOE, 2008), discussion continues around the use of Proficiency as the performance goal. It is hoped that through studies like this one, future decisions about instructional initiatives can be informed by the voices of the young people who lived them. Achievement? It's the thing that I can take away from an experience when I can reflect and think-What did I learn from this? School should be that place where every day students get to extend their thinking beyond the basic expectations to find personal gratification from being challenged. Because of gifted, it's what I had for a little piece of heaven every week and it's what I want for my children every day. I hope it will be there when they need it!--Mia 


\section{REFERENCES}

Ablard, K. W. (1997). Self-perceptions and needs as a function of type of academic ability and gender. Roeper Review, 20, 110-115.

Arnold, M., Gaddy, B. \& Dean, C. (2004). A look at the condition of rural education research: Setting a direction for future research. Aurora, CO: Mid-continent Research for Education and Learning.

Baker, J. A., Bridger, R., \& Evans, K. (1998). Models of underachievement among gifted preadolescents: The role of personal, family and school factors. Gifted Child Quarterly, 42, 5-15.

Battle, D., Grant, D., \& Heggoy, S. (1995). Decision making of rural gifted females: Case studies of precollege influences. Roeper Review, 18, 33-38.

Baum, S., Renzulli, J., \& Hébert, T. (1995). The prism metaphor: A new paradigm for reversing underachievement (CRS95310). Storrs, CT: The National Research Center on the Gifted and Talented.

Baum, S., Renzulli, J., \& Hébert, T. (2004). Reversing underachievement: Creative productivity as a systematic intervention. In S. Moon \& S. Reis (Ed.), Social emotional issues, underachievement, and counseling of gifted and talented students (pp. 133-156). Thousand Oaks, CA: Corwin Press.

Beach, R. H. \& Lindahl, R. (2004). Identifying the knowledge base for school improvement. Planning and Changing, 35(2), 2-4. 
Beisser, S. R. (2008). Unintended consequences of No Child Left Behind mandates on gifted students. The Forum on Public Policy. Retrieved from http://www. forumonpublicpolicy.com/summer08papers/archivesummer08/beisser.pdf

Benbow, C., Argo, T., \& Glass, L. (1992). Meeting the needs of the gifted in rural areas through acceleration. Gifted Child Today. 18(2) 15-19.

Berlin, J. E. (2009). It's all a matter of perspective: Student perceptions on the impact of being labeled gifted and talented. Roeper Review. 31, 217-221.

Biklen, S \& Casella, R. (2007). A practical guide to the qualitative dissertation. New York: Teachers College Press.

Bloom, B. S. (Ed.). (1985). Developing talent in young people. New York: Ballantine Books.

Bogdan, R.C. \& Biklen, S.K. (2003). Qualitative research for education: An introduction to theories and methods. Boston: Pearson Educational Group, Inc.

Borko, H. \& Elliott, R. (1999). Hands-off accountability tensions between competing commitments for exemplary math teachers in Kentucky. Phi Delta Kappan, 80, 394-399.

Borman, G. D., Hewes, G. M., Overman, L. T., \& Brown, S. (2003). Comprehensive school reform and achievement: A meta-analysis. Review of Educational Research, 73, 125-230.

Bowen, G. (2005). Preparing a qualitative research-based dissertation: Lessons learned. The Qualitative Report. 10, 208-222. 
Brounstein, P. J., Holahan, W., \& Dreyden, J. (1991). Change in self-concept and attributional styles among academically gifted adolescents. Journal of Applied Social Psychology, 21, 198-218.

Bruns, J. (1992). They can but they don't. New York: Viking.

Butler-Por, N. (1987). Underachievers in schools: Issues and intervention. New York: John Wiley and Sons.

Callahan, C. M., Tomlinson, C. A., Reis, S. N., \& Kaplan, S. N. (2000). TIMSS and highability students: Message of doom or opportunity for reflection? Phi Delta Kappan. 81, 787-788.

Callahan, S. \& Spalding, S. (2006). Can high-stakes writing assessment support highquality professional development? The Educational Forum. 70, 337-343.

Cashion, M., \& Sullenger, K. (2000). “Contact us next year”: Tracing teachers' use of gifted practices. Roeper Review, 23, 18-22.

Chen, M. (2010). Education nation: Six leading edges of innovation in our schools. Hoboken, NJ: Jossey-Bass.

Cissell, G. (2010). Chalk talks - Kentucky and education reform: The issue of pay-forperformance. Journal of Law and Education. 39(1), 119-122.

Clark, B. (2008). Growing up gifted: Developing the potential of children at home and at school ( $7^{\text {th }}$ ed.). Upper Saddle River, NJ: Prentice Hall.

Cloud, J. (2007). Are we failing our geniuses? Time. 170(9), 3-6.

Colangelo, N., Assouline, S., \& Gross, M., (2004). A nation deceived: How schools hold back America's brightest students. Iowa City, IA: The Connie Belin \& Jacqueline N. Blank International Center for Gifted Education and Talent Development. 
Coleman, L. J., \& Cross, T. L. (1988). Is being gifted a social handicap? Journal for the Education of the Gifted, 11, 41-56.

Coleman, L. J., \& Sanders, M. D. (1993). Understanding the needs of gifted students. Journal of Secondary Gifted Education, 11, 22-25.

Collins, B. (2008). Dixie: Evolution and its effect on rural special education. Rural Special Education Quarterly, 27(3), 10-15.

Crandall, V. J., Katknovsky, W., \& Preston, A. (1960). A conceptual formulation for some research on children's achievement development. Child Development, 31, 787-797.

Creswell, J. W. (1994). Research design: Qualitative and quantitative approaches. Thousand Oak, CA: SAGE Publications.

Creswell, J. (1998). Qualitative Inquiry and Research Design Choosing Among Five Traditions. Thousand Oaks, CA: Sage Publications.

Creswell, J. W. (2006). Qualitative inquiry \& research design. London: SAGE Publications.

Cross, T., Coleman, L., \& Stewart, R. (1993). The social cognition of gifted adolescents: An exploration of the stigma of giftedness. Roeper Review, 16, 37-40.

Cross, T. \& Burney, V. (2005). High ability, rural, and poor: Lessons from project ASPIRE and implications for school counselors. Gifted Child Today, 16(4), 148156.

Crouch, R. (2009). Demographic trends for state policymakers. In Book of the States. Lexington, KY: Council of State Governments. 
Csikszentmihalyi, M. (1990). Flow: The psychology of optimal experience. New York: Harper \& Row.

Darling-Hammond, L. (2010). Teacher education and the American future. Journal of Teacher Education, 61(1), 35-39.

Davalos, R., \& Griffin, G. (1999). The impact of teachers' individualized practices on gifted students in rural, heterogeneous classrooms. Roeper Review, 21, 308-314.

Delcourt, M. A. B., \& Evans, K. (1994). Qualitative extension of the learning outcomes study. Storrs, CT: The National Research Center on the Gifted and Talented.

Dowdall, C. B., \& Colangelo, N. (1982). Underachieving gifted students: Review and implications. Gifted Child Quarterly, 26, 179-184.

Duncan, A. (2010, September 2). Beyond the bubble tests: The next generation of assessments. Speech presented at Achieve America Diploma Project Leadership Team Meeting, Washington, DC. Retrieved from U. S. Department of Education website: http://www.ed.gov/news/speeches/beyond-bubble-tests-next-generationassessments-secretary-arne-duncans-remarks-state-1

Easton, L. B. (2008). Professional development to professional learning: If schools are to change to meet their increasingly urgent needs. Phi Delta Kappan, 89, 755758.

Eisner, E.W. (1998). The enlightened eye: Qualitative inquiry and the enhancement of educational practice. Columbus, Ohio: Prentice Hall.

Elliott, A. J., \& Dweck, C.S. (2005). Handbook of competence and motivation. New York: Guilford Press. 
Emerick, L. J. (1992). Academic underachievement among the gifted: Students' perceptions of factors that reverse the pattern. Gifted Child Quarterly, 36, 140146.

Ford, D.Y. (1992). Determinants of underachievement as perceived by gifted, aboveaverage, and average black students. Roeper Review, 14, 130-136.

Ford, M. A. (1989). Students' perceptions of affective issues impacting the social emotional development and school performance of gifted/talented youngsters. Roeper Review, 11, 131-139.

Four pillars of No Child Left Behind (NCLB): Guide to education and No Child Left Behind.(2004). http.://www.ed.gov/print/nclb/overview/intro/4pillars.html (accessed August 31, 2010)

Fredricks, J., Alfeld, C., \& Eccles, J. (2010). Developing and fostering passion in academic and nonacademic domains. Gifted Child Quarterly, 54, 18-30.

Fullan, M. G. (1993). Change forces: Probing the depths of educational reform. New York: Farmer Press.

Fullan, M. G. (2010). All systems go: The change imperative for whole system reform. Thousand Oaks, CA: Corwin Press.

Gallagher, J., Harradine, C. C., \& Coleman, M. R. (1997). Challenge or boredom: Gifted students' views on their schooling. Roeper Review, 19, 132-136.

Gardner, W. (2010). Gifted children are stepchildren in school reform. Education Week. http://edweek.org/edweek/walt_gardners_reality_check/2010/05/gifted_children_ are_stepchildren_in_public_schools.html (accessed August 31, 2010) 
Gentry, M. (2006). No child left behind: Neglecting excellence. Roeper Review, 29(1), 24-32.

Gentry, M., \& Ferrisss, S. (1999). StATS: A model of collaboration to develop science talent among rural students. Roeper Review, 21, 316-320.

Gentry, M., \& Owen, S. (1999). An investigation of the effects of total school flexible cluster grouping on identification, achievement, and classroom practices. Gifted Child Quarterly, 43, 224-243.

Gentry, M., Rizza, M. G., \& Owen, S. V. (2002). Examining perceptions of challenge and choice in classrooms: The relationship between teachers and their students and comparisons between gifted students and other students. Gifted Child Quarterly, 46 (2), 145-155.

.Gentry, M., Rizza, M. G., \& Gable, R. K. (2001). Gifted students' perceptions of their class activities: Differences among rural, urban, and suburban student attitudes. Gifted Child Quarterly, 45, 115-129.

Goetz, J. \& LeCompte, M. (1984). Ethnography and qualitative design in educational research. New York: Academic Press.

Gohm, G., Humphreys, L., \& Yao, G. (1998). Underachievement among spatially gifted students. American Educational Research Journal. 35, 515-531.

Gonzales, P., Williams, T., Jocelyn, L., Roey, S., Kastberg, D., \& Brenwald, S. (2008). Highlights From TIMSS 2007:Mathematics and Science Achievement of U.S. Fourth-and Eighth-Grade Students in an International Context (NCES 2009-001 Revised). National Center for Education Statistics, Institute of Education Sciences, U.S. Department of Education. Washington,DC. 
Goodlad, J. (1984). A place called school: Prospects for the future. New York: McGrawHill.

Grant, H., \& Dweck, C. S. (2003). Clarifying achievement goals and their impact. Journal of Personality and Social Psychology, 85, 541-553.

Grobman, J. (2006). Underachievement in exceptionally gifted adolescents and young adults: A psychiatrist's view. The Journal of Secondary Gifted Education, 17, 199-210.

Haas, T., \& Lambert, R. (1995). To establish the bonds of common purpose and mutual enjoyment. Phi Delta Kappan, 77, 136-142.

Hambleton, R. K., Jaeger, R. M., Koretz, D., Linn, R. L., Millman, J., \& Phillips, E. E. (1995). Review of the measurement quality of the Kentucky Instructional Results Information Systems, 1991-1994. Frankfort, KY: Office of Education Accountability.

Hawley, W. D. (Ed.). (2007). The keys to effective schools: Educational reform as continuous improvement. Thousand Oaks, CA: National Education Association. Hayes, P., Norris, J., \& Flaitz, J. (1998). A comparison of oral narrative abilities of underachieving and high-achieving gifted adolescents: A preliminary investigation. Language, Speech, and Hearing Services in Schools, 29, 58-71.

Heacox, D. (1991) Up from underachievement: How teachers, students, and parents can promote student success. Minneapolis, MN: Free Spirit Press.

Hébert, T. P. (1997). Jamison's story: Talent nurtured in troubled times. Roeper Review, $19,142-148$. 
Hébert, T. P. (1998). Gifted black males in an urban high school: Factors that influence achievement and underachievement. Journal for the Education of the Gifted, 12, $385-414$

Hébert, T. P., \& Beardsley, T. M. (2001). Jermaine: A critical case study of a gifted black child living in rural poverty. Gifted Child Quarterly, 45, 85-103.

Heine, C. (2009). A Glossary of Kentucky Educational Terms. Lexington, KY: Pritchard Committee.

Heine, C. (2006). Kentucky school updates: A parent/citizen guide. Lexington, KY: Pritchard Committee.

Hertberg-Davis, H. L. \& Brighton, C. M. (2006). Support and sabotage: Principals' influence on middle school teachers' responses to differentiation. Journal of Secondary Gifted Education, 17(2), 90-96.

Hoekman, K., McCormick, J., \& Gross, M. U. (1999). The optimal context for gifted students: A preliminary exploration of motivational and affective considerations. Gifted Child Quarterly, 43, 170-193.

Hoge, R. D., \& McSheffrey, R. (1991). An investigation of self-concept in gifted children. Exceptional Children, 57, 238-245.

Hoover-Schultz, B. (2005). Gifted underachievement: Oxymoron or educational enigma? Gifted Child Today, 28(2), 46-49.

Howley, A. A. (2002). The progress of gifted students in a rural district that emphasized acceleration strategies. The Roeper Review, 24, 158-164. 
Howley, A. A., Pendarvis, E. E., \& Howley, C. B. (1988). Gifted students in rural environments: Implications for school programs. Rural Special Education Quarterly, 8(4), 43-50.

Howley, A., Rhodes, M., \& Beall, J. ( 2009). Challenges facing rural schools: Implications for gifted students. Journal for the Education of the Gifted. 32, 515536.

Howley, C. B. (1998). Distortions of rural student achievement in the era of globalization. (Report No. RC021-478). Athens, OH: Rural Center Appalachia Educational Laboratory and Educational Studies Department. (ERIC Document Reproduction Service No. ED419634).

Howley, C. B. (2009). The meaning of rural difference for bright rednecks. Journal for the Education of the Gifted, 32, 537-564.

Hoyt, W. (2000). An evaluation of the Kentucky education reform act. Lexington, KY. Center for Business and Economic Research.

Innes, R. (2010). Is the dream of KERA over? Bowling Green, KY: Bluegrass Institute for Public Policy Solutions.

Jennings, B. (1990, April 16). KERA legislation signed into law. Lexington Herald Leader. pp. A1, A8.

Johnsen, S. K., Haensly, P. A., Ryser, G. R., \& Ford R. F. (2002). Changing general education classroom practices to adapt for gifted students. Gifted Child Quarterly, 46, 45-63.

Johnson, J. (Ed.). (2009). Why rural matters 2009: State and regional challenges and opportunities. Arlington, VA: Rural School and Community Trust. 
Johnson, J., Strange, M. \& Madden, K. (2010). The rural dropout problem: An invisible achievement gap. Arlington, VA: Rural School and Community Trust.

Jones, E. D. \& Southern, W. T. (1992). Programming, grouping, and acceleration in rural school districts: A survey of attitudes and practices. Gifted Child Quarterly, 37, $112-117$.

Jones, K. \& Whitford, B. L. (1997). Kentucky's conflicting reform principles: Highstakes school accountability and student performance assessment. Phi Delta Kappan, 72, 276-283.

Kane, T. \& Staiger, D. (2002). The promise and pitfalls of using imprecise school accountability measures. The Journal of Economic Perspectives, 16, 91-114.

Kannapel, P., Coe, P., Aagaard, L., \& Reeves, C. (1999). Mandated achievement in rural Kentucky: Contrasting responses. Journal of Research in Rural Education, 15, 515.

Kaplan, S. N. (2004). Where we stand determines the answers to the question: Can the No Child Left Behind legislation be beneficial to gifted students? Roeper Review, $26,124-128$.

Karmer, L. (2002). Achieving equitable education through the courts: A comparative analysis of three states. Journal of Law and Education, 31(1), 1-16.

Karnes, F. \& Bean, S. (2005). Methods and materials for teaching gifted. Waco: TX. Prufrock Press.

Kanevsky, L., \& Keighley, T. (2003). To produce or not to produce? Understanding boredom and the honor in underachievement. The Roeper Review. 26(1), 20-25. 
Keating, D. P. (1991). Curriculum options for the developmentally advanced: A developmental alternative to gifted education. Exceptionality Education Canada, $1,53-84$.

Kentucky Administrative Regulation 3:340 (1990). Primary school program guidelines. Kentucky Administrative Regulation 3:285 (1994). Programs for the gifted and talented. Kentucky Department of Education. (1983). Gifted and talented program review. Frankfort, KY.

Kentucky Department of Education (1990). Kentucky Education Reform Act of 1990 House Bill 940. Frankfort, KY.

Kentucky Department of Education. (1999). Primary 2000 and beyond: Implementing Kentucky's primary program. Frankfort, KY.

Kentucky Department of Education. (2000). Results matter: A decade of difference in Kentucky's public schools 1990-2000. Frankfort, KY.

Kentucky Department of Education. (2003). Kentucky writing development handbook update. Frankfort, KY.

Kentucky Department of Education. (2004). Gifted and talented program assurances. Frankfort, KY.

Kentucky Department of Education. (2005). Kentucky assessment data analysis. Frankfort, KY.

Kentucky Department of Education. (2006). Kentucky writing handbook. Frankfort, KY. Kentucky Department of Education. (2008). Fact sheet reconsidering myths surrounding writing instruction and assessment in Kentucky. Frankfort, KY. 
Kentucky Department of Education. (2009a). Gifted and talented frequently asked questions. Frankfort, KY.

Kentucky Department of Education (2009b). Kentucky accountability system Senate Bill 1. Frankfort, KY.

Kentucky Department of Education. (2009c). No Child Left Behind briefing packet. Frankfort, Ky.

Kentucky Department of Education. (2009d). School receipts and expenditures report 2008-2009. Frankfort, KY.

Kentucky Department of Education. (2010, October). Next generation learners accountability model. Presented at the meeting of the Kentucky Board of Education: A report to the Kentucky Board of Education, Frankfort, KY.

Kerr, B. (1988). Raising career aspirations of gifted girls. Vocational Guidance Quarterly, 32(1), 37-43.

Kerr, B. (1991). A handbook for counseling the gifted and talented. Alexandria, VA: American Association for Counseling and Development.

Kerr, B. (1994). Smart girls: A new psychology of girls, women, and giftedness. Scottsdale, AZ: Great Potential Press.

Klecker, B. M., Austin, J. L., \& Burns, L. T. (2000). An in-depth analysis of decisions made by Kentucky's school based decision-making councils. Education, 120, 655-657.

Kolb, K. J., \& Jussim, L. (1994). Teacher expectations and underachieving gifted children. Roeper Review, 17, 26-30. 
Kline, B. E. \& Short, E. B. (1991). Changes in emotional resilience: Gifted adolescent girls. Roeper Review, 13, 118-121.

Kuhs, T. M. (1994). Portfolio assessment: Making it work for the first time. The Mathematics Teacher, 87, 332-336.

Kvale, S., \& Brinkmann, S. (2009). Interviews: Learning the craft of qualitative research interviewing. Thousand Oaks, CA: SAGE Publications.

Lamb, J. \& Daniels, R. A. (1993). Gifted girls in a rural community: Math attitudes and career options. Exceptional Children, 2(4), 14-22.

Lawrence, B. (2009). Rural gifted education: A comprehensive literature review. Journal for the Education of the Gifted, 32, 461-494.

Lieberman, A. \& Pointer-Mace, D. H. (2008). Teacher learning: The key to educational reform. Journal of Teacher Education, 59, 226-230.

Lincoln, Y.S. \& Guba, E. G. (1985). Naturalistic Inquiry. Newbury Park, CA: Sage Publications.

Lindle, J. (1996). Site-based management: Making it work—Lessons from Kentucky about school-based decision making. Educational Leadership, 53(4), 20-23.

Liu, K. S., Cheng, Y. Y., Chen, Y. L., \& Wu, Y. Y. (2009). Longitudinal effects of educational expectations and achievement attributions on adolescents' Academic achievements. Adolescence, 44(176), 911-917).

LoCicero, K. A., \& Ashby, J. S. (2000). Multidimensional perfectionism in middle school age gifted students: A comparison to peers from the general cohort. Roeper Review, 22, 182-185. 
Luscombe, A., \& Riley, T. (2001). An examination of self-concept in academically gifted adolescents: Do gender differences occur? Roeper Review, 24(1), 20-22.

Lyons, R. (2009). Measuring the gap: The state of equity of student achievement in Kentucky. Policy Review, 153, 55-66.

Mann, R. (2006). Effective teaching strategies for gifted/learning-disabled students with spatial strengths. Journal of Secondary Gifted Education, 17(2), 112-115.

Maker, C., \& Nielson, Al. (1995). Teaching models in education of the gifted. ( $2^{\text {nd }}$ ed.). Austin, TX: Pro-Ed.

Marland, S. (1972). Education of the gifted and talented. Report to the Congress of the United States by the U.S. Commissioner of Education. Washington, DC: U.S. Government Printing Office.

McCoach, B., \& Siegle, D. (2001). A comparison of high achievers' and low achievers' attitudes, perceptions, and motivations. Academic Exchange Quarterly, 5(2), 7175.

McCoach, B. \& Siegle, D. (2003). The structure and function of academic self-concept in gifted and general education students. Roeper Review, 25(2), 61-70.

McGrail, L. (1998). Modifying regular classroom curriculum for gifted and talented students. Gifted Child Today, 21(2), 27-31.

Megay-Nespoli, K. (2001). Beliefs and attitudes of novice teachers regarding instruction of academically talented learners. Roeper Review, 23, 178-182.

Miles, M. B. \& Huberman, A. M. (1994). Qualitative data analysis: An expanded sourcebook. Thousand Oaks, CA: SAGE Publications. 
Miller, W. (2005). Are multi-age grouping practices a missing link in the educational reform debate? Education and Urban Society, 37, 135-150.

Montgomery, D. (2004). Broadening perspectives to meet the needs of gifted learners in rural schools. Rural Special Education Quarterly. 23(1), 3-7.

Moon, T. R., Callahan, C. M., Tomlinson, C. A., \& Miller, E. M. (2002). Middle school classrooms: Teachers' reported practices and students' perceptions. NAGC Research Briefs. Washington, DC: National Association for Gifted Children.

Moon, S. M., \& Reis, S. M. (Eds.). (2004). Social/emotional issues, underachievement, and counseling of gifted and talented students. Thousand Oaks, CA: Corwin Press.

Moon, T. R., Brighton, C. M., \& Callahan, C. M. (2003). State standardized testing programs: Friend or foe of gifted education. Roeper Review. 25, 49-54.

Moore, J., \& Benton, J. (1998). New teacher standards and learner diversity: Ideas for authentic assessment. Paper presented at the annual meeting of the American Association of Colleges for Teacher Education. New Orleans, LA. (ERIC Document Reproduction Service No. ED418060)

Moustakas, C. (1994). Phenomenological research methods. Thousand Oaks, CA: Sage Publications.

Mpofu, E. \& Ortiz, S. (2009). Equitable assessment practices in diverse contexts. In E. Grigorenko (Ed.), Multicultural psychoeducational assessment (pp. 41-76). New York: Springer Publishing Company.

National Rural Development Institute. (1986). Toward a definition of rural and small schools. Bellingham, WA: National Rural Development Institute. 
Neihart, M. (2006). Dimensions of underachievement, difficult contexts, and perceptions of self: Achievement/affiliation conflicts in gifted adolescents. Roeper Review, $28,196-201$.

Neihart, M. (2007). The socioaffective impact of acceleration and ability grouping: Recommendations for best practice. Gifted Child Quarterly, 51(4), 330-341.

Neihart, M. (2002). The social emotional development of gifted children: What do we know? Austin, TX: Prufrock Press.

Nichols, S. \& Berliner, D. (2007). Collateral damage: How high-stakes testing corrupts America's schools. Cambridge, MA: Harvard Education Press.

Office of Educational Accountability. (2009). Kentucky district data profiles school year 2009. Research report 268. Frankfort, KY: Legislative Research Commission.

Pankratz, R., \& Petrosko, J. (2000). All children can learn: Lessons for the Kentucky reform experience. Hoboken, NJ: John Wiley \& Sons.

Parker, W. D., \& Mills, C. J. (1996). The incidence of perfectionism in gifted students. Gifted Child Quarterly, 40, 194-199.

Pepperell, J. L. \& Rubel, D. J. (2009). The experience of gifted girls transitioning from elementary school to sixth and seventh grade: A grounded theory. The Qualitative Report, 14(2), 341-345.

Peterson, J. S. (2000). A follow-up study of one group of achievers and underachievers four years after high school graduation. Roeper Review, 22, 217-24.

Peterson, J. S. (2001). Gifted and at-risk: Four longitudinal case studies of post-highschool development. Roeper Review, 24(1), 31-39. 
Peterson, J. S., \& Colangelo, N. (1996). Gifted achievers and underachievers: A comparison of patterns found in school files. Journal of Counseling and Development, 74, 339-407.

Peterson, K. D., Bennet, B., \& Sherman, D. F. (1991). Themes of uncommonly successful teachers of at-risk students. Urban Education, 26, 176-194.

Petrosko, J. M. (1997) Assessment and Accountability. Review of research on the Kentucky Education Reform Act. Frankfort, KY: Kentucky Institute for Educational Reform.

Pintrich, P. R., Marx, R. W., \& Boyle, R. A. (1993). Beyond cold conceptual change: The role of motivational beliefs and classroom contextual factors in the process of conceptual change. Review of Educational Research, 63, 167-199.

Porath, M. (1996). Affective and motivational considerations in the assessment of gifted learners. Roeper Review, 19, 13-17.

Provasnik, S., KewalRamani, A., Coleman, M., Gilbertson, L., Herring, W., \& Xie, Q. (2007). Status of education in rural America, (NCES 2007-040). National Center for Education Statistics, Institute of Education Sciences. Washington, DC: U.S. Department of Education.

Queen, J. (2000). Block scheduling revisited. Phi Delta Kappan, 82, 214-216.

Rayneri, L., Gerber, B., \& Wiley, L. (2003). Gifted achievers and gifted underachievers: The impact of learning style preferences in the classroom. The Journal of Secondary Gifted Education, 16(4), 197-204. 
Rayneri, L., Gerber, B., \& Wiley, L. (2006). The relationship between classroom environment and the learning style preferences of gifted middle school students and the impact on levels of performance. Gifted Child Quarterly, 50(2), 104-118.

Redding, R. E. (1990). Learning preferences and skill patterns among underachieving gifted adolescents. Roeper Review, 34, 72-75.

Reis, S. M. (1998). Work left undone: Choices \& compromises of gifted females. Mansfield Center, CT: Creative Learning Press.

Reis, S. M. (2003). Gifted girls, twenty-five years later: Hopes realized and new challenges found. Roeper Review, 25, 154-159.

Reis, S. M., \& McCoach, D. (2000). The underachievement of gifted students: What do we know and where do we go? Gifted Child Quarterly, 44, 152-170.

Reis, S. M., Westberg, K. L., Kulikowich, J., Caillard, F., Hébert, T., Plucker, L., Purcell, J. H., Rogers, J. B., \& Smist, J. M. (1993). Why not let high ability students start school in January? The curriculum compacting study (Research Monograph No. 93106). Storrs, CT: National Research Center on the Gifted and Talented, The University of Connecticut.

Renzulli, J. S. (2002). Expanding the umbrella: An interview with Joseph Renzulli. Roeper Review, 26(2), 65-69.

Renzulli, J. S., Reid, B. D., \& Gubbins, E. J. (1992). Setting an agenda: Research priorities for the gifted and talented through the year 2000. Storrs, CT: University of Connecticut, The National Research Center on the Gifted and Talented. 
Renzulli, J. S., \& Reis, S. M. (1985). The schoolwide enrichment model: A comprehensive plan for educational excellence. Mansfield Center, CT: Creative Learning Press.

Renzulli, J. S. \& Reis, S. M. (1987). The schoolwide enrichment model: A how-to guide for educational excellence ( $2^{\text {nd }}$ ed.). Mansfield Center, CT: Creative learning Press.

Renzulli, J. S. \& Reis, S. M. (1991) The reform movement and the quiet crisis in gifted education. Gifted Child Quarterly, 35 (1), 26-35.

Rimm, S. B. (1990). Underachievement syndrome causes and cures. Appleton, WI: Apple Publishing.

Rimm, S. B. (1995). Why bright kids get poor grades and what you can do about it. New York: Crown Publishers, Inc.

Rimm, S. B. (2004). Perfectionism: When excellence isn't good enough. Duke Gifted Letter, 4(2), 12-13.

Rimm, S. B. \& Lovance, K. J. (1992). The use of subject and grade skipping for the prevention and reversal of underachievement. Gifted Child Quarterly, 36(2), 100105.

Roeder, P. (2008). School district performance in Kentucky (1993-2001): Do teaching and financial resources moderate the negative effects of poverty? Educational Resources Information Center, 20, 1-38.

Rogers, K. (2002). Reforming gifted education: Matching the program to the child. Scottsdale, AZ: Great Potential Press. 
Rubin, B. C. \& Silva, E. M. (Eds.) (2003). Critical voices in school reform: Students living through change. London: RoutledgeFalmer.

Saldana, J. (2009). The coding manual for qualitative researchers. Thousand Oaks, CA: SAGE Publications.

Schuler, P. A. (1999). Voices of perfectionism: Perfectionistic gifted adolescents in a rural middle school. Storrs, CT: National Research Center on the Gifted and Talented.

Seidman, I. (2006). Interviewing as qualitative research: A guide for researchers in education and the social sciences. New York: Teachers College Press.

Senate Bill 1 (2009). Frankfort, KY: Kentucky State Legislature.

Sexton, R. (1996). Trends and issues affecting primary and secondary education. In S. Clements (Ed.), Exploring the frontier of the future: How Kentucky will live, learn and work (pp. 85-93). Chicago, IL: University of Chicago.

Shaffer, S. M. (1986). Gifted girls: The disappearing act. Washington, DC: Mid-Atlantic Center for Sex Equity. (ERIC Document Reproduction Service No. ED 301 994)

Sherman, R. \& Webb, R. (Eds.) (2001). Qualitative research in education: Focus and methods. London: RoutledgeFalmer.

Siegle, D., \& Schuler, P. A. (2000). Perfectionism differences in gifted middle school students. Roeper Review, 23, 39-44.

Silverman, L. K. (Ed.). (1993). Counseling the gifted and talented. Denver, CO: Love Publishing.

Smith, E. (2007). Analyzing underachievement in schools. London: Continuum International Publishing Group. 
Smutney, J. (2004, December). Meeting the needs of gifted underachieversindividually! 2e-Twice Exceptional Newsletter. Retrieved from http://www.davidsongifted.org/db/Articles_id_10442.aspx.

Speirs-Neumeister, K. L. \& Hébert, T. P. (2003). Underachievement versus selective achievement: Delving deeper and discovering the difference. Journal for the Education of the Gifted, 26, 221-238.

Spicker, H. H., Southern, W. T. \& Davis, B. (1987). The rural gifted child. Gifted Child Quarterly, 31(4).

Spradley, J. P. (1979). The ethnographic interview. Belmont, CA: Wadsworth Cengage Learning.

Stanley, G. K., \& Baines, L. (2002). Celebrating mediocrity? How schools shortchange gifted students. Roeper Review, 25(1), 11-15.

Strauss, A., \& Corbin, J. (1990). Basics of qualitative research: Grounded theory procedures and techniques. Newbury Park, CA: Sage.

Strong, S. \& Sexton, L. (2000). A validity study of Kentucky's performance based assessment system with national merit scholars and national merit commended. Journal of Instructional Psychology, 27, 202-204.

Swanson, J. D. (1995). Gifted African American children in rural schools: Searching for the answers. Roeper Review, 17, 261-276.

Suchsland-Schneider, J. (2006). Effects of a legislated mandate: The comprehensive school improvement process and middle-level gifted and talented programming. Roeper Review, 28, 224-228. 
Supovitz, J. A. \& Weinbaum, E. H. (Eds.). (2008). The implementation gap: Understanding reform in high schools. New York: Teachers College Press.

Supplee, P. L. (1989). Students at risk: The gifted underachiever. Roeper Review, 11, 163-166.

Teddlie, C. \& Reynolds, D. (Eds.) (2000). The international handbook of school effectiveness research. London: Falmer.

Teddlie, C. \& Tashakkori, A. (2009). Foundations of mixed methods research: Integrating quantitative and qualitative approaches in the social and behavioral sciences. Thousand Oaks, CA: SAGE Publications.

ThinkKentucky. (2000). Educational attainment of Kentucky counties. http://www.thinkkentucky.com/EDIS/Deskbook/files/EduAttainmentCty.PDF

Treffinger, D. J. (1986). Fostering effective, independent learning through individualized programming. In J. S. Renzulli (Ed:), Systems and models for developing programs for the gifted and talented (pp.429-460). Mansfield Center, CT: Creative Learning Press.

Tucker, P. D. \& Strong, J. H. (2005). Linking teacher evaluation and student learning. Alexandria, VA: Association for Supervision and Curriculum Development.

Tung, R. (2010). Including performance assessments in accountability systems: A review of scale-up efforts. Boston, MA: Center for Collaborative Education.

U. S. Department of Agriculture. (2010a) Rural economy. Retrieved from http: www.ers.usda.gov/statefacts/KY.htm

U. S. Department of Agriculture. (2010b). State fact sheets: Kentucky. Retrieved from http: www.ers.usda.gov/statefacts/ky.htm 
U.S. Department of Education. (2002). No Child Left Behind. Washington, DC: Office of Elementary and Secondary Education.

U. S. Department of Education. (2007). Trends in international mathematics and science study (TIMSS), Washington, DC: National Center for Education Statistics.

U.S. Department of Education. (2009a). ESEA blueprint for reform, Washington, DC: Office of Planning, Evaluation and Policy Development.

U. S. Department of Education. (2009b). Race to the top executive summary. Washington, DC: U.S. Government Printing Office.

Vaidya, S. R. \& Zaslavsky, H. N. (2000). Teacher education reform effort for inclusion classrooms: Knowledge versus pedagogy. Education, 121(1), 145.

Van Boxtel, H.W. \& Monks, F.J. (1992). General, social and academic self-concepts of gifted adolescents, Journal of Youth and Adolescence, 21(2), 169-185.

VanTassel-Baska, J., Johnson, D., \& Avery, L. D. (2002). Using performance tasks in the identification of economically disadvantaged and minority gifted learners:

Findings from Project STAR. Gifted Child Quarterly, 46 (2), 110-123.

Van Tassel-Baska, J. \& Olszewski-Kubilius, P. (1989). Patterns of influence on gifted learners. New York: Teachers College, Columbia University.

Van Tassel-Baska, J., Olszewski-Kubilius, P., \& Kulieke, M. (1994). A study of selfconcept and social support in advantaged and disadvantaged seventh and eighth grade gifted students. Roeper Review, 16, 186-191.

Weinbaum, E. H. \& Supovitz, J. A. (2010). Planning ahead: Making program implementation more predictable. Phi Delta Kappan, 91(7), 68-72. 
Wendel, R., \& Heiser, S. (1989). Effective instructional characteristics of teachers of junior high school gifted students. Roeper Review, 11, 151-153.

Westburg, K. L., Archambault, F. X., Dobyns, S. M., \& Salvin, T. J. (1993). An observational study of instructional and curricular practices used with gifted and talented students in regular classrooms. (Research Monograph 93104). Storrs, CT: The National Research Center on the Gifted and Talented.

Weston-Perkins, S. \& Sexton, R. (2009). Substantial and yet not sufficient: Kentucky's effort to build proficiency for each and every child. Education, Equity, and the Law, No. 2. New York: Columbia University.

Wolf, S., Borko, H., Elliott, R., \& McIver, M. (2000). “That dog won't hunt!”: Exemplary school change efforts within the Kentucky reform. American Educational Research Journal, 37, 349-393.

Whitmore, J. R. (1980). Giftedness, conflict, and underachievement. Boston, MA: Allyn and Bacon.

Winebrenner, S. (2009). Teaching gifted kids in the regular classroom: Strategies and techniques every teacher can use to meet the academic needs of the gifted and talented. Minneapolis, MN: Free Spirit Publishing.

Winner, E. (1996). Gifted children: Myths and realities. New York: Basic Books. 
Graduated in

First Interview: Structured Interview Questions

Thank you for your willingness to participate in this research study. I am interested in learning from individuals who were identified and served as gifted students during the era of the Kentucky Education Reform Act about your perceptions of the impact of the reform initiatives on your achievement or underachievement during school and as a young adult. We have reviewed the informed consent forms for $U$ of $L$ and WKU, but I am glad to answer any other questions you may have.

I am going to ask you to think about each of the Kentucky Reform Initiatives across your school career, thinking about your elementary years, your middle school years, your high school years, and the impact on your post-high school years.

Portfolios:

1. What can you tell me about the implementation of portfolios (writing and math) in your school career?

2. What impact did the writing portfolio have on your achievement as a student? As an adult?

3. What impact did the math portfolio have on your achievement as a student? As an adult?

Ungraded Primary

4. Tell me about the organizational structure of your primary school experience.

5. What impact did the organization and instruction within the primary school have on your achievement?

KIRIS/CATS Assessment

6. How did the state assessment program impact the instructional program during your school career? Did it have more influence at different points along the way? What factors made it different at different levels?

7. What impact did the KIRIS/CATS assessment have on your achievement as a student? As an adult?

8. How would you describe your performance on the state assessment? What factors influenced that performance? 
Emphasis on Proficiency

9. The KERA goal was to get everyone to proficiency. How did you see yourself in relation to that goal? How did that school goal influence your own achievement?

10. Tell me about your perceptions of your achievement throughout your school career. Were there points where you experienced sustained or pervasive underachievement? What factors most influenced your achievement levels?

\section{School Based Decision Making Council}

11. Describe your awareness of the School Based Decision Making Council when you were a student.

12. Tell me about actions of the council(s) that influenced your achievement as a student.

\section{Rural Gifted}

13. What was it like to be a gifted student in a rural Kentucky school district?

How did the rural setting impact your achievement as a student? As an adult?

14. Tell me what it was like to be a gifted student in your regular classroom. What factors had the most influence in fostering your achievement? Underachievement?

15. How would you compare your school experiences with those of your peers? Did they demonstrate similar levels of achievement? Similar levels of confidence? Similar levels of satisfaction with school? Tell me how your peers influenced you.

16. Tell me about the relationship between your gifted services and the KERA initiatives during your school career.

17. What else can you tell me about the influence of the Kentucky Education Reform Act on your levels achievement and success? 


\section{Appendix B}

Semi-structured Interview: These questions represent some of the follow-up questions based on the responses from Interview 1 that needed clarification or expansion.

1. How do you define Achievement? What is the relationship between grades and achievement?

2. When you chose to underachieve so that others would not notice you, what strategies did you use? What kept you from using those strategies all the time? How did you overcome the tendency to use those strategies?

3. What factors in the Ungraded Primary contributed to your achievement/underachievement? Talk to me about the role each characteristic played in your achievement. (multi-age grouping, thematic instruction, authentic assessment, continuous progress, primary talent pool)

4. How did teacher attitudes toward various KERA components influence their implementation? Your achievement?

5. What teacher qualities were most significant in influencing your achievement/underachievement/

6. What specific aspects of gifted services were influential in your levels of achievement or underachievement?

7. What specific aspects of the rural educational setting impacted your achievement and underachievement?

8. What factors were beneficial in overcoming obstacles to achievement?

9. As an adult, what specific educational components do you feel have had lasting impact on your achievement and underachievement?

10. What other information do you feel is important to understand what it was like to be a gifted student in rural Kentucky experiencing the components of KERA?

Interview \#3

Semi-structured Interview After sharing the significant statements, implications, and themes from the first two rounds of interviews, participants were asked to verify the findings and to expand upon or clarify earlier responses in the context of emerging themes. 


\section{CURRICULUM VITAE}

NAME: Jan Kathryn Weaver Lanham

ADDRESS: 11305 Danville Highway

Gravel Switch, KY 40328

DOB: $\quad$ Marion, Indiana-September 6, 1954

EDUCATION

\& TRAINING: $\quad$ B. S., Elementary Education and Music

Western Kentucky University

1971-1975

M.A. Education

Western Kentucky University

1978-1982

Ph.D., Educational Leadership

University of Louisville/Western Kentucky University

2010

AWARDS

\& HONORS: $\quad$ Finalist, NAESP National Distinguished Principals Award

2010

Kentucky Teacher Hall of Fame

2008

Service and Advocacy Award,

Kentucky Association of Gifted Education

2008

Ashland Teacher of the Year

1999

Lebanon/Marion County Educator of the Year

PROFESSIONAL

SOCIETIES:

Kentucky Association for Gifted Education, President 2010-2012

Kentucky Association of Elementary School Principals

National Association of Elementary School Principals 
Kentucky Association of School Administrators

Council for Exceptional Children

International Reading Association

Kentucky Education Association/National Education Association

International Reading Association

Association for Supervision and Curriculum Development

Council for Children with Behavior Disorders

National Writing Project

National Association for Gifted Children

\section{PRESENTATIONS:}

Post-Secondary Symposium-Shakertown, KY-2010

Essentials of Preservice Training for $21^{\text {st }}$ Century Teachers

Kentucky Association for Gifted Education Annual Conference--Differentiation

Kentucky Association for Gifted Education Fall Conference-RTI and Gifted

Glasgow Independent Schools-Social-emotional Needs of Gifted Students

Marion County Schools-Writing Across the Curriculum 